\title{
Effect of an Axial Electric Field on Detonation Waves
}

\author{
Vsevolods Kamenskihs \\ Degree of Master of Engineering \\ Department of Mechanical Engineering, McGill University \\ Montreal, Quebec, Canada
}

August 2, 2011

A thesis submitted to McGill University in partial fulfillment of the requirements of the degree of Master of Mechanical Engineering

(C) Vsevolods Kamenskihs 2011 


\section{DEDICATION}

This thesis is dedicated to my family and friends who supported and helped me throughout my research work. 


\section{ACKNOWLEDGMENTS}

I would like to thank Prof. John H.S. Lee for providing guidance throughout the course of my research work. The knowledge and advice that he shared with me during numerous discussions in his office allowed me to keep this project on the right track and make this contribution to the field of detonations.

I would also like to thank Anne Jesuthasan and Jean-Sébastien Grondin, who worked together with me in the lab, for creating an enjoyable work environment and sharing their experience and knowledge. In addition, I would like to thank Lydia Ouerdane for her interest and continuous help during the experimental part of this project.

Finally, I gratefully acknowledge the financial support I received from NSERC (Natural Sciences and Engineering Research Council of Canada) and FQRNT (Le Fonds Québécois de la Recherche sur la Nature et les Technologies) throughout the course of my thesis work. 


\section{TABLE OF CONTENTS}

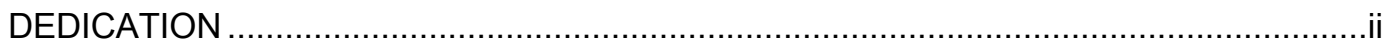

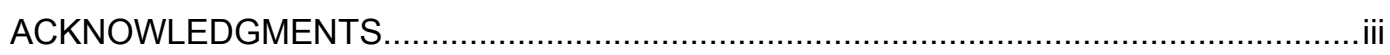

TABLE OF CONTENTS .....................................................................................

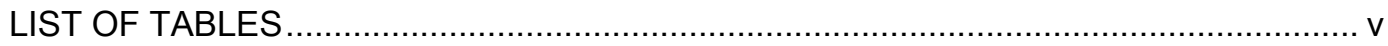

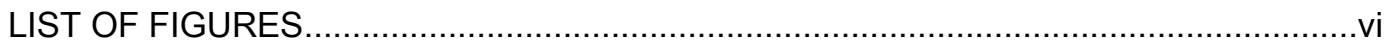

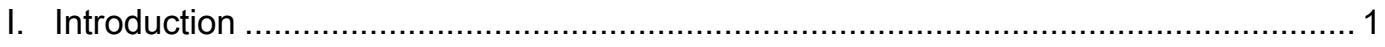

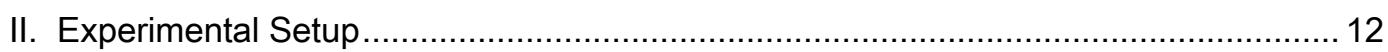

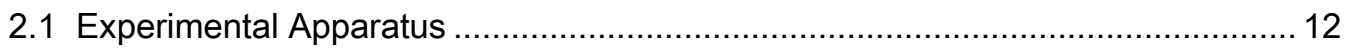

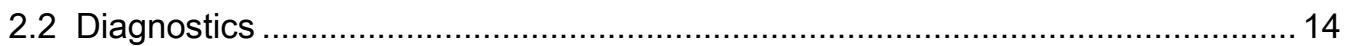

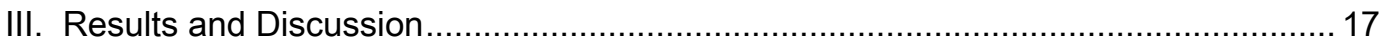

3.1 Detonation wave without an applied electric field............................................ 17

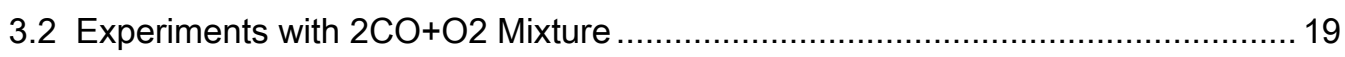

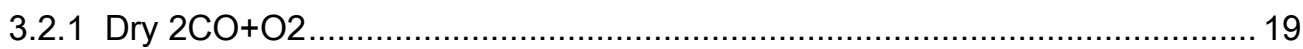

3.2.2 Moist 2CO+O2

3.3 Interaction between a detonation and electric field ......................................... 22

3.4 Experimental investigation of interaction of a detonation and an electric field...... 24

3.5 Interaction between a detonation and the electric field from two electrodes ......... 33

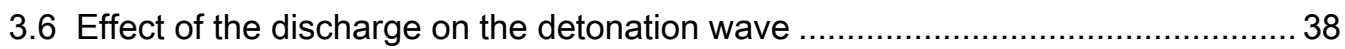

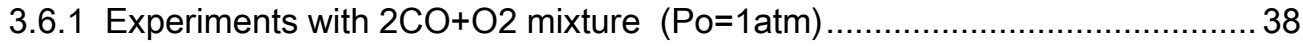

3.6.2 Experiments with $\mathrm{C} 2 \mathrm{H} 2+\mathrm{O} 2+85 \%$ Ar Mixture $(\mathrm{Po}=28 \mathrm{kPa}) \ldots \ldots \ldots \ldots \ldots \ldots \ldots \ldots . . . . . . . . . . . . . .40$

3.6.3 Minor effects of the discharge on the detonation wave................................ 41

3.6.4 Large effects of the discharge on the detonation wave ............................... 44

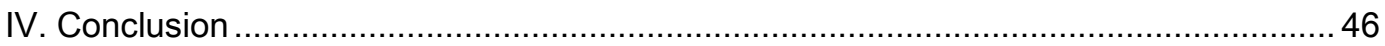

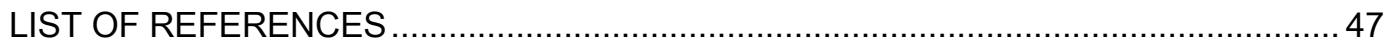

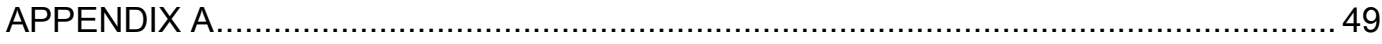

A.1 Undistorted Electric Field (single electrode) ............................................... 50

A.2 Undistorted Electric Field (prior to arrival of the detonation) (two electrodes) ...... 52

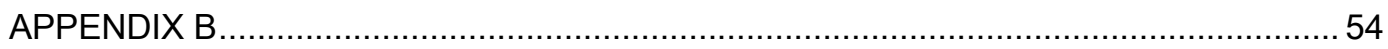

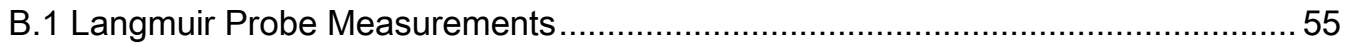

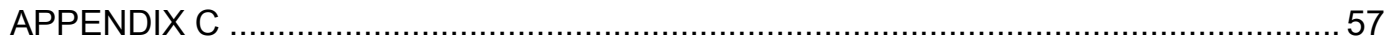

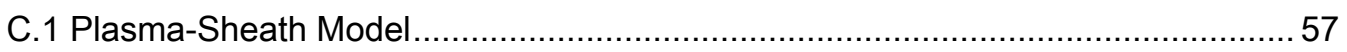




\section{LIST OF TABLES}

Table 1-1: Experimental results with moist $2 \mathrm{CO}+\mathrm{O} 2$ at varying potential gradients [2] ....6

Table 3-1: Saturation current values for various mixtures. ............................................ 23

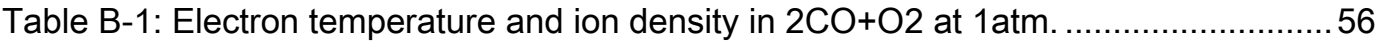




\section{LIST OF FIGURES}

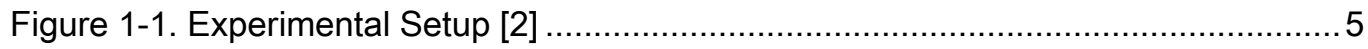

Figure 1-3. Bone et al. [2] Figure 39. 2CO+O2 (dry), $\mathrm{Po}=1 \mathrm{~atm}, \mathrm{E}=10 \mathrm{kV} / \mathrm{cm} \ldots \ldots \ldots \ldots \ldots . . .7$

Figure 1-4. Summary of experiments in $2 \mathrm{CO}+\mathrm{O} 2$ (moist) ........................................ 8

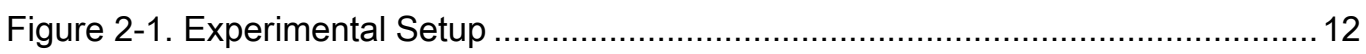

Figure 2-2. Experimental Setup - Field Test Section .............................................. 13

Figure 2-3. Experimental Setup - Gas Manifold ....................................................... 14

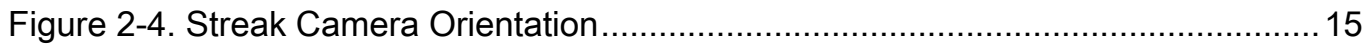

Figure 2-5. Field of view of streak camera and corresponding image of the detonation 16

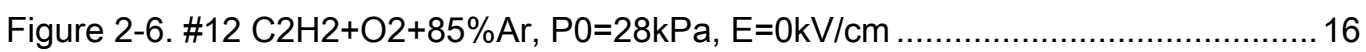

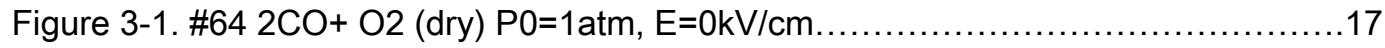

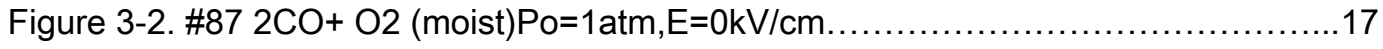

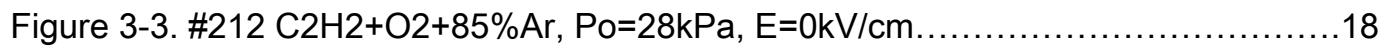

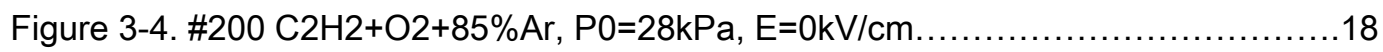

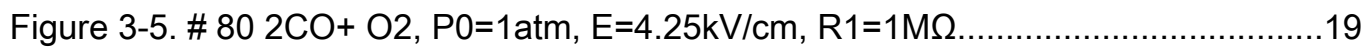

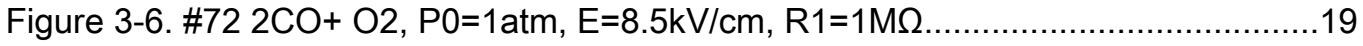

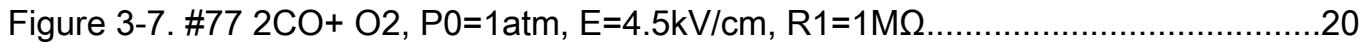

Figure 3-8. \#103 2CO+ O2, P0=1atm, E=5.2kV/cm, R1=1M $\Omega \ldots \ldots \ldots \ldots \ldots \ldots \ldots \ldots \ldots \ldots . . .20$

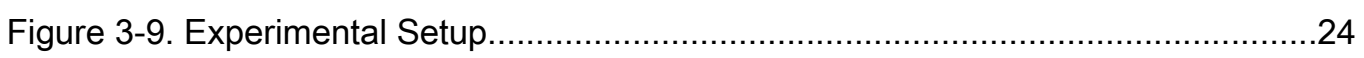

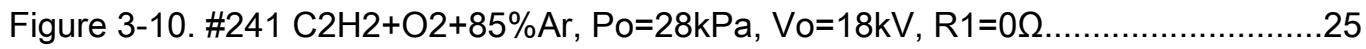

Figure 3-11. \#253 C2H2+O2+85\%Ar, $\mathrm{Po}=28 \mathrm{kPa}, \mathrm{Vo}=-18 \mathrm{kV}, \mathrm{R} 1=0 \Omega \ldots \ldots \ldots \ldots \ldots \ldots \ldots \ldots . . .25$

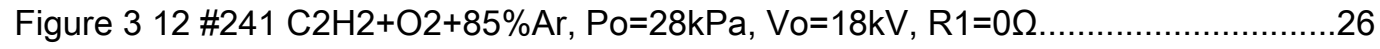

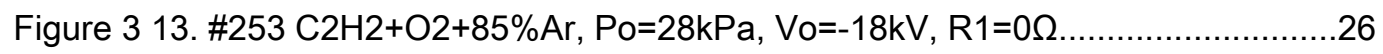

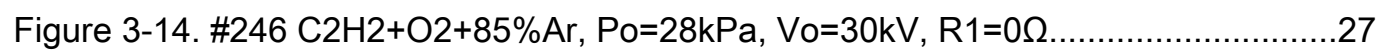

Figure 3 15. \#260 C2H2+O2+85\%Ar, $\mathrm{Po}=28 \mathrm{kPa}, \mathrm{Vo}=-30 \mathrm{kV}, \mathrm{R} 1=0 \Omega \ldots \ldots \ldots \ldots \ldots \ldots \ldots \ldots . .27$

Figure 3-16. \#246 C2H2+O2+85\%Ar, $\mathrm{Po}=28 \mathrm{kPa}, \mathrm{Vo}=30 \mathrm{kV}, \mathrm{R} 1=0 \Omega \ldots \ldots \ldots \ldots \ldots \ldots \ldots \ldots . . .28$

Figure 3-17 \#260 C2H2+O2+85\%Ar, $\mathrm{Po}=28 \mathrm{kPa}, \mathrm{Vo}=-30 \mathrm{kV}, \mathrm{R} 1=0 \Omega \ldots \ldots \ldots \ldots \ldots \ldots \ldots \ldots . .28$

Figure 3-18. Voltage distribution near a positively charge electrode..............................29

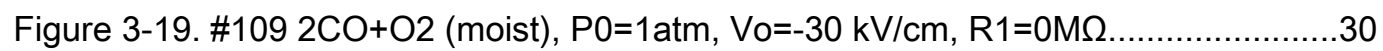

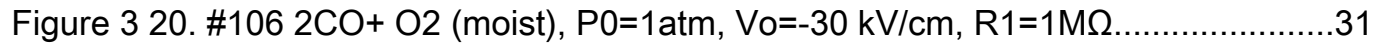

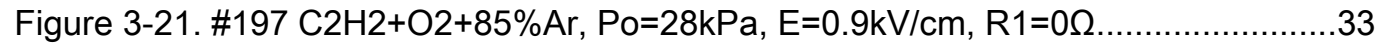

Figure 3-22. \#218 C2H2+O2+85\%Ar, Po=28kPa, $E=0.8 \mathrm{kV} / \mathrm{cm}, \mathrm{R} 1=0 \Omega \ldots \ldots \ldots \ldots \ldots \ldots \ldots . . .33$

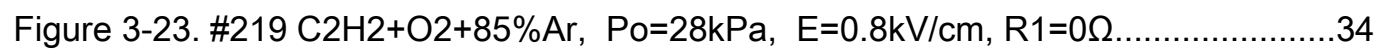

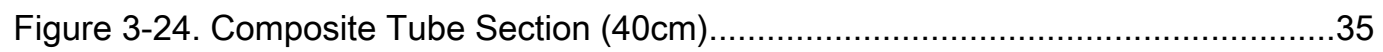

Figure 3-25. Current vs time (\#54_C2H2-O2-85\%Ar, $\mathrm{Po}=25 \mathrm{kPa}, \mathrm{E}=0.45 \mathrm{kV} / \mathrm{cm}) \ldots \ldots \ldots . .35$ 
Figure 3-26. Voltage evolution between two electrodes (40cm apart) (\#54_C2H2-O2-

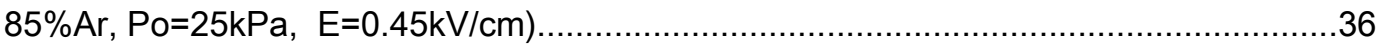

Figure 3-27. \#116 2CO+ $\mathrm{O} 2$ (moist), $\mathrm{P} 0=1 \mathrm{~atm}, \mathrm{E}=5 \mathrm{kV} / \mathrm{cm}, \mathrm{R} 1=0 \mathrm{M} \Omega \ldots \ldots \ldots \ldots \ldots \ldots \ldots \ldots . . . .38$

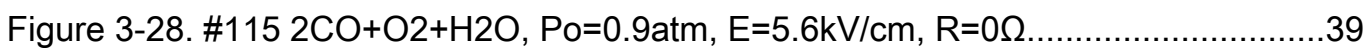

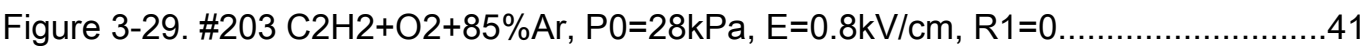

Figure 3-30. \#12 $\mathrm{C} 2 \mathrm{H} 2+\mathrm{O} 2+85 \% \mathrm{Ar}, \mathrm{P} 0=28 \mathrm{kPa}, \mathrm{E}=0.8 \mathrm{kV} / \mathrm{cm}, \mathrm{R} 1=0 \ldots \ldots \ldots \ldots \ldots \ldots \ldots \ldots . . .41$

Figure 3-31. \#203 C2H2+O2+85\%Ar, $\mathrm{P0}=28 \mathrm{kPa}, \mathrm{E}=0.8 \mathrm{kV} / \mathrm{cm}, \mathrm{R} 1=0 \ldots \ldots \ldots \ldots \ldots \ldots \ldots \ldots . . .42$

Figure 3-32. \#268 C2H2+O2+85\%Ar, $\mathrm{P0}=28 \mathrm{kPa}, \mathrm{E}=0.85 \mathrm{kV} / \mathrm{cm}, \mathrm{R} 1=0 \ldots \ldots \ldots \ldots \ldots \ldots \ldots . . .42$

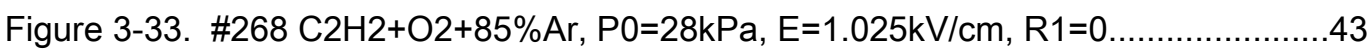

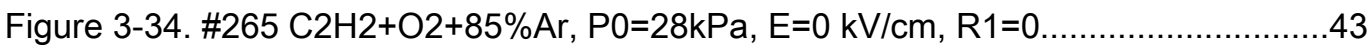

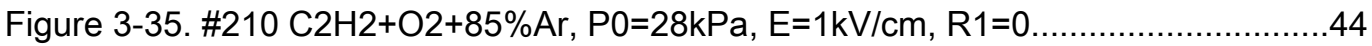

Figure 3-36 \#207 C2H2+O2+85\%Ar, P0=28kPa, E=0.95kV/cm, R1=0 .....................44

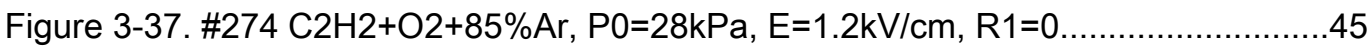

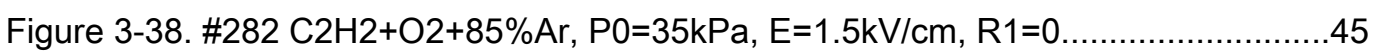

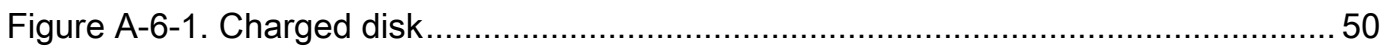

Figure A-6-2. Combination of charged shell and two charged disks .............................50

Figure A-6-3. Initial Voltage Distribution at 18kV ...................................................... 51

Figure A-6-4. Initial Electric Field Distribution at 18kV ................................................ 52

Figure A-6-5. Voltage Profile (two electrodes) at 18kV ................................................53

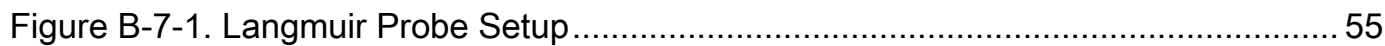

Figure B-7-2. IV Characteristic for a double Langmuir Probe).................................. 55

Figure C-1. Distribution of density of charged particles and potential in plasma and

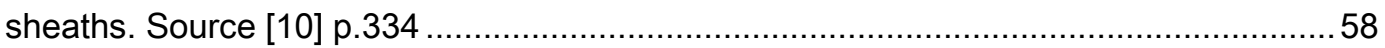

Figure C-2. Electric potential variation near the surface of a negatively charged probe.

Source: [10] p.61 .59 


\begin{abstract}
The present thesis reports an investigation of the effects of an axial electric field $(200 \mathrm{~V} / \mathrm{cm}-8000 \mathrm{~V} / \mathrm{cm})$ on the propagation of detonation waves in mixtures of $2 \mathrm{CO}+\mathrm{O} 2$ and $\mathrm{C} 2 \mathrm{H} 2+\mathrm{O} 2+85 \%$ Ar. High speed streak camera together with photodiodes was used for detonation velocity and position measurements. Additionally, the voltage across the axial electrodes and the current in the field circuit were also monitored as the detonation traversed the electric field region. The experimental results show that the charged particles within the detonation reaction zone are attracted to the surface of the electrode creating a sheath at the boundary of the electrode that shields the bulk of the detonation plasma from further influence of the DC electric field of the electrode. The present results also show that the neither the detonation structure nor its velocity are influenced by the presence of the sheath and the resulting current to the electrode. It is also found that the conducting gas behind the detonation wave carries the voltage across the test section to the second (ground) electrode. In an axial electrode configuration the detonation wave essentially reduces the gap between the two electrodes progressively as it propagates in the test section. The increase of the electric field ahead of the detonation may result in a breakdown of the unburned mixture ahead of the detonation and the development of a discharge. For a sufficiently high electric field an arc discharge occurs ahead of the detonation
\end{abstract}


igniting the unburnt mixture upstream of the detonation. The lack of fresh mixture ahead of the detonation results in failure of the detonation, but subsequent reinitiation of the detonation may occur. The present study also indicates that contrary to the previous observations by Bone et el, no significant effect of the applied electric field on the detonation is observed except for cases where breakdown of the unburned mixture ahead of the detonation occurs. 


\begin{abstract}
ABRÉGÉ
Cette étude décrit une analyse expérimentale dans le but de déterminer les effets que produit un champ électrique axiale ( $200 \mathrm{~V} / \mathrm{cm}-8000 \mathrm{~V} / \mathrm{cm}$ ) sur la propagation d'une vague de détonation gazeuse dans les mélanges stœchiométriques de $2 \mathrm{CO}+\mathrm{O}_{2}$ et $\mathrm{C}_{2} \mathrm{H}_{2}+\mathrm{O}_{2}$, dilué avec $85 \%$ d'argon. Des photographies de haute vitesse ainsi que des photodiodes ont été utilisées pour obtenir des mesures de la vitesse et de la position de la détonation. De plus, des mesures du voltage entre les électrodes positionnées axialement ainsi que du courant passant par le circuit du champs électrique ont été enregistrées durant la traversée de la détonation dans la zone du champs électrique.

Les résultats expérimentaux montrent que les particules chargées dans la zone de réaction de la détonation sont attirées vers la surface de l'électrode. Ce phénomène crée une couche de protection à la frontière de l'électrode qui rends ainsi le coeur du plasma de détonation impérméable à l'influence du champs electrique DC provenant de celle-ci.

Ces résultats permettent aussi de démontrer que ni la structure de la détonation ni sa vitesse ne sont influencées par la présence de cette couche de protection ainsi que par le courant généré par le mouvement des ions.

Il se dégage de ces expériences que le gas conducteur derrière l'onde de choc de la détonation conduit le voltage le long de la section de test jusqu'à la
\end{abstract}


seconde électrode ( terre). Dans ce type de configuration, l'onde de choc en se propageant dans la section de test réduit la distance inter-électrode progressivement . L'augmentation du champs électrique devant la détonation peut être interprété par la rupture diélectrique du mélange non brûlés devant la détonation, ce qui entraine le développement d'une décharge électrique. Pour un champ électrique assez fort, un arc électrique peut allumer le mélange non brûlé en amont de la détonation. Le manque de mélange frais (non-brûlé) devant la détonation entraine l'échec de celle-ci, mais un réallumage peut se produire ultérieurement.

L'étude démontre ainsi que contrairement à l'observation précédente faites par Bone \& al, le champs electrique appliqué n'a que peu d'effet sur la détonation sauf lorsque les gazs frais rompent diélectriquement en amont de l'onde de détonation. 


\section{Introduction}

Due to chemi-ionization and to a much lesser extent, thermal ionization, there is a concentration of ions and electrons in the non-equilibrium reaction zone and in the product of a detonation wave. Hence, in the presence of an electric and magnetic field, there will be an interaction of the detonation wave with the electromagnetic field. The interaction may modify the distribution of the charged species and hence may influence the chemical reactions. Also, body forces (electrostatic and Lorentz) may be generated that can influence the propagation of the detonation. The interaction of a detonation with an electromagnetic field has not received much attention in the past. In the present thesis the results of a study of the propagation of a detonation in an axial electric field is presented.

\section{Literature Review}

The research work on the electrical nature of the detonation waves can be split into two main categories: 1 . Studies focused on measurements of electrical properties of the detonations such as the degree of ionization and conductivity and 2. Studies that investigate the behavior of the detonation when an external electromagnetic field is applied. Both of these categories of research are important since they are closely interconnected.

\section{Electrical properties of the detonations}

The electrical properties of ionized gas largely depend on electron density, which in an equilibrium plasma is equal to ion density. Various researchers used different methods for estimating the electron density in detonation plasma. Cavenor [7] used a simple D.C. probe technique in $\mathrm{H} 2-\mathrm{O} 2$ detonations at 1atm.A Langmuir symmetric double probe was mounted on the detonation tube wall. As the detonation swept by the probe the current drawn by the probe was recorded for various bias voltages. Using Langmuir theory the electron and ion concentrations were obtained from the saturation current measurements. He observed a decreasing gradient of ion concentration from $10^{13}$ ions $/ \mathrm{cm}^{-3}$ near the 
head of the detonation to $10^{12}$ ions $/ \mathrm{cm}^{-3}$ in the end of the combustion zone. The ion density in the combustion products zone was found to be in good agreement with theoretical values, obtained from solving the Saha equation. The high ion densities in the reaction zone of the detonation were attributed to chemi-ionization. The gradient of charged species throughout the reaction zone suggests a gradient in the conductivity of detonation plasma, which implies a non-uniform interaction with the electric field. Basu and Fay [6] obtained ion concentrations similar to Cavenor [7] in the oxy-acetylene detonations at various initial pressures. From the electron density they calculated the value of the specific conductivity $\sigma(\mathrm{mho} / \mathrm{cm})$ for various initial pressures. Details of this calculation are given by Chapman [17]. Their results indicate an order of magnitude increase in conductivity from $\sim 10^{-4} \mathrm{mhos} / \mathrm{cm}$ to $10^{-3} \mathrm{mhos} / \mathrm{cm}$ as the pressure is increased from $0.02 \mathrm{~atm}$ to $1 \mathrm{~atm}$. This result suggests that the behaviour of the detonation in an electric field should not significantly change with pressure. Edwards and Lawrence [16] used measurements of the reflection and transmission of $3 \mathrm{~cm}$ wavelength microwaves by detonation waves in stoichiometric oxyhydrogen seeded with nitrogen, and oxy-acetylene mixtures to determine the ion concentration and level of conductivity in these mixtures. They reported a relatively small increase conductivity $\left(0.3 * 10^{-4}-\right.$ $2.3 * 10^{-4} \mathrm{mhos} / \mathrm{cm}$ ) in oxyhydrogen detonations as the initial pressure was increased from $0.01 \mathrm{~atm}$ to $1 \mathrm{~atm}$. Their experiments with oxyacetylene detonations at an initial pressure of $13 \mathrm{kPa}$ yield values of ion density and gas conductivity that are in agreement with the previous studies to within an order of magnitude. Similar to the results reported by Cavenor for oxyhydrogen detonations, Edwards and Lawrence showed that the ion concentration in the ionized gas behind the detonation is not uniform, but follows a decreasing gradient. They determined that that the ion concentration decays in accordance with a second-order rate equation $\frac{d N}{d t}=-\alpha N^{2}$, where $\alpha$ is the ion-electron recombination rate constant. From the slope of the inverse of ion concentration $[1 / \mathrm{N}] \mathrm{vs}$ gas time behind the detonation $\alpha$ was found to be $1.5 * 10^{-7} \mathrm{~cm}^{3} / \mathrm{s}$, which is in reasonable agreement with the value found by King (I957) of $2.5 * 10^{-7} \mathrm{~cm}^{3} / \mathrm{s}$ for a methane-air detonation at a pressure of $6 \mathrm{kPa}$, using a Langmuir probe technique. The second order nature of the ion-electron recombination rate suggests that the gas behind 
the detonation stays weakly ionized for a relatively long time after the passage of the detonation. Thus, the combustion products behind the detonation are not a perfect insulator and an axial electric field can still be transmitted through them.

In summary, most of the studies on electrical properties of detonations observed low conductivities of the detonation plasma $\left(\sim 10^{-3}-10^{-4} \mathrm{mhos} / \mathrm{cm}\right)$ and low electron and ion densities in the reaction zones of the detonation $\left(\sim 10^{11} \mathrm{~cm}^{-3}-\sim 10^{13} \mathrm{~cm}^{-3}\right)$. These quantities were reported to follow a decreasing gradient in the reaction zone and vary within an order of magnitude for various initial pressures (0.1-1atm). Similar values of ion concentration and electrical conductivity were found for mixtures of various compositions.

\section{Interaction of detonation with EM field}

One of the early studies on the interaction of detonations with an electromagnetic field was carried out by Dixon and coworkers (1914) [1]. They followed a suggestion by Sir J.J. Thomson, who speculated that if the free electrons and ions were present in the reaction zone of a detonation wave then a magnetic or an electric field could influence the distribution of the charged species in the reaction zone, which could modify the rates of chemical reactions in the combustion zone and therefore can have a significant effect on the propagation of the detonation. For the case of a magnetic field the electrons would curl up in the magnetic field and start revolving in circular paths, which are perpendicular to the direction of the field. With this idea in mind Dixon and coworkers [1] studied detonations in five different mixtures in $1914(2 \mathrm{H} 2+\mathrm{O} 2,2 \mathrm{CO}+\mathrm{O} 2, \mathrm{C} 2 \mathrm{H} 2+5 \mathrm{O} 2$, $\mathrm{C} 2 \mathrm{~N} 2+\mathrm{O} 2+\mathrm{N} 2$ and $\mathrm{CS} 2+3 \mathrm{O} 2$ ) in a transverse magnetic field of up to 10,000 gauss. However, no visible influence of the field on the detonation was observed [1]. Subsequently in 1935 Bone and coworkers [2] conducted similar experiments with a higher transverse magnetic field (up to 35,000 gauss), however, no significant disturbance of the detonation was recorded. The electric field, on the other hand, provided a more promising means of influencing the combustion wave. It is known flames conduct electricity due to the presence of free electrons and ions in the combustion zone. Several studies (e.g Lawton and Mayo [15]) showed that when an 
electric field is applied to a flame, the flame is pulled in the direction of positive ion flow towards the negative electrode. This effect is referred to as the ionic wind induced by the presence of an electric field. Numerous other studies $[13,14]$ further confirmed that for low velocity $(\sim 0.4 \mathrm{~m} / \mathrm{s})$ flame systems the body force exerted on the ions by the electric field $\left(\sim 400 \mathrm{dyn} / \mathrm{cm}^{3}\right)$ can significantly change the shape of the flame due to momentum transfer by positive ions. Bone and coworkers in their earlier experiment (1931) have successfully shown that a $2 \mathrm{CO}+\mathrm{O}_{2}$ flame that was ignited at a point mid-way between the two poles of a strong field was positively affected when travelling toward the negative pole and its propagation was slowed in the direction of the positive electrode. This experiment confirmed their view that the combustion process is influenced by presence of CO+ ions. In a follow up study in 1935, Bone and coworkers [2] decided to investigate the influence of electric fields on spinning detonation in $2 \mathrm{CO}+\mathrm{O}_{2}$ since the spiralling head of the detonation contains the large concentration of $\mathrm{CO}+$ ions due to intense combustion in that zone. The main objective of their study was to see if a strong electric field can disperse or consequently arrest the detonation by pulling the positive $\mathrm{CO}+$ ions from the reaction zone of the detonation. In their experiments with $2 \mathrm{CO}+\mathrm{O} 2$ they observed a $40 \%$ velocity deficit when the detonation entered the region of high electric field. Bone and coworkers [2] speculated that the reason for the observed effect was the decrease in the ion concentration due to the presence of the electric field that pulls the $\mathrm{CO}+$ ions out of the reaction zone. The decrease in ion concentration in would slow down the rates of chemical reactions in the reaction zone and could potentially lead to the failure of the detonation. In order to better understand the results obtained by Bone and co-workers [2] a more detailed review of their experiments is provided in the next section.

Review of the study by Bone, Fraser and Wheeler [2]

\section{Experimental Details}

The experimental setup used in Bone and coworkers' [2] experiment consisted of a

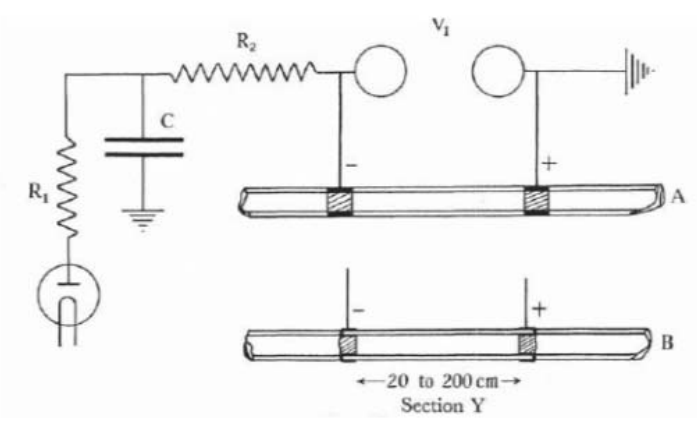

$13 \mathrm{~mm}$ (I.D.) glass detonation tube and stainless steel cylinder electrodes that were inserted in series with the tube. The spacing

Figure 1-1. Experimental Setup [2] 
between electrodes was varied from $10 \mathrm{~cm}$ to $200 \mathrm{~cm}$. The electric field was applied in between the two electrodes though a HV transformer, providing electric field gradients of $500-10,0000 \mathrm{~V} / \mathrm{cm}$. It should be noted that in their diagram of the field generating circuit

(Figure 1-2) Bone and coworkers [2] marked the grounded electrode as ' + ' and the high voltage electrode as ' - '. Thus, the high voltage electrode was negatively biased (below ground potential). This was done to achieve maximum influence on the positive $\mathrm{CO}+$ ions as the detonation swept by the electrode. The high voltage electrode was connected to the output of the HV transformer through a resistor $\mathrm{R}_{2}=1 \mathrm{M} \Omega$ and a smoothing capacitor $\mathrm{C}=0.007 \mu \mathrm{F}$. Resistor $\mathrm{R}_{1}$ was used as a charging resistor for the capacitor and $\mathrm{R}_{2}=1 \mathrm{M} \Omega$ was used as a current limiting resistor in the case a discharge occurs between the two electrodes occurs. In a typical experiment the $2 \mathrm{CO}+\mathrm{O}_{2}$ was admitted into the detonation tube at atmospheric conditions, the electric field was applied and the mixture was ignited. A high speed streak camera was used to photograph the resulting detonation wave as it entered, passed through, and emerged from the electric field. Bone [2] reported that there was never any visible sign of discharge during the passage of the [detonation] flame between electrodes.

\section{$\underline{\text { Results }}$}

In their study Bone and coworkers [2] investigated the effect of an axial electric field in several mixtures: 1 . moist (saturated with water) $2 \mathrm{CO}+\mathrm{O}_{2}, 2$. dry $2 \mathrm{CO}+\mathrm{O}_{2}$, and 3 . stoichiometric mixture of $\mathrm{CH}_{4}-\mathrm{O}_{2}$. All experiments were conducted at atmospheric initial pressure. For each mixture the applied electric field strength was varied from $0.5 \mathrm{kV} / \mathrm{cm}$ to $10 \mathrm{kV} / \mathrm{cm}$. Bone and coworkers [2] classified their results into four categories, based on the effect of the electric field had on the detonation. More specifically, Bone and coworkers [2] reported minimum, small, medium and maximum effects of the electric field.

\section{Minimum Effects}

Experiments where no significant change in the detonation speed, and only a slight momentarily disturbance of the spinning structure of the detonation wave were observed, 
were classified under minimum effects of the electric field. In all the experiments with dry $2 \mathrm{CO}+\mathrm{O}_{2}$ even at the highest $10 \mathrm{kV} / \mathrm{cm}$ potential gradient (Figure 1-3) only the minimum effect was observed. Also none of the experiments with $\mathrm{CH}_{4}-\mathrm{O}_{2}$ showed any measurable effects of electric field on the detonation. For moist $2 \mathrm{CO}+\mathrm{O}_{2}$ a total of 42 experiments were conducted, varying the potential gradient from $0.5 \mathrm{kV} / \mathrm{cm}$ to $5.7 \mathrm{kV} / \mathrm{cm}$. Table 1. summarizes the results of these experiments. As seen in the table minimum effects were observed in 7 out of 42 experiments.

\begin{tabular}{|c|c|c|c|c|c|c|c|c|c|}
\hline \multirow[b]{3}{*}{$\begin{array}{l}\text { Potential } \\
\text { gradient } \\
\text { Volts/cm }\end{array}$} & \multicolumn{2}{|c|}{ XI-EFFEGTs } & $\begin{array}{r}2 \mathrm{CO}+\mathrm{O}_{2} \\
\text { Positive }\end{array}$ & \multicolumn{2}{|c|}{$\begin{array}{l}\text { Detonation in } \\
\text { Elegtric Fields }\end{array}$} & \multicolumn{4}{|c|}{ Traversing Negative to } \\
\hline & Distance & Time for & & & & & & $\begin{array}{l}\text { Appro } \\
\text { percen }\end{array}$ & 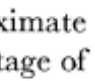 \\
\hline & $\begin{array}{c}\text { apart of } \\
\text { electrodes } \\
\mathrm{cm}\end{array}$ & $\begin{array}{l}\text { flame to } \\
\text { traverse } \\
\text { field } \\
\text { millisec }\end{array}$ & $\begin{array}{l}\text { Total } \\
\text { experi- } \\
\text { ments }\end{array}$ & $\begin{array}{l}\text { Minimum } \\
\text { effect }\end{array}$ & $\begin{array}{r}\text { Small } \\
\text { effects }\end{array}$ & $\begin{array}{l}\text { Medium } \\
\text { effects }\end{array}$ & $\begin{array}{l}\text { Maximum } \\
\text { effect }\end{array}$ & $\begin{array}{l}(a) \\
\text { Min. } \\
\text { Eff }\end{array}$ & $\begin{array}{l}(b) \\
\text { Max. } \\
\text { cts }\end{array}$ \\
\hline $500-600$ & 200 & $1 \cdot 14$ & 12 & 3 & 6 & 1 & 2 & 25 & 17 \\
\hline 2,000 & 50 & $0 \cdot 29$ & 10 & 2 & 5 & 0 & 3 & 20 & 30 \\
\hline $3,000-3,500$ & 30 & $0 \cdot 17$ & 9 & 2 & 1 & 2 & 4 & 20 & 45 \\
\hline $5,250-5,750$ & 20 & $0 \cdot 114$ & 11 & 0 & 0 & 1 & 10 & Nil & 90 \\
\hline Totals & - & - & 42 & 7 & 12 & 4 & 19 & - & - \\
\hline
\end{tabular}

Table 1-1. Experimental results with moist $2 \mathrm{CO}+\mathrm{O} 2$ at varying potential gradients [2]

\section{$\underline{\text { Small Effects }}$}

Experiments where a $50-100 \mathrm{~m} / \mathrm{s}$ change in the detonation speed, and only a slight disturbance of the spinning structure of the detonation wave were observed were classified under small effects of the electric field. Small effects were observed in 12 out of 42 experiments in moist $2 \mathrm{CO}+\mathrm{O}_{2}$. The majority of these effects were observed in the range of potential gradients between $0.5 \mathrm{kV} / \mathrm{cm}$ and $2 \mathrm{kV} / \mathrm{cm}$.

\section{$\underline{\text { Medium Effects }}$}

Experiments where there was a visible disturbance of the spinning structure accompanied by a detonation velocity deficit of $100-350 \mathrm{~m} / \mathrm{s}$ were classified as medium effects of the electric field. These effects were least observed in the experiments. They occurred in only 
4 out of 42 experiments in the range of potential gradients between $3 \mathrm{kV} / \mathrm{cm}$ and $5.7 \mathrm{kV} / \mathrm{cm}$.

\section{Maximum Effects}

A complete suppression of the spinning structure of the detonation accompanied by a large detonation velocity deficit $(800 \mathrm{~m} / \mathrm{s})$ was observed in 19 out of 42 experiments (Figure 1-2). These effects were classified under the maximum effects of the electric field. The majority of these effects were observed in the experiments with the potential gradient of $5.2 \mathrm{kV} / \mathrm{cm}$ to $5.7 \mathrm{kV} / \mathrm{cm}$. The remaining 8 experiments occurred in range of $0.5 \mathrm{kV} / \mathrm{cm}$ to $3 \mathrm{kV} / \mathrm{cm}$.

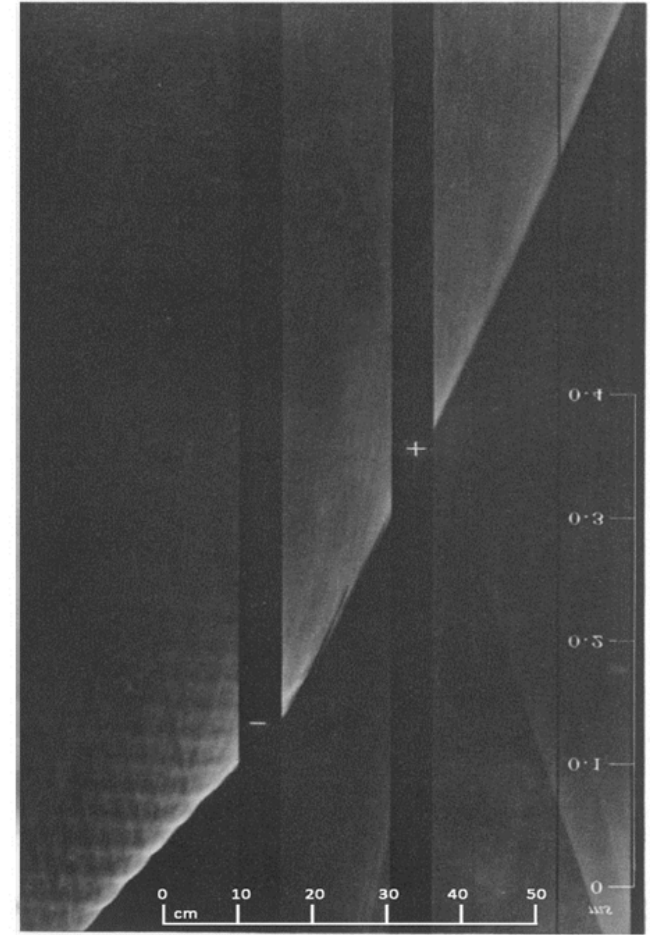

Figure 1-2. Bone et al. [2] Figure 32. $2 \mathrm{CO}+\mathrm{O} 2$ (moist), $\mathrm{Po}=1 \mathrm{~atm}, \mathrm{E}=5 \mathrm{kV} / \mathrm{cm}$

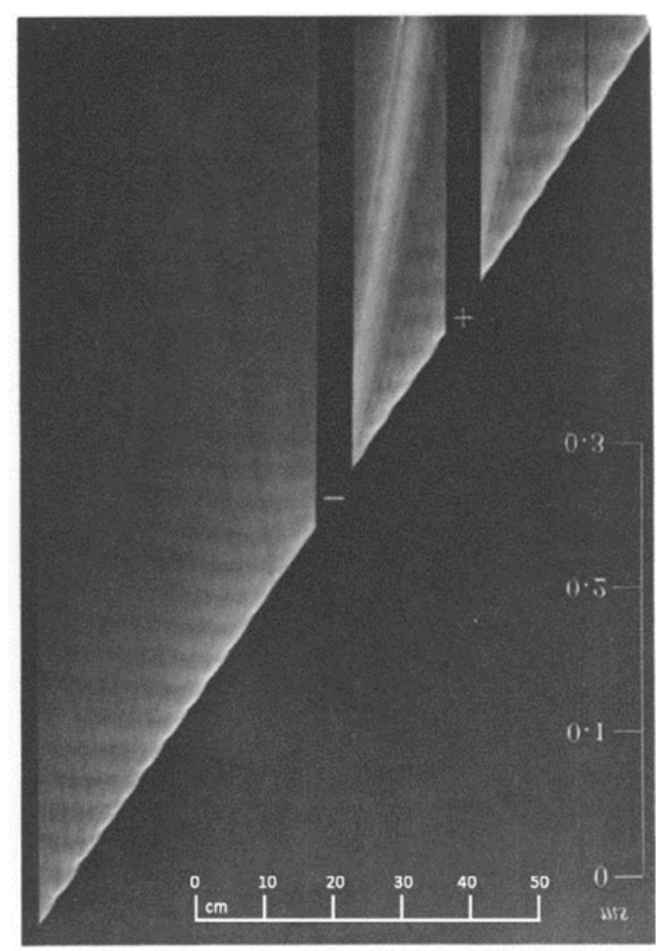

Figure 1-3. Bone et al. [2] Figure 39. $2 \mathrm{CO}+\mathrm{O} 2$ (dry), $\mathrm{Po}=1 \mathrm{~atm}, \mathrm{E}=10 \mathrm{kV} / \mathrm{cm}$

In summary, Bone and coworkers [2] observed no effect of electric field on detonation waves in dry $2 \mathrm{CO}+\mathrm{O}_{2}$ and in $\mathrm{CH}_{4}-\mathrm{O}_{2}$. The effects observed for the moist $2 \mathrm{CO}+\mathrm{O}_{2}$ range from small to maximum and follow a broad distribution across the range of electric 


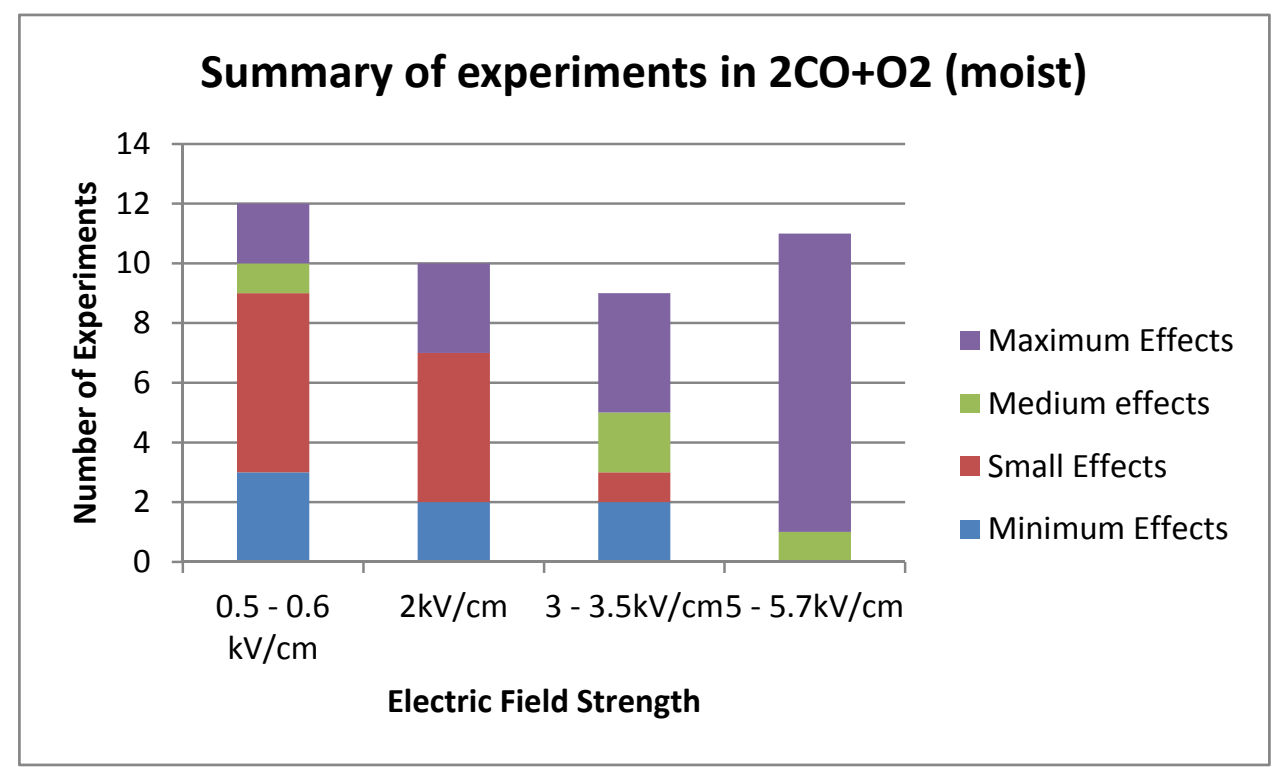

Figure 1-4. Summary of experiments in $2 \mathrm{CO}+\mathrm{O} 2$ (moist)

field strength as seen in Figure 1-3. The figure above shows that as the electric field strength increases the presence of small effects (in red) of the electric field decreases and the presence of maximum effects (in purple) increases. Even though the majority of the maximum effects were observed at the highest field strength of around $5 \mathrm{kV} / \mathrm{cm}$ there are still 2 experiments where these effects were observed at the lowest applied field strength of $0.5 \mathrm{kV} / \mathrm{cm}$. Thus, the relationship between the presence of a large velocity deficit ( $40 \%$ $\mathrm{CJ}$ for maximum effects) and the electric field strength is not clear and needs further investigation. In his conclusion Bone suggests that the observed decrease in propagation velocity of the spinning detonation wave is a result of $\mathrm{CO}+$ ions being pulled back by the electric field from the reaction zone. The resulting decrease in ion concentration in the reaction zone slows down the rates of chemical reactions and has an adverse effect on the detonation. However, these are only speculations on part of Bone and coworkers [2]. Using the value of $\sim 10^{13} \mathrm{~cm}^{-3}$ for ion density in the front of the reaction zone the body force associated with an external electric field can be readily calculated $F=E e N_{i} A L \approx$ $0.03 N$, where $\mathrm{E}$ is the value of the applied electric field, $e$ is the electron elementary charge, $N_{i}$ is the ion density, A is the tube cross sectional area and $\mathrm{L}$ is the tube length. For a $10 \mathrm{~cm}$ long, $12.7 \mathrm{~mm}$ diameter tube the associated electric field body force is 
negligible as compared to the dynamic pressure forces of the detonation. Therefore, the effect observed by Bone and co-workers [2] cannot be attributed to the body force of the electric field. Thus, the results obtained by Bone and co-workers [2] are inconclusive and further research into the interaction between an axial electric field and the detonation wave is required.

Other studies on interaction of detonation with EM field

In order to better understand the interaction of detonation and an electromagnetic field a number of studies using both electric and magnetic fields were carried out over the past decades motivated largely by the possibility of power generation from ionized gas flow in MHD channels. Kelly and Toong [3] studied the propagation of detonation waves in a transverse magnetic and electric field. They observed only a slight (10\%) velocity deficit in unseeded oxyacetylene detonations at 30-100 Torr when a detonation passed through a region of high axial magnetic and transverse electric field. They attributed this velocity deficit to Hall effect and Lorenz force that altered the current distribution in the ionized gas behind the detonation. They also stated that the increased turbulence of the boundary layer at the electrode surface due to development of arc discharges contributed to the velocity deficit. These results suggest that unlike an axial field a transverse electric field has only marginal effects on detonation wave. Moreover, the results of Kelly and Toong [3] suggest that the effect of a transverse field largely depends on the presence of an external magnetic field and on relatively high current (order of a few amperes) passing through the reaction zone. Even though no current measurements were performed in the study by Bone and coworkers [2] the presence of a $1 \mathrm{M} \Omega$ resistor in series with the capacitor (see Figure 1-1.) indicates that any current passing through the detonation would be on the order or mA. Thus, an axial field could provide a higher influence on the detonation at a lower power.

Another study on application of the transverse electric field to detonation waves was conducted by G.O. Thomas and coworkers [4]. G.O. Thomas and coworkers [4] investigated the enhancement of the detonation wave in oxyacetylene mixtures at 100200 Torr by supplementing the chemical energy release in the detonation reaction zone 
by heat energy generated via ohmic heating. However, the enhancement of the detonation wave was small since the ratio of ohmic heating to combustion chemical energy release was small (0.01). The main reason for low energy conversion potential of the detonation plasma is due to low electrical conductivity $\left(\sim 10^{-3}-10^{-4} \mathrm{mhos} / \mathrm{cm}\right.$ ) (when no discharges are present). Moreover, Thomas [4] observed that the efficiency of ohmic heating of the gas behind the detonation was reduced by the development of an arc discharge, which altered the gas conductivity values and prevented uniform heating of the gas, since all the energy release was constricted to a very narrow arc channel. The development of an arc discharge in the presence of a high electric field was also reported by Kelly and Toong [3] and even though Bone and co-workers [2] did not observe any discharge in their streak photographs the presence or absence of a discharge in an axial field configuration is still unknown and needs further investigation.

In summary, most of the studies on the interaction of electromagnetic field and detonation wave do not show a significant influence of the field on the detonation. This can be attributed to the low degree of ionization and large differences between the force due to the dynamic pressure of the detonation and the electrostatic and Lorenz forces of the electromagnetic field. The study by Bone and co-workers [2] is the only one that shows a large velocity deficit. However, the results of Bone and co-workers [2] experiment are inconclusive. Moreover, their experiment was never reproduced and the effect of an axial electric field on the detonation is not covered in the published literature. Thus, the mechanism of interaction between an axial DC electric field and the detonation needs further investigation.

\section{$\underline{\text { Research objectives }}$}

The main objective of the current study is to understand the mechanisms of interaction between the detonation wave and an axial DC electric field and determine under which conditions an axial DC electric field can have a significant influence on the detonation wave. 
In the first part of the current study the experiment conducted Bone and coworkers [2] is repeated at the same initial conditions in order to confirm if the observations reported by them can be reproduced. In addition to the $2 \mathrm{CO}+\mathrm{O} 2$ (dry and moist) mixture at $1 \mathrm{~atm}$ (used by Bone and coworkers [2]) the current study will test the effect of an axial electric field in low pressure $(0.28 \mathrm{~atm}) \mathrm{C} 2 \mathrm{H} 2+\mathrm{O} 2+85 \% \mathrm{Ar}$ mixture. The second part of the study will focus on investigating the mechanisms of interaction between a detonation wave in an axial DC field. In order to determine the how the detonation interacts with the axial field both at high and low initial pressure, measurements of current and voltage in the field test section are conducted alongside with the high speed streak photography. 


\section{Experimental Setup}

\subsection{Experimental Apparatus}

The experiments were conducted in a detonation tube consisting of two sections - the driver and the test section (Figure 2-1). The driver section is a $50.8 \mathrm{~mm}$ diameter

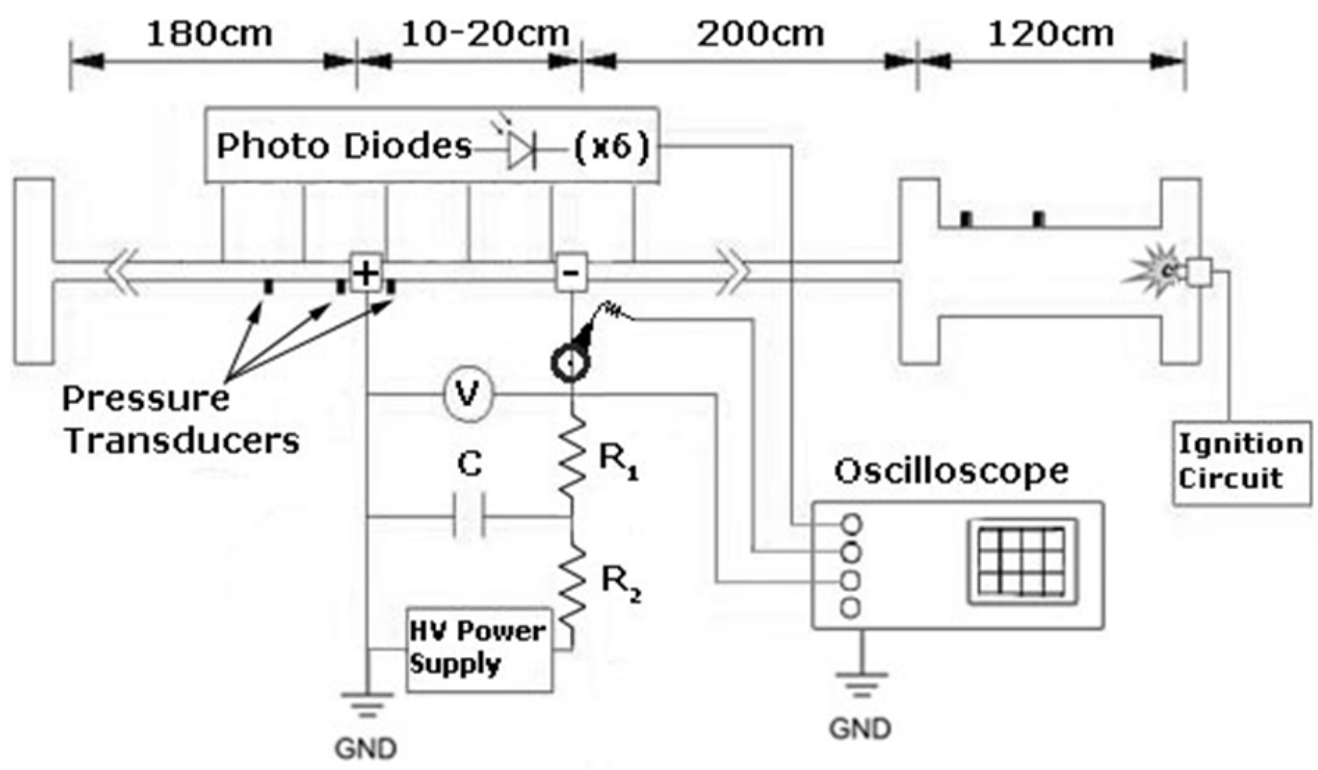

Figure 2-1. Experimental Setup

steel tube, $1.2 \mathrm{~m}$ long. The detonation was initiated in the driver section by a spark discharge from a $2 \mathrm{uF} \mathrm{HV}$ capacitor bank. Two pressure transducers were mounted in the driver section to make sure a steady $\mathrm{CJ}$ detonation was initiated in the steel tube prior to entering the test section. Three pressure transducers were also mounted near the grounded electrode to monitor the pressure upstream of the detonation as it traversed the electric field. The test section consists of a polycarbonate tube $12.7 \mathrm{~mm}$ in diameter with a total length of $4 \mathrm{~m}$. Two polished stainless steel cylinders were used as electrodes in the test section. These electrodes (marked "-" and "+" in Figure 2-1) were inserted in series with the transparent polycarbonate tube to form a continuous detonation tube (Figure 2-2). The spacing between the electrodes was varied from $4 \mathrm{~cm}$ to $20 \mathrm{~cm}$. 
Photoprobes

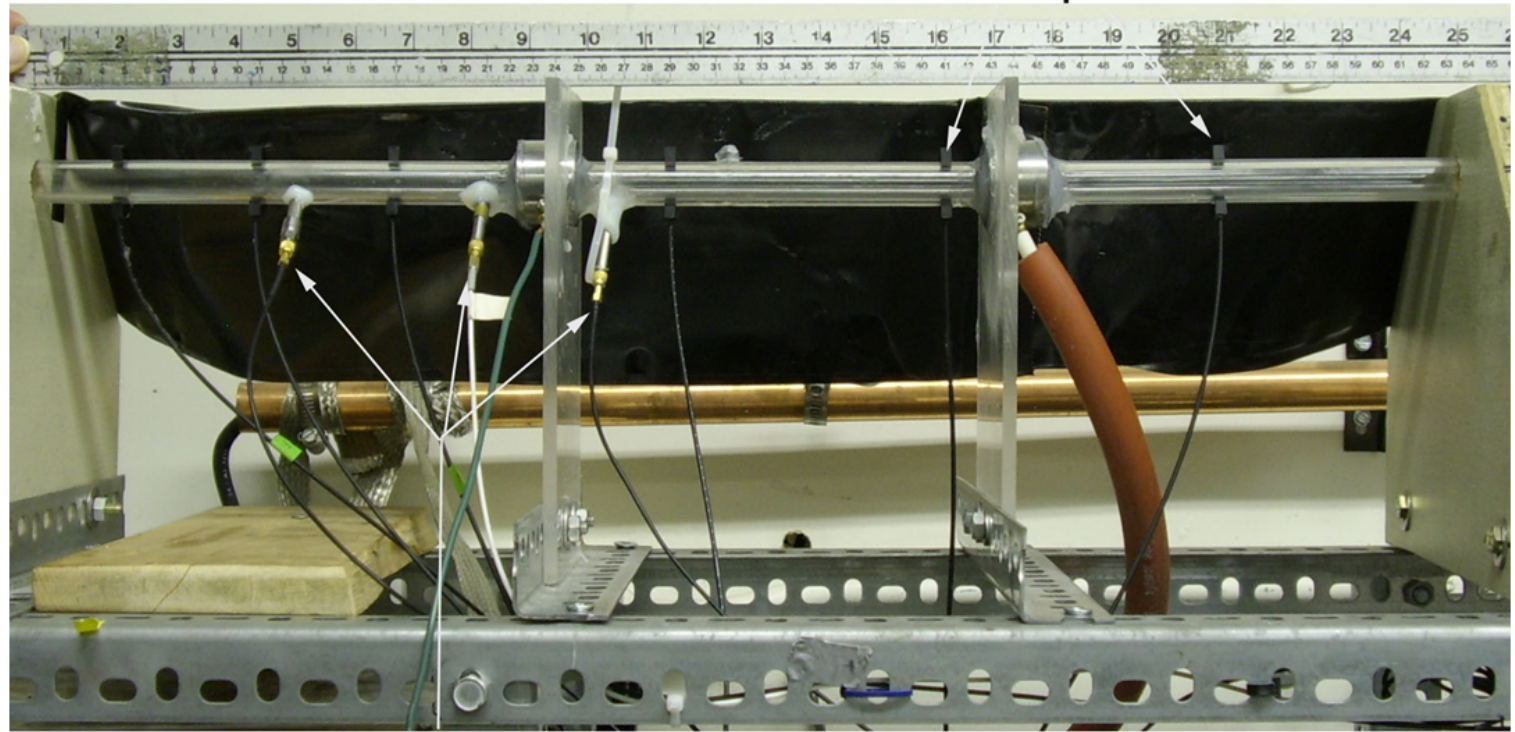

Pressure Transducers

Figure 2-2. Experimental Setup - Field Test Section

The live electrode was connected to a HV capacitor $(C=0.005-0.007 \mu F)$ which was charged by a HVDC power supply through a charging resistor $\mathrm{R}_{2}=2 \mathrm{M} \Omega$ to a specified initial voltage. An optional $\mathrm{R}_{1}=1 \mathrm{M} \Omega$ resistor was inserted in series with the capacitor to limit the current in the field section as the detonation traversed between the two electrodes. The second electrode was grounded. The electrode configuration is similar to that used by Bone et al. [2]. The electric field strength between the two electrodes was varied from $200 \mathrm{~V} / \mathrm{cm}$ to $8000 \mathrm{~V} / \mathrm{cm}$ using the HVDC power supply submerged in an oil bath. In order to prevent arcing between the two electrodes the voltage applied between the two electrodes was always kept below the breakdown value. Smoked foils were not used as a diagnostic in this experiment since the natural conductivity of the soot promoted arcing and did not allow for the use of high electric fields.

The experiments were carried out with stoichiometric mixtures of dry $2 \mathrm{CO}+\mathrm{O} 2$ at $1 \mathrm{~atm}$, $2 \mathrm{CO}+\mathrm{O} 2$ at $1 \mathrm{~atm}$ saturated in water at $22^{\circ} \mathrm{C}$ and $\mathrm{C} 2 \mathrm{H} 2+2.5 \mathrm{O} 2+85 \% \mathrm{Ar}$ at $28 \mathrm{kPa}$ and $35 \mathrm{kPa}$. All mixtures were initially premixed at a given initial pressure in storage tanks by partial pressures. 


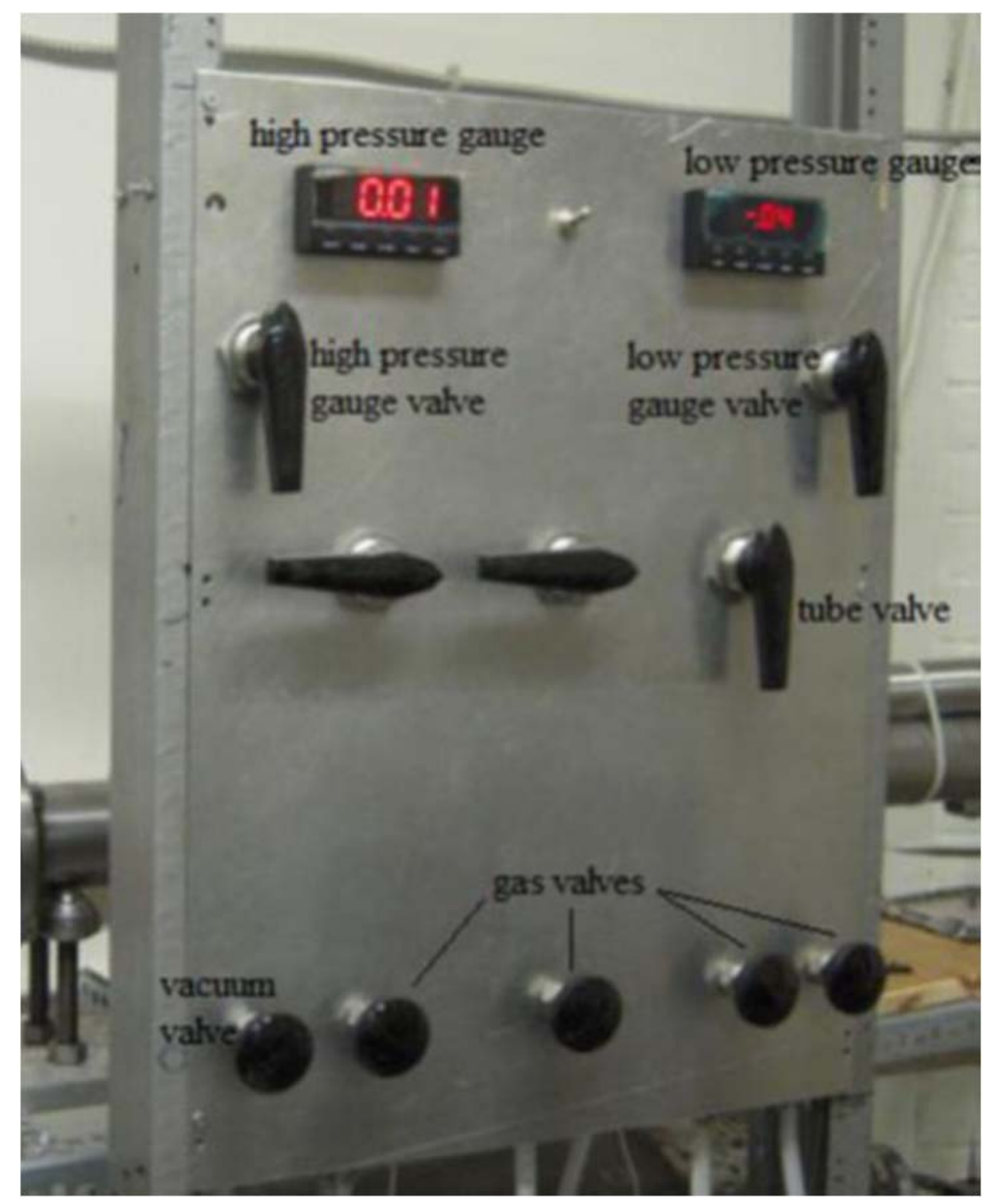

Figure 2-3. Experimental Setup - Gas Manifold

The tube and storage tanks were filled in through a gas manifold (Figure 2-3). The manifold connected the storage tanks to the tube and gas bottles. It was equipped with an Edwards RV-3 vacuum pump used for evacuating the tube prior to filling and for removal of the combustion products after the experiment. The initial pressure of the mixture in the tube was controlled using two pressure gauges mounted on the manifold (Figure 2-3).

\subsection{Diagnostics}

A Pearson VD-305A capacitive voltage divider was connected across the electrodes to monitor the voltage drop as the detonation traversed the field test section. A Pearson 1025 current transformer was used to simultaneously monitor the current in the circuit. Six photo diodes were spaced regularly along the tube to monitor the detonation velocity 
as it traversed the field section. Three PCB 113A24 pressure transducers were mounted flush with the tube wall at the locations indicated in Figure 2-1. The voltage divider, current transformer, photo probes and pressure transducers were connected to a LeCroy WaveJet 334A oscilloscope that collected and stored data from the experiment. When additional recording channels were required a Tektronix TDS3052 oscilloscope was used. The data from the two oscilloscopes was synchronized during the data processing stage by matching the signals of the photo diodes. A rotating drum high speed streak camera pointed and focused at test section was also used for observing the change in the detonation structure as well as the detonation velocity.

\section{$\underline{\text { Streak Camera }}$}

The streak camera is placed in front of the test section and is focused on the test section (a region of $40 \mathrm{~cm}$ that includes both electrodes) as seen in Figure 2-4. As the detonation traverses the test section the streak camera captures the light from the detonation wave on

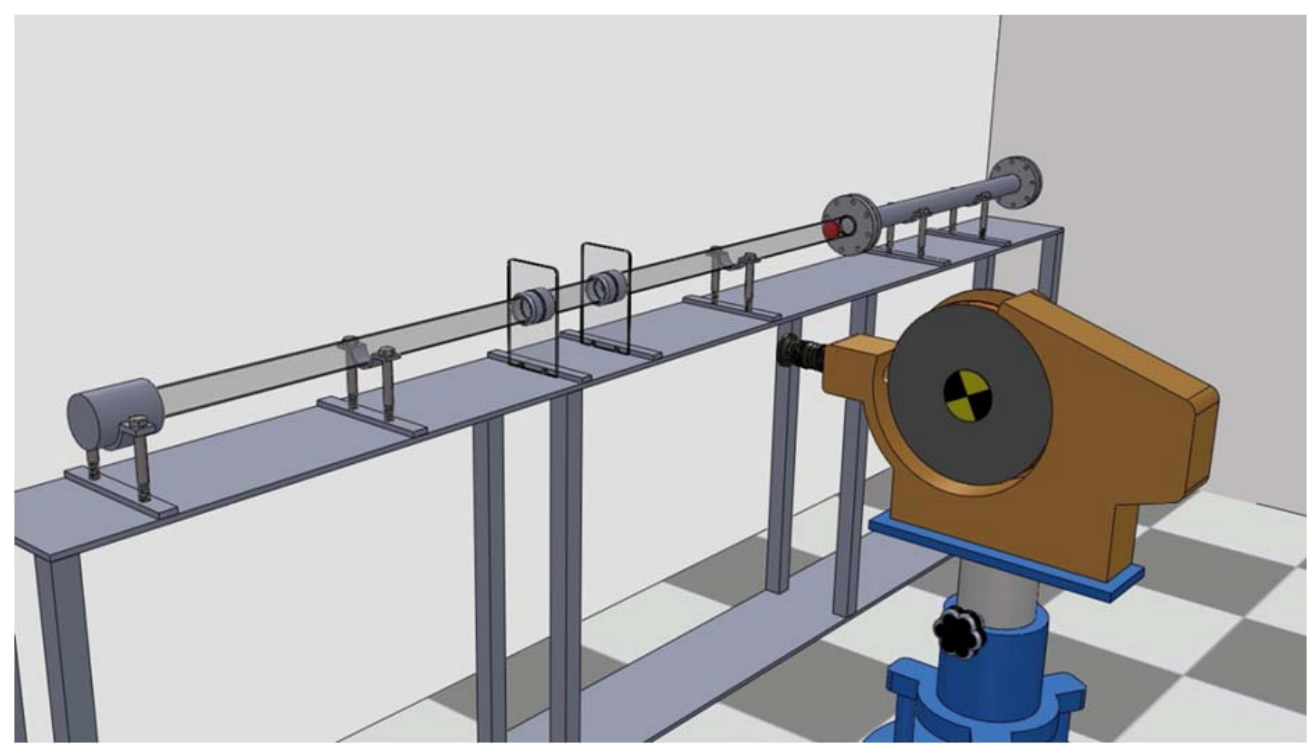

Figure 2-4. Streak Camera Orientation

strip of constantly rotating black and white negative film. Due to the constant rotation of the drum the light from the detonation traces a streak line on the film which can be converted into an xt diagram of the detonation as it traverses the test section. The field of view of the camera and the strip of film on which the camera records the image are 
shown in Figure 2-5 for different detonation (red line) positions: at $100 \mu$ s and $240 \mu \mathrm{s}$, respectively.
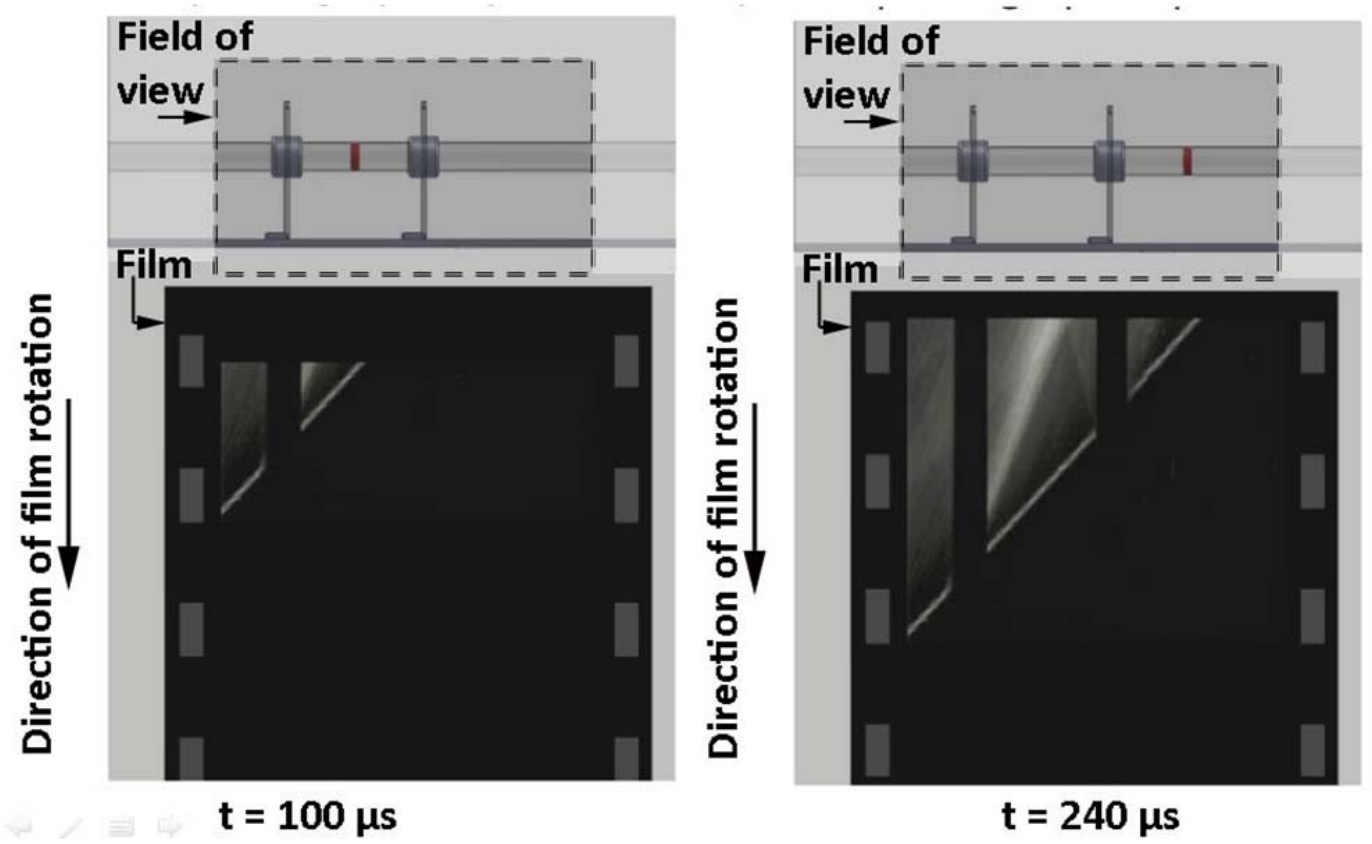

Figure 2-5. Field of view of streak camera and corresponding image of the detonation

Knowing the rotational speed of the drum and the magnification of the lens the streak image on the film can be converted to an xt diagram (Figure 2-6.). The detonation speed can be determined from the slope of the streak line as follows: First, the linear speed of

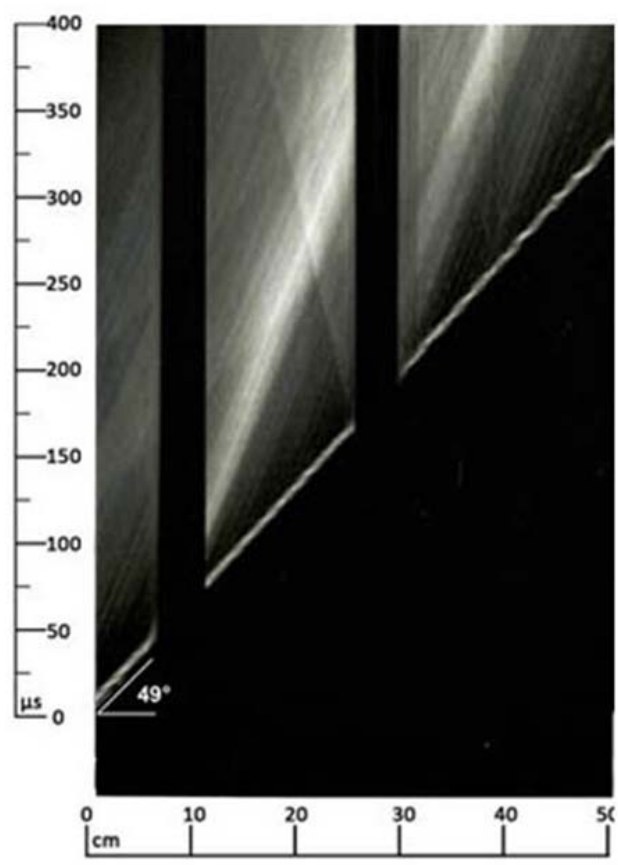

Figure 2-6. \#12 $\mathrm{C} 2 \mathrm{H} 2+\mathrm{O} 2+85 \% \mathrm{Ar}$, $\mathrm{P} 0=28 \mathrm{kPa}, \mathrm{E}=0 \mathrm{kV} / \mathrm{cm}$ the rotating drum is determined $V_{\text {drum }}=$ $5200 \mathrm{rpm} \times \frac{1}{60 \mathrm{sec}} \times 0.971 \mathrm{~m}=84.15 \mathrm{~m} / \mathrm{s}$. The angular speed of drum (5200rpm) was measured using a stroboscope. The circumference of the streak camera drum is equal to $0.971 \mathrm{~m}$. Using the streak in Figure 2-6 the speed of the detonation is determined as follows: $D=$ $\frac{V_{\text {drum }}}{\mu \tan (\alpha)}=\frac{84.15 \mathrm{~m} / \mathrm{s}}{0.05 \tan (45)}=1463 \mathrm{~m} / \mathrm{s}$

Where $\alpha$ is the slope angle of the detonation in Figure 2-6 and $\mu$ is the magnification factor. 


\section{Results and Discussion}

\subsection{Detonation wave without an applied electric field}

Before looking at the interaction of the detonation wave and the electric field it is necessary establish a benchmark for the velocity and structure of the detonation without the presence of the electric field. These experiments will serve as a basis for determining if the application of an electric field has any influence of either the structure or the velocity of the detonation wave. The single head spinning detonation wave traversing the test section without an applied electric field is shown in Figure 3-1 and Figure 3-2 for $2 \mathrm{CO}+\mathrm{O} 2$ mixture at 1atm and in Figure 3-3 and Figure 3-4 for $\mathrm{C}_{2} \mathrm{H}_{2}+\mathrm{O}_{2}+85 \% \mathrm{Ar}$ mixture at $28 \mathrm{kPa}$. Figure 3-1 shows the case when $3 \mathrm{~cm}$ long electrodes were used in the test section and Figure 3-2 shows the case when $10 \mathrm{~cm}$ long electrodes were used. The spinning structure of the detonation is clearly evident. The luminous regions downstream of the electrodes are due to combustion of soot particles ablated from the metal electrode surface. As seen in Figure 3-1 and Figure 3-2, the detonation propagates through the test section without suffering any change in either its structure or velocity. Figure 3-3 and

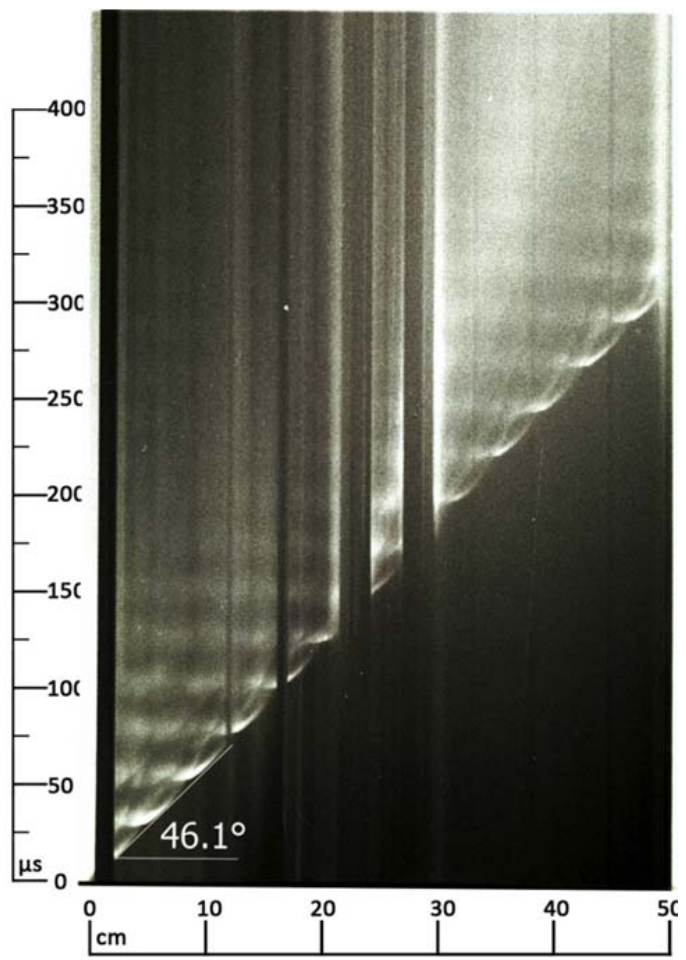

Figure 3-1. \#64 2CO+ O2 (dry) $\mathrm{P}_{0}=1 \mathrm{~atm}, \mathrm{E}=0 \mathrm{kV} / \mathrm{cm}$

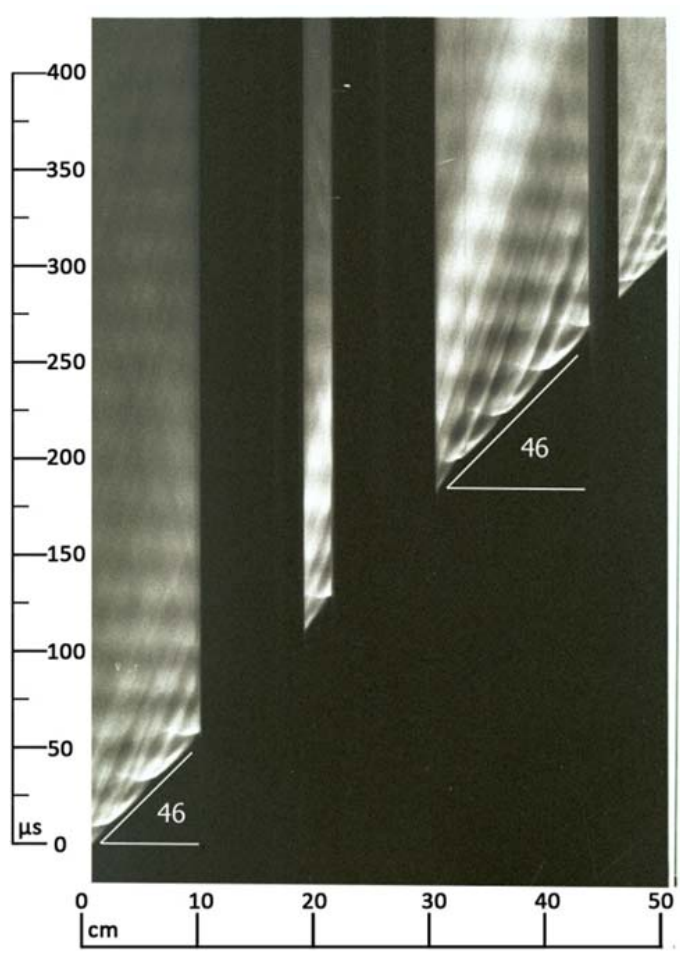

Figure 3-2. \#87 2CO+ O2 (moist) 


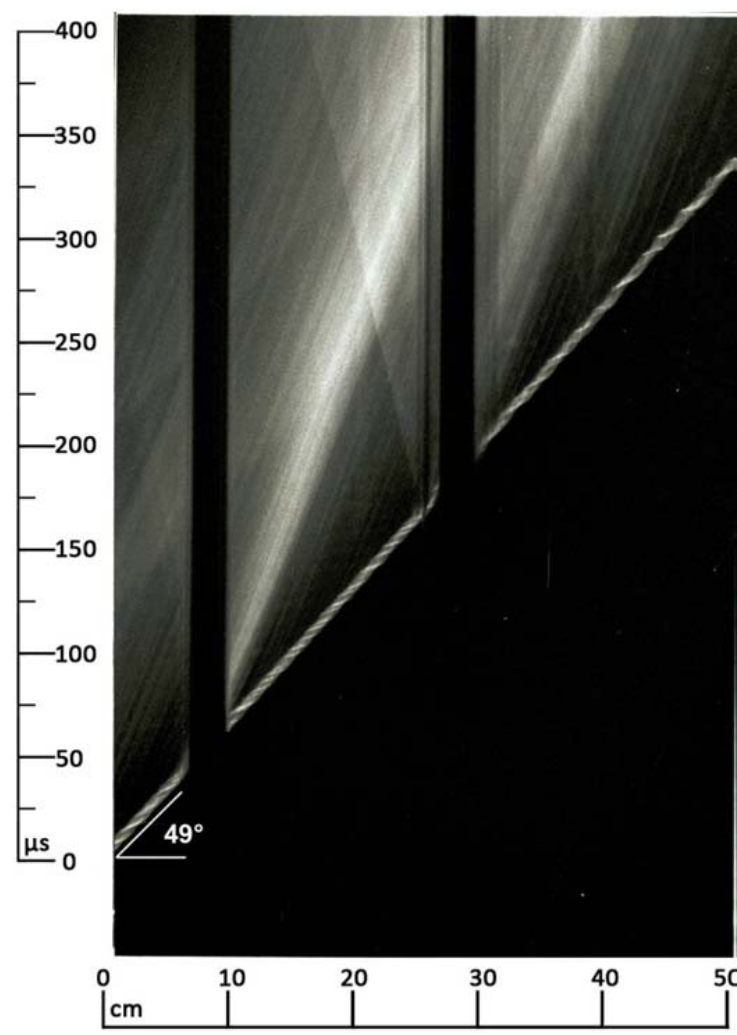

Figure 3-3. \#212 $\mathrm{C} 2 \mathrm{H} 2+\mathrm{O} 2+85 \% \mathrm{Ar}$, $\mathrm{Po}=28 \mathrm{kPa}, \mathrm{E}=0 \mathrm{kV} / \mathrm{cm}$

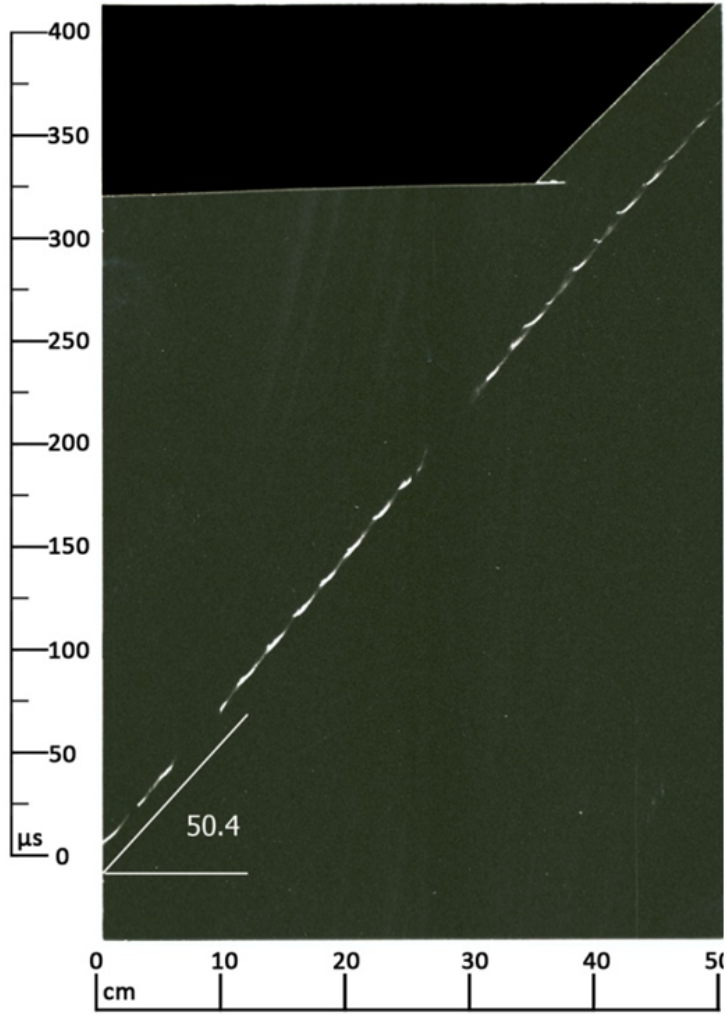

Figure 3-4. \#200 $\mathrm{C} 2 \mathrm{H} 2+\mathrm{O} 2+85 \% \mathrm{Ar}$, $\mathrm{P}_{0}=28 \mathrm{kPa}, \mathrm{E}=0 \mathrm{kV} / \mathrm{cm}$

Figure 3-4 show the streak photographs of the detonation wave in the mixture of $\mathrm{C}_{2} \mathrm{H}_{2}+$ $\mathrm{O}_{2}+85 \% \mathrm{Ar}$ at $28 \mathrm{kPa}$. Figure 3-3 illustrates the case when the aperture of the camera lens was fully open, and Figure 3-4 shows the case when the aperture was half way closed. As seen in both Figure 3-3 and Figure 3-4 the detonation structure and velocity are not perturbed by the presence of the electrodes. In Figure 3-3 a weak reflected wave emanates from a location $1 \mathrm{~cm}$ before the second electrode. This is due to the presence of a pressure transducer at this location which is not perfectly flush with the tube inner wall. However, as seen in the streak photograph this slight disturbance does not affect the detonation wave. The streak photographs in Figures 3-1 -3-4 show that the presence of electrodes in the test section does not influence the propagation of the detonation. Thus, when the electric field is applied between the electrodes, any changes that occur in the structure or velocity of the detonation will be a result of the applied electric field. 


\subsection{Experiments with 2CO+02 Mixture}

The following set of experiments was conducted with $2 \mathrm{CO}+\mathrm{O} 2$ mixture at an initial pressure of $1 \mathrm{~atm}$. The initial conditions for these experiments are chosen to correspond to the conditions under which Bone and coworkers [2] observed a strong influence of the electric field. As mentioned earlier, Bone and coworkers carried out experiments with both dry and moist $2 \mathrm{CO}+\mathrm{O} 2$ mixtures and only observed the effect of the electric field in the moist mixture. In the current study both mixtures are tested as well.

\subsubsection{Dry 2C0+02}

A number of experiments were performed with dry $2 \mathrm{CO}+\mathrm{O} 2$ mixture at initial pressure of 1atm. The two representative streak photographs of these experiments are shown below:

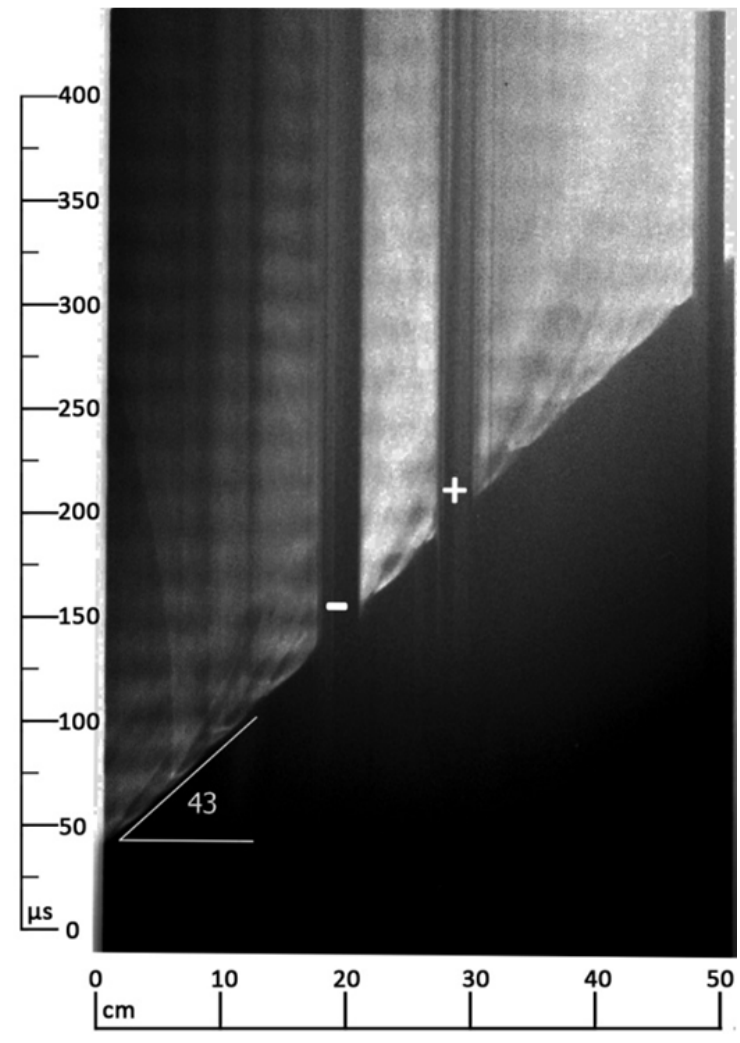

Figure 3-5. \# $802 \mathrm{CO}+\mathrm{O} 2, \mathrm{P} 0=1 \mathrm{~atm}$, $\mathrm{E}=4.25 \mathrm{kV} / \mathrm{cm}, \mathrm{R}_{1}=1 \mathrm{M} \Omega$

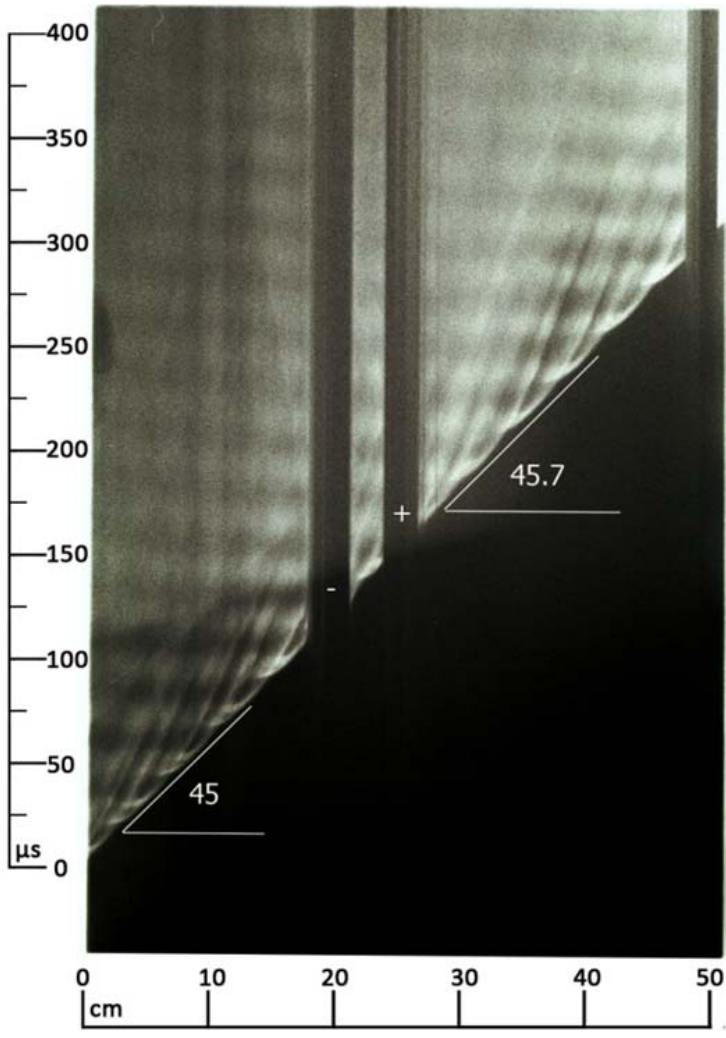

Figure 3-6. \#72 2CO+O2, $\mathrm{P} 0=1 \mathrm{~atm}$, $\mathrm{E}=8.5 \mathrm{kV} / \mathrm{cm}, \mathrm{R} 1=1 \mathrm{M} \Omega$ 
In the streak photograph shown Figure 3-5 the electrode spacing is $8 \mathrm{~cm}$ long. Thus, when the first electrode is charged to the potential of $-34 \mathrm{kV}$ a $4.25 \mathrm{kV} / \mathrm{cm}$ constant electric field is set up in the inter electrode gap. In Figure 3-6 the streak photograph represents the case when the electric field strength was doubled $(8.5 \mathrm{kV} / \mathrm{cm})$ by shortening the gap between the electrodes to $4 \mathrm{~cm}$. A slight disturbance of the spin and a small drop (less than $60 \mathrm{~m} / \mathrm{s}$ ) is observed, however, in general in both cases no significant effect on the detonation was observed. These results are in agreement with the results obtained by Bone and co-workers [2]. For the next set of experiments a moist $2 \mathrm{CO}+\mathrm{O} 2$ mixture was used.

\subsubsection{Moist 2CO+02}

Bone and co-workers [2] reported that when an axial electric field of $5 \mathrm{kV} / \mathrm{cm}$ is applied to a spinning detonation in moist $2 \mathrm{CO}+\mathrm{O} 2$ mixture, a significant dampening of the spinning structure and a velocity deficit of $40 \%$ was observed. According to Bone this effect was observed in 9 out of 10 experiments. In 1 out of 10 experiments no change

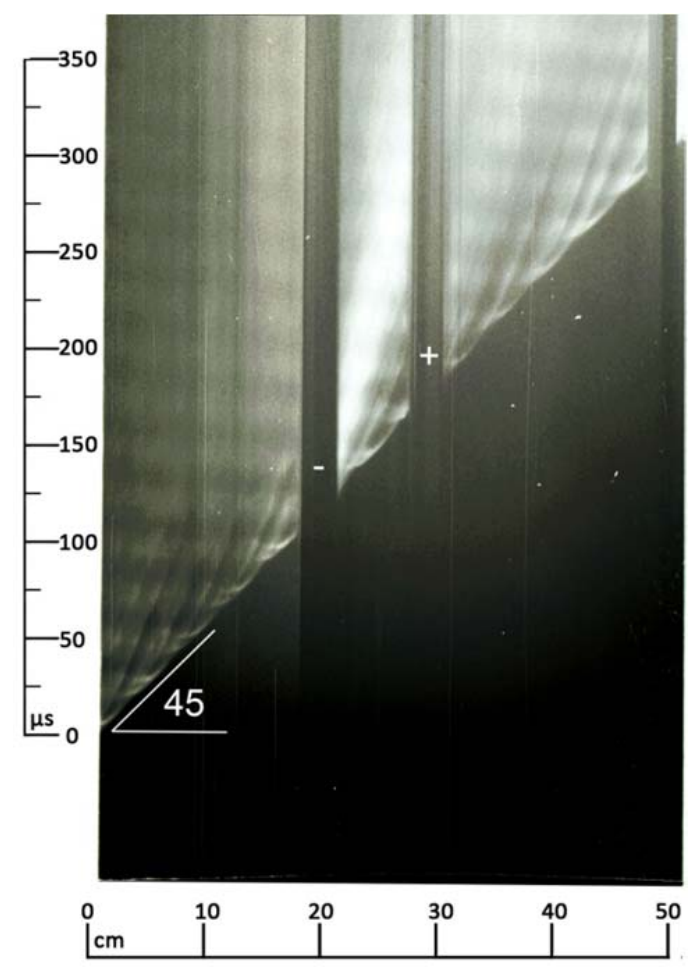

Figure 3-7. \#77 2CO+O2, $\mathrm{P}_{0}=1 \mathrm{~atm}$, $\mathrm{E}=4.5 \mathrm{kV} / \mathrm{cm}, \mathrm{R}_{1}=1 \mathrm{M} \Omega$

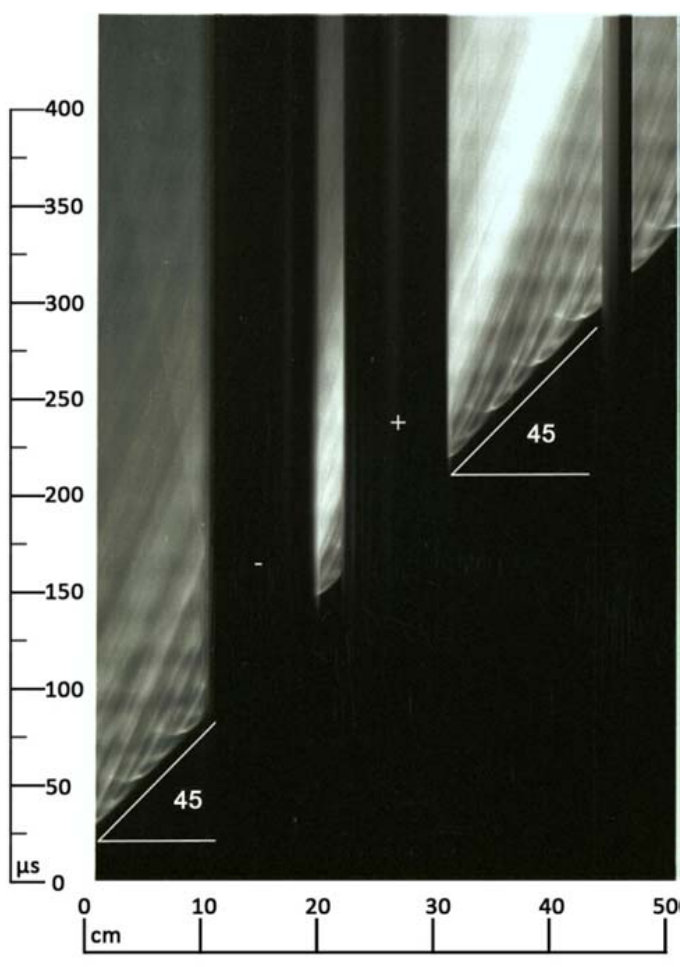

Figure 3-8. \#103 2CO+O2, $\mathrm{P}_{0}=1 \mathrm{~atm}$, $\mathrm{E}=5.2 \mathrm{kV} / \mathrm{cm}, \mathrm{R}_{1}=1 \mathrm{M} \Omega$ 
in the detonation structure or velocity was reported. Figure 3-7 and Figure 3-8 are representative streak photographs of more than 20 experiments conducted with moist $2 \mathrm{CO}+\mathrm{O} 2$ mixture at $1 \mathrm{~atm}$ with field gradients between $4 \mathrm{kV} / \mathrm{cm}$ to $7 \mathrm{kV} / \mathrm{cm}$. Figure $3-7$ represents the experiments where $3 \mathrm{~cm}$ electrodes were used and Figure 3-8 represents the cases when a pair of $10 \mathrm{~cm}$ electrodes was used in the test section. As can be observed in Figure 3-7 and Figure 3-8 the electric field appears to have no effect on either the detonation structure or velocity. No effect on the detonation due to the applied electric field was observed in all the experiments. Thus, the present finding is in contrast to what Bone and co-workers [2] observed. The fact that no discernable change in the detonation velocity was observed in the presence of an electric field can be partly attributed to the very low ion concentration in the reaction zone of the detonation. The body force of the electric field on the ions in the detonation plasma is directly proportional to the ion concentration. Low ion concentration leads to a very insignificant body force created by the electric field.

Electric field body force on ions in the detonation plasma

Measurements of ion concentrations, conducted using a symmetrical double Langmuir probe (see Appendix B), indicate ion densities of the order of $\sim 3 \times 10^{12} \mathrm{~cm}^{-3}$ and $\sim 4 \times 10^{11} \mathrm{~cm}^{-3}$ in the reaction zone and in the equilibrium product gases, respectively. These concentrations are in agreement with the ionization levels reported by Basu and Fay [6] for oxyacetylene detonations at atmospheric pressure. As a result of the low ion concentration, the body force due to the electric field is negligibly small compared to the dynamic pressure forces of the detonation. Using the values for ion densities in the chemi-ionization zone the body force associated with an external electric field can be readily calculated $F=\operatorname{EeN}_{i} A L \approx 0.03 N$, where $\mathrm{E}$ is the value of the applied electric field, $e$ is the electron elementary charge, $N_{i}$ is the ion density, A is the tube cross sectional area and $\mathrm{L}$ is the tube length. The very small mechanical body force of the electric field is only one of the reasons why no influence of the electric field is observed. In order to fully understand why no significant effect on the detonation is observed in the presence of an electric field we need to look at the electrical interaction of the detonation 
and the field. The measurements of current and voltage, as the detonation traverses the test section, will provide further insight into the interaction process.

\subsection{Interaction between a detonation and electric field}

In order to understand how the detonation wave interacts with the electric field we first look at the simplest case: interaction of a detonation wave with a single charged electrode. The electric field and the spacial voltage distribution created by a single charged electrode are described in detail in Appendix A. For the following set of experiments the mixture of $\mathrm{C} 2 \mathrm{H} 2+\mathrm{O} 2+85 \% \mathrm{Ar}$ at the initial pressure of $28 \mathrm{kPa}$ will be used. This mixture produces significantly lower amount of soot than the $2 \mathrm{CO}+\mathrm{O} 2$ mixture at 1atm. The soot particles settle on the walls of the tube and the surface of the electrode and can change the conductivity of the mixture or promote arcing between the two electrodes unless the apparatus is regularly cleaned. Nonetheless, a few representative experiments in the $2 \mathrm{CO}+\mathrm{O} 2$ mixture at latm will be also included in this section to show the similar behavior of the detonation across different mixtures and pressures. This is expected since the levels of ionization and conductivity do not significantly vary with mixture composition and pressure. Before looking at the interaction of the detonation with an electric field created by the electrode we need to look at the general interaction process between plasma and a charged boundary.

\section{Plasma - Sheath Model and theory of Ion current (for more details see Appendix C)}

In order to understand and quantify how the ionized gas (plasma) interacts in the presence of a charged electrode we have to understand basic interaction between plasma and the DC electric field. In general, as plasma passes a charged boundary, the charged species within plasma reorient themselves (polarize) in a way that will shield (or screen) the bulk of the plasma from the external electric field. This way the condition of quasi neutrality of plasma (the number of negative charges equals to the number of positive charges $n_{e}=n_{i}$ ) is preserved. In the absence of external electric field the plasma has net zero charge: it is quasi-neutral, and thus, in the presence of an external electric field it seeks to preserve this state by creating a thin layer of charged species (sheath) at the boundary of 
the electrode that shields it from the influence of the DC electric field. For example, if the electrode is negatively biased all the electrons are repelled from the electrode and the electric field is screened by the thin layer of positive ions which are attracted to the surface of the electrode. As the ions strike the wall of the electrode they are neutralized and thus more ions are needed to maintain the layer of positive charge around the electrode. This movement of ions toward the negative electrode is referred to as the ion current. The analytically calculated values for the ion current in both $\mathrm{CO}$ and acetylene mixtures are shown in Table 3-1.

\begin{tabular}{|l|l|r|r|r|r|r|}
\hline Mixture & lons & Pressure $\mathbf{( k P a )}$ & $\mathbf{n}_{\mathbf{e}}\left(\mathbf{c m}^{-\mathbf{3}}\right)$ & $\mathbf{T}_{\mathbf{e}}(\mathbf{e v})$ & $\mathbf{A}_{\text {electrode }}\left(\mathbf{c m}^{\mathbf{2}}\right)$ & $\mathbf{I}_{\text {sat }}(\mathbf{m A})$ \\
\hline \hline $2 \mathrm{CO}+\mathrm{O} 2$ & $\mathrm{CO}+$ & 101.3 & $8.00 \mathrm{E}+11$ & 0.30 & 23.14 & 180.9 \\
\hline $\mathrm{C} 2 \mathrm{H} 2+\mathrm{O} 2+85 \% \mathrm{Ar}$ & $\mathrm{CHO}+$ & 28 & $3.00 \mathrm{E}+11$ & 0.26 & 5.19 & 15.2 \\
\hline
\end{tabular}

Table 3-1. Saturation current values for various mixtures

In summary, as the detonation approaches the region of electric field created by the charged electrode a sheath consisting of a layer of positive charge develops around the electrode. The sheath shields the bulk of the plasma from the applied DC field. In order to maintain the sheath positive ions are drawn in by the electrode resulting in an ion current. In order to confirm this interaction mechanism between the detonation and the electric field the current to the electrodes is measured in the following set of experiments and its effects on the detonation are discussed. 


\subsection{Experimental investigation of interaction between a detonation and an electric field.}

\section{Measurement of ion current}

To experimentally measure the effect of high axial electric field and the resulting current on the detonation we need to combine streak photographs with measurements of voltage and current that are conducted using the experimental setup in Figure 3-9. The voltage probe is connected to the first electrode and it measures the electrode potential relative to ground. The current probe is mounted directly on the wire connecting the electrode to the capacitor plate. Any ions that get attracted to the surface of the charged electrode will be neutralized by the electrons supplied from the capacitor. The resulting current will be recorded by the probe. In order to maximize the current drawn in by the electrode the resistor $\mathrm{R}_{1}$ is removed from the circuit. The voltage and current measurements are recorded as a function of time on the oscilloscope and are combined with the streak photographs of the detonation to see the see the time evolution of these quantities as the detonation passes by the electrode. Since the electrode is directly connected to one of the

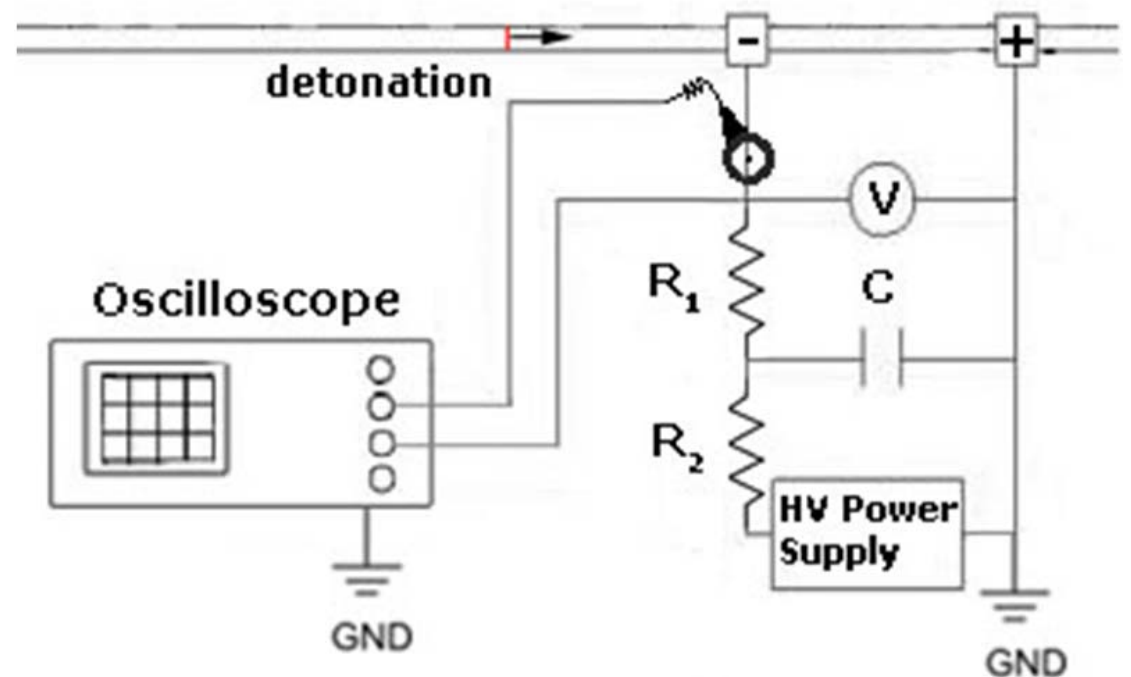

Figure 3-9. Experimental Setup

capacitor plates $\left(\mathrm{R}_{1}=0 \Omega\right.$ in Figure 3-9), the voltage that is measured on the electrode is essentially the voltage across the capacitor. The current supplied by the capacitor is 
defined as $i=C d V / d t$, where $\mathrm{C}$ is the capacitance value and $d V / d t$ is the time derivative of the voltage across the capacitor. Therefore, by fitting a $6^{\text {th }}$ order polynomial through the measured voltage signal and differentiating it with respect to time we can obtain the current profile as the detonation crosses the charged electrode. This analytical calculation of current is used in conjuction with the measurements of current by the current transformer.

Interaction between the detonation and the electric field from a single charged electrode at $18 \mathrm{kV}$

Figure 3-10 and Figure 3-11 show composite streak photographs where the voltage at the first electrode is superimposed on the streak photograph of the detonation. Figure 3-10

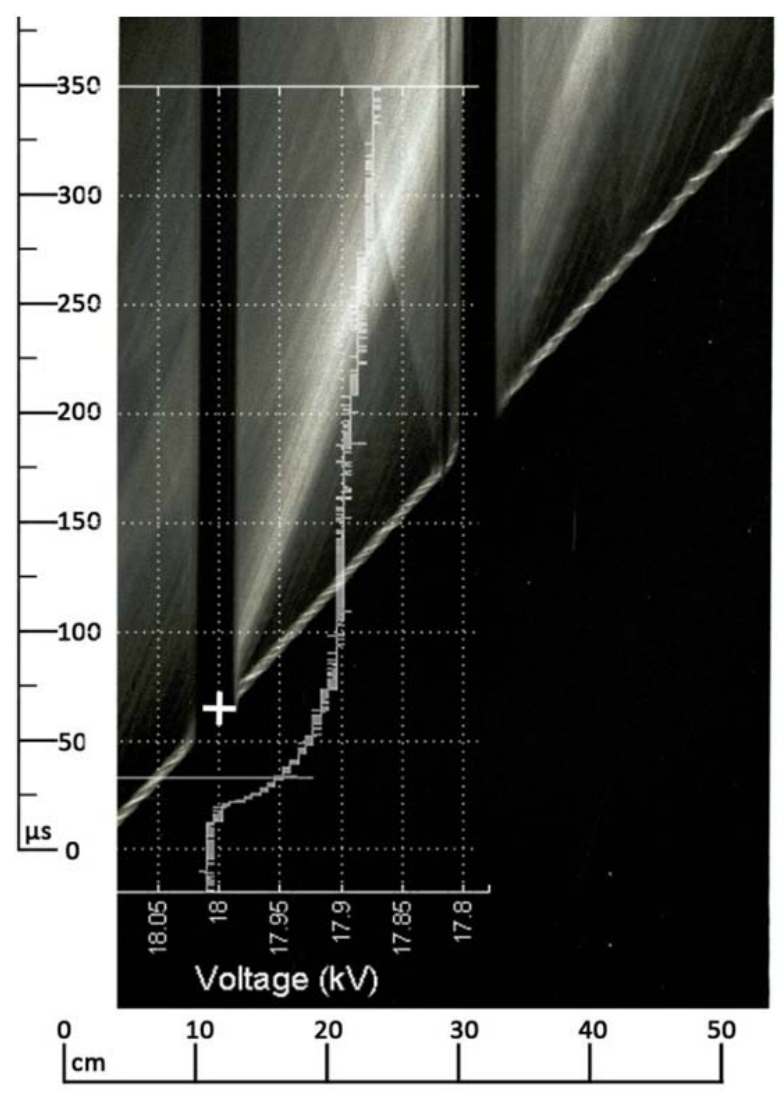

Figure 3-10. \#241 C2H2+O2+85\%Ar, $\mathrm{Po}=28 \mathrm{kPa}, \mathrm{Vo}=18 \mathrm{kV}, \mathrm{R} 1=0 \Omega$

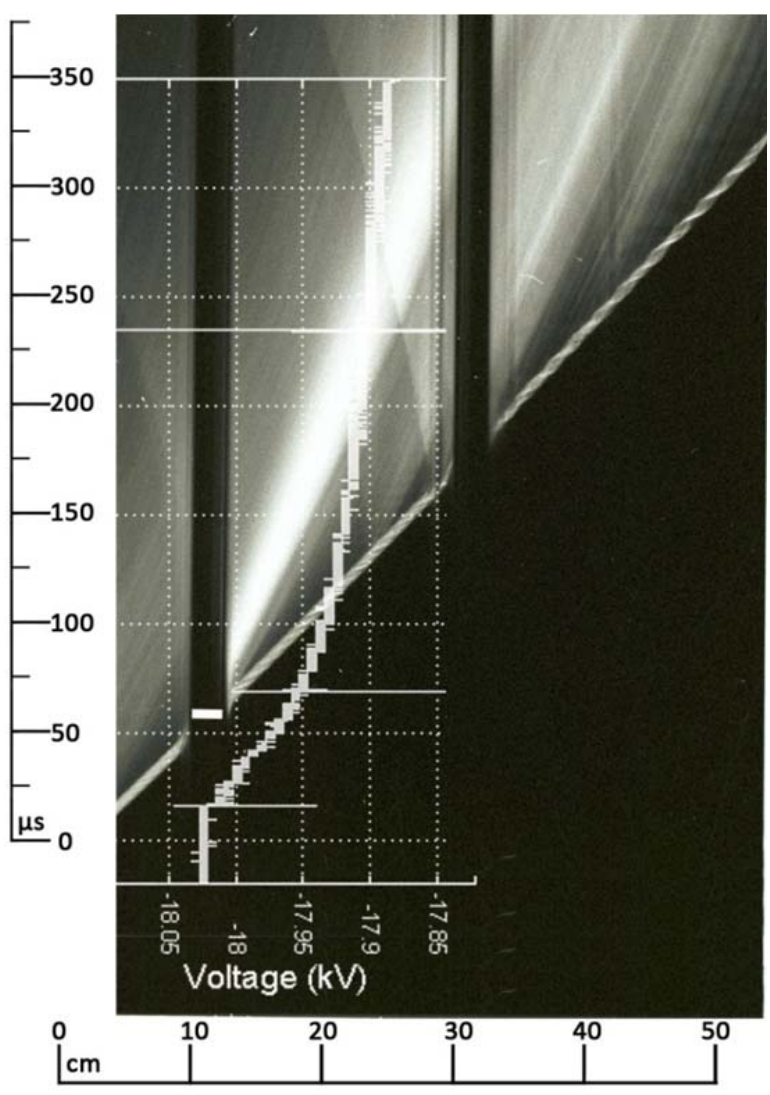

Figure 3-11. \#253 $\mathrm{C} 2 \mathrm{H} 2+\mathrm{O} 2+85 \% \mathrm{Ar}$, $\mathrm{Po}=28 \mathrm{kPa}, \mathrm{Vo}=-18 \mathrm{kV}, \mathrm{R} 1=0 \Omega$ 
represents the case when the electrode was positively biased (18kV) and Figure 3-11 represents the case when the electrode was negatively biased $(-18 \mathrm{kV})$. An important fact that should be noted is that looking at the streak photographs the detonation does not suffer any perturbation in either its structure or velocity in the viscinity of the charged electode, however there is still an electrical interaction between the detonation and the electric field. Before the arrival of the detonation wave in the region of the electric field, the voltage on the charged electrode remains constant. As the detonation front approaches the test section it starts to distort the initial voltage/electric field profile. Looking at Figure 3-10 and Figure 3-11 it is obvious that the interaction between the detonation and the electric field starts before the detonation wave reaches the electrode. From the above figures for both positively and negatively biased electrode it is seen that the voltage on the electrode starts to change when the detonation is about $5 \mathrm{~cm}$ away from it. The drop
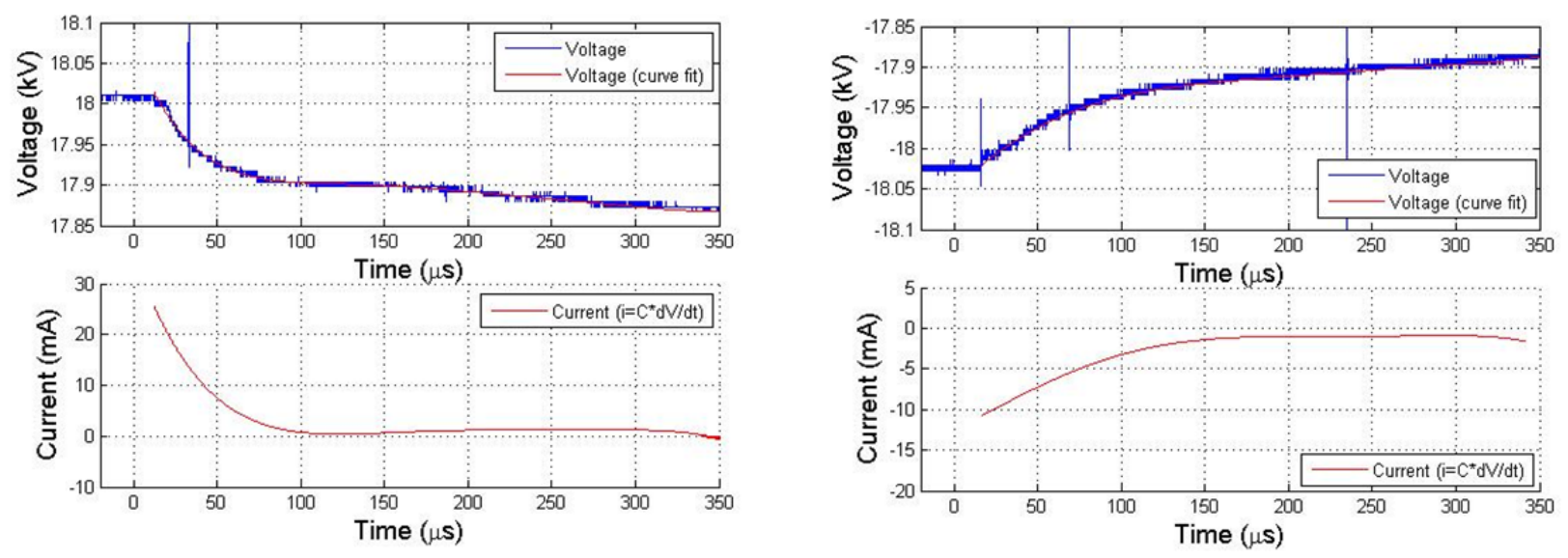

Figure 3-12 \#241 C2H2+O2+85\%Ar, $\mathrm{Po}=28 \mathrm{kPa}$, $\mathrm{Vo}=18 \mathrm{kV}, \mathrm{R}_{1}=0 \Omega$

Figure 3-13. $\# 253 \mathrm{C} 2 \mathrm{H} 2+\mathrm{O} 2+85 \% \mathrm{Ar}, \mathrm{Po}=28 \mathrm{kPa}$, $\mathrm{Vo}=-18 \mathrm{kV}, \mathrm{R}_{1}=0 \Omega$

in voltage indicates that the electrode starts to draw current. The current profiles shown in Figure 3-12 and Figure 3-13 and correspond to the cases when the electrode was charged to $+18 \mathrm{kv}$ and $-18 \mathrm{kV}$, respectively. The current traces clearly show a decreasing current function, which starts off from the time of initial interaction, i.e. when the detonation is about $5 \mathrm{~cm}$ before the elcrode and goes to zero when the detonation is about $10 \mathrm{~cm}$ past the electrode. The value of the current is in agreement with the theoretical calculations in Table 3-1, indicating that, indeed the electrode, draws in current from the detonation plasma. The bias of the electrode determines the type of current is drawn in by the 
electrode. For a positively biased electrode an electron current is drawn by the electrode and for a negatively biased electrode an ion current is collected by the electrode. In order to determine if higher electrode voltage would have a effect on the detonation the voltage on the electrode was increased to $30 \mathrm{kV}$.

Interaction between the detonation and the electric field from a single charged electrode at $30 \mathrm{kV}$

The time histories of voltage variation as the detonation crosses the charged electrode are shown in Figure 3-14 and Figure 3-15 for positive and negative bias. The results at 30kV

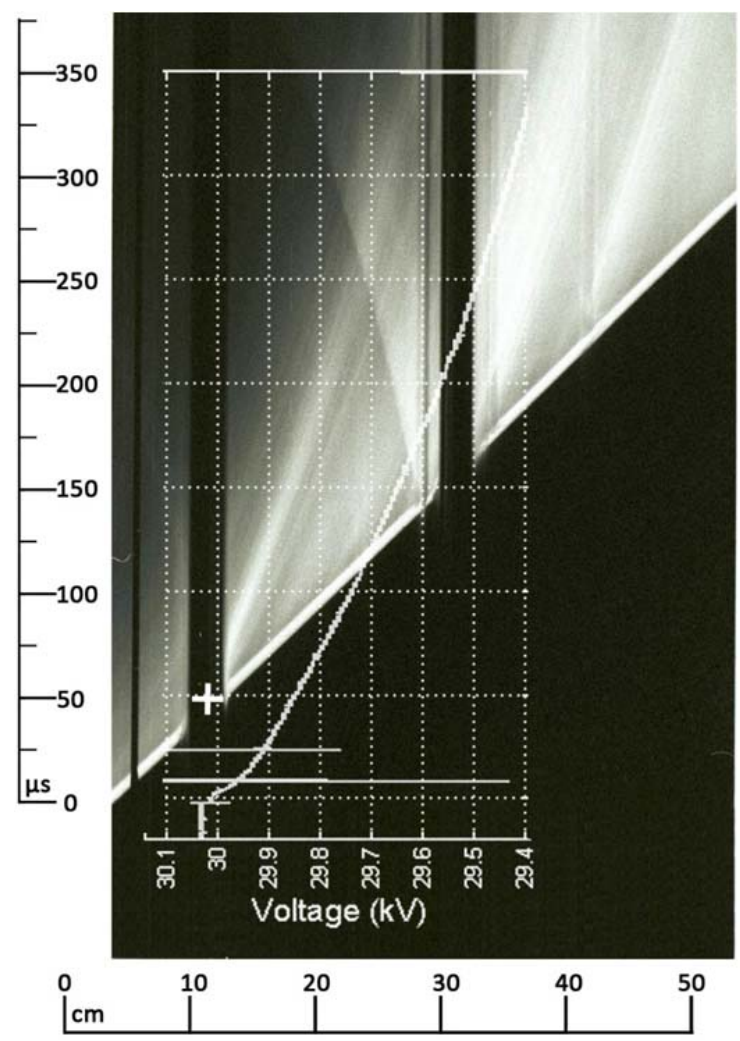

Figure 3-14. \#246 C2H2+O2+85\%Ar, $\mathrm{Po}=28 \mathrm{kPa}, \mathrm{Vo}=30 \mathrm{kV}, \mathrm{R}_{1}=0 \Omega$

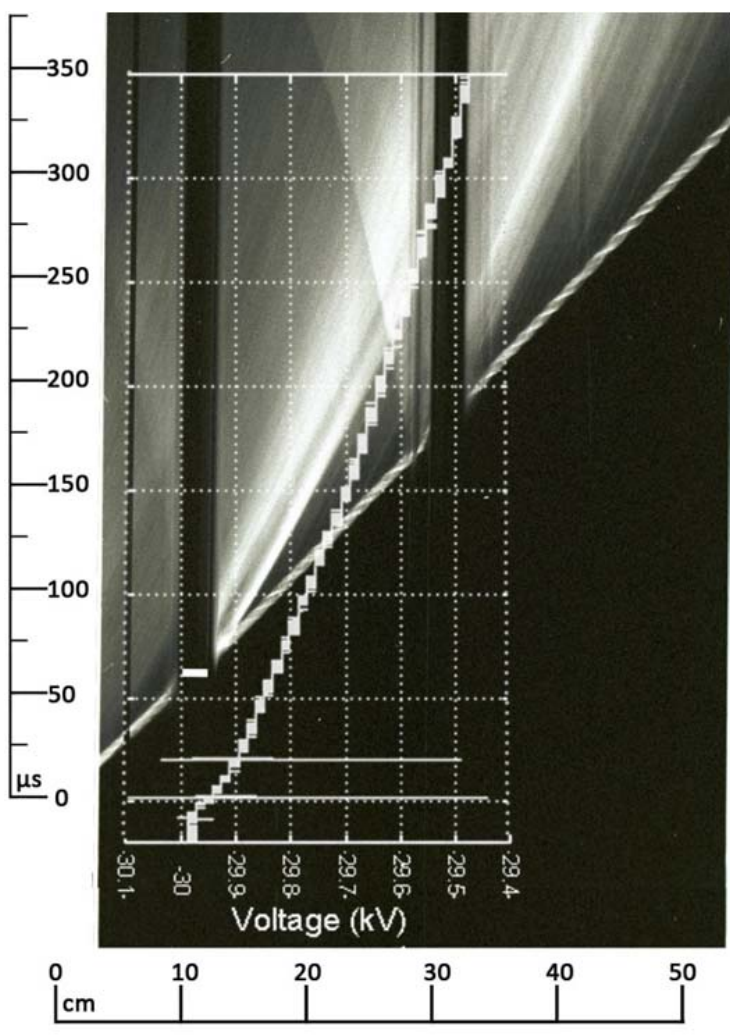

Figure 3-15. \#260 $\mathrm{C} 2 \mathrm{H} 2+\mathrm{O} 2+85 \% \mathrm{Ar}$, $\mathrm{Po}=28 \mathrm{kPa}, \mathrm{Vo}=-30 \mathrm{kV}, \mathrm{R}_{1}=0 \Omega$ 
are silimar to the results at $18 \mathrm{kV}$.Only a slight voltage drop (1.6\%) is recorded for both cases (Figure 3-14 and Figure 3-15). Similarly, there is no evidence in the streak photographs that the electric field from the charged electrode has any influence on the detonation. The current traces for the two cases (Figure 3-16 and Figure 3-17) show the same decreasing behavior of the current (both electron and ion current). One key difference between the two cases $(18 \mathrm{kV}$ vs $30 \mathrm{kV})$ is in the start of the voltage drop. At $30 \mathrm{kV}$ the voltage starts to change when the detonation is about $9 \mathrm{~cm}$ from the charged electrode, and when the electrode is at $18 \mathrm{kV}$ the voltage on the electrode starts to drop when the detonation is $5 \mathrm{~cm}$ away from the electrode.
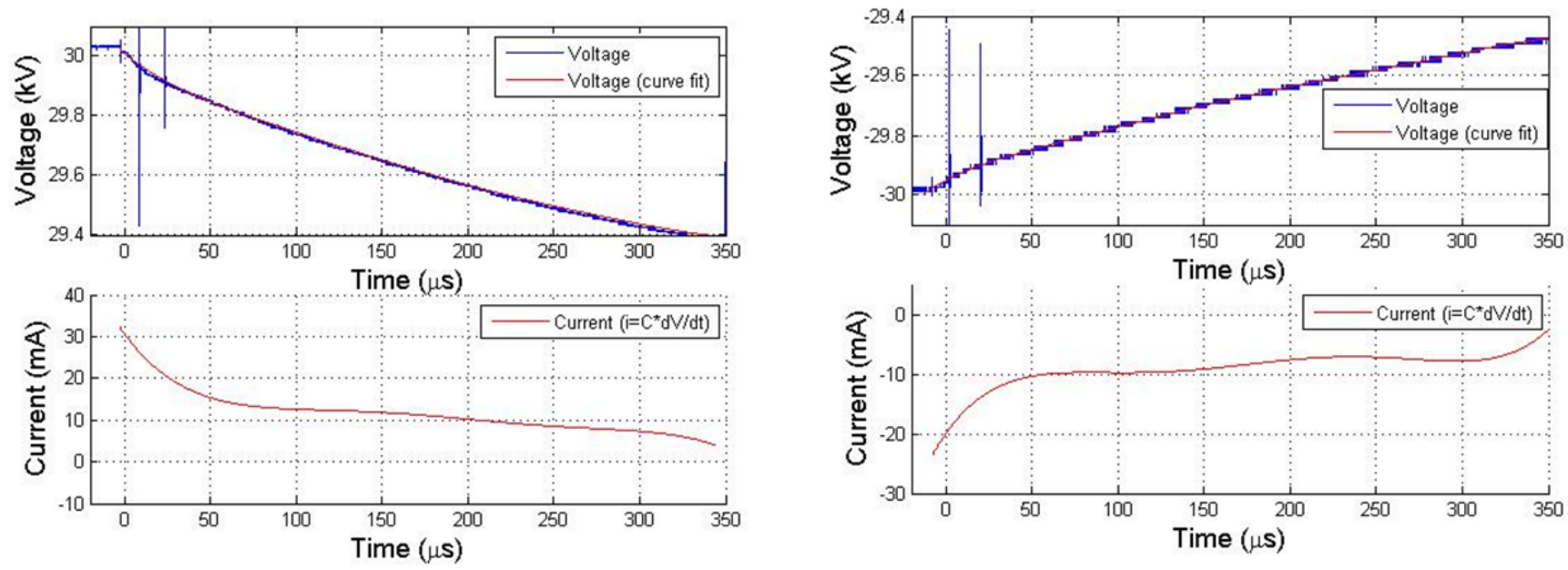

Figure 3-16. \#246 C2H2+O2+85\%Ar, $\mathrm{Po}=28 \mathrm{kPa}$, $\mathrm{Vo}=30 \mathrm{kV}, \mathrm{R}_{1}=0 \Omega$

Figure 3-17 \#260 C2H2+O2+85\%Ar, $\mathrm{Po}=28 \mathrm{kPa}, \mathrm{Vo}=-30 \mathrm{kV}, \mathrm{R}_{1}=0 \Omega$

Comparing the initial voltage distribution at the location of the initial interaction between the detonation wave and the charged electrode (Figure 3-18) we can see that the potential at that location is around $8 \mathrm{kV}$ for both cases. Before the detonation reaches the electric field region the plasma behind the detonation front is essentially at equilibrium state (same number of ions and electrons = zero potential). As it approaches the positively charged electrode the electric field in the gap separating the detonation front from the charged electrode keeps increasing. Since $E=\Delta V / \Delta x$ the magnitude of the electric field 


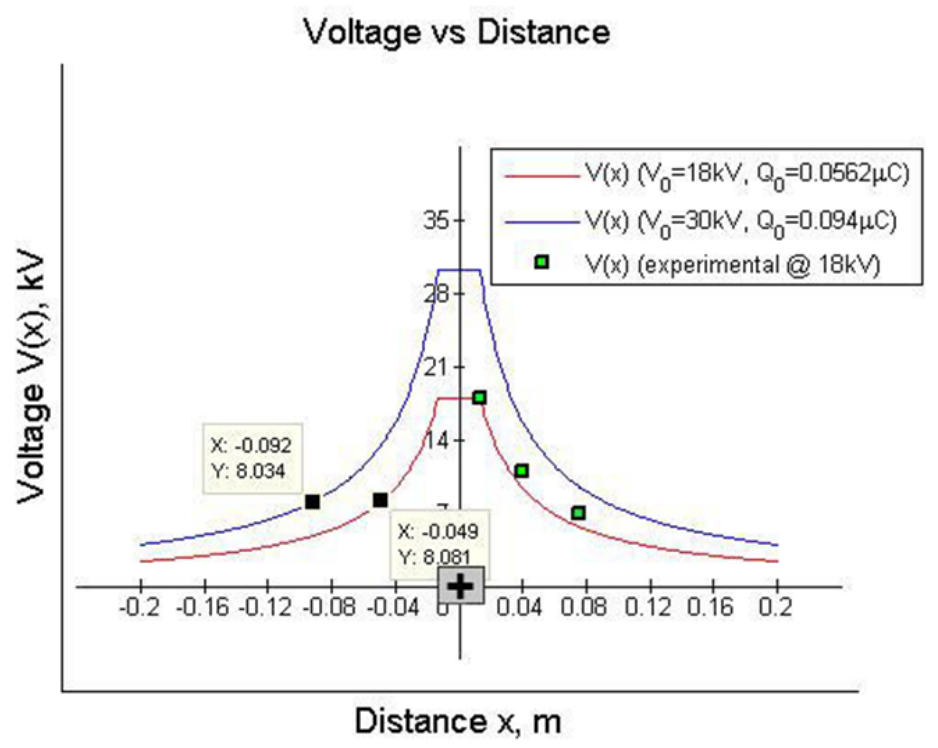

Figure 3-18. Voltage distribution near a positively charge electrode $(+18 \mathrm{kV}$ and $+30 \mathrm{kV})$

in the gap grows as $\Delta \mathrm{V}$ increases (see Figure 3-18) on approach to the electrode and $\Delta \mathrm{x}$ decreases. As soon as the electric field get strong enough, and in our case this occurs at the location where $\mathrm{V}=8 \mathrm{kV}$, the electrons start moving towards the electrode creating an electron current and causing a slight voltage drop on the electrode. In the case of negatively charged electrode, the positive ions move to the electrode creating an ion current. The magnitude of the ion current is smaller than the electron current due to the fact that ions are much larger than the electrons and thus have lower mobility. Both cases, when the electrode is at a potential of $18 \mathrm{kV}$ and $30 \mathrm{kV}$ confirm the presence of ion or electron current, indicating the presence of a sheath which shields the detonation plasma from the effects of electric field. To see if this effect is present in the mixture of $2 \mathrm{CO}+\mathrm{O} 2$ at $1 \mathrm{~atm}$ a similar set of experiments with a single electrode were conducted. 
Interaction between the detonation and the electric field from a single charged electrode in $2 \mathrm{CO}+\mathrm{O} 2$ mixture.

The effect of the electric field created by the single electrode on the detonation wave in $2 \mathrm{CO}+\mathrm{O} 2$ mixture at an initial pressure of $1 \mathrm{~atm}$ is similar to the one observed for
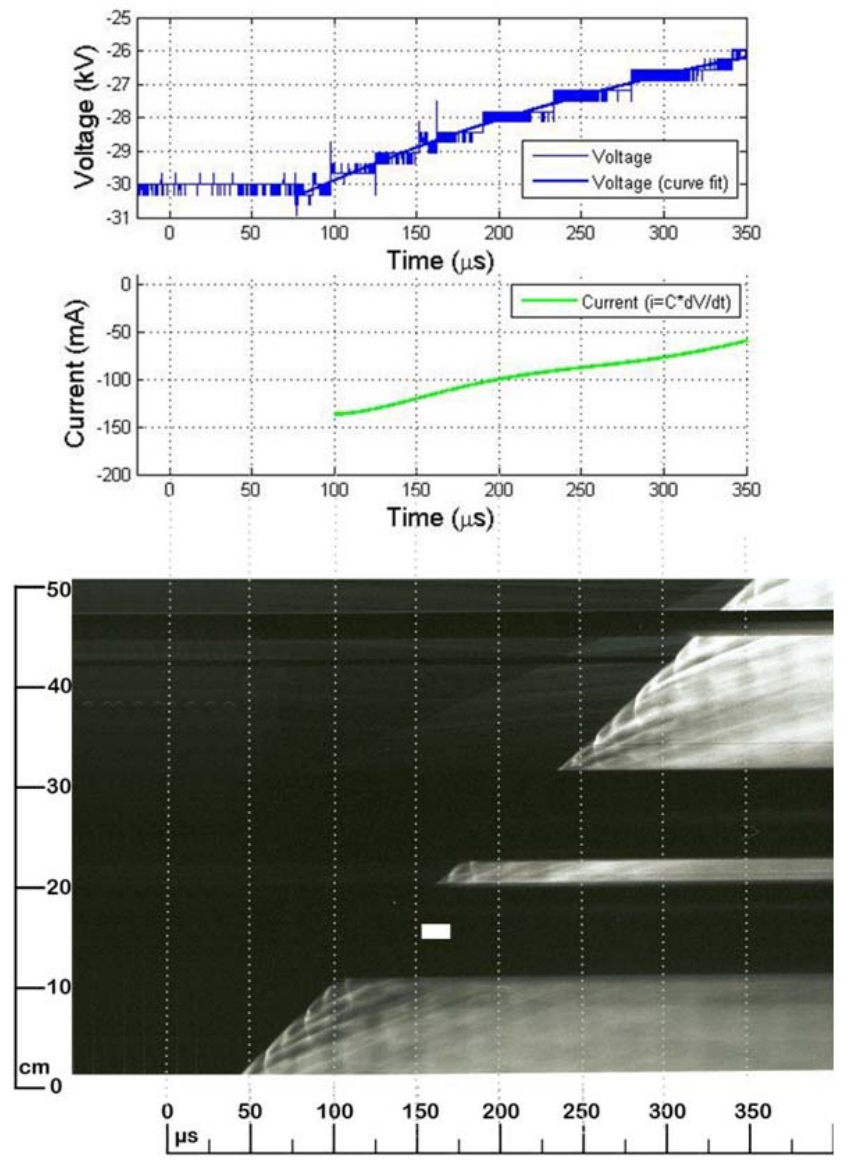

Figure 3-19. \#109 2CO+O2 (moist), $\mathrm{P}_{0}=1 \mathrm{~atm}, \mathrm{Vo}=-$ $30 \mathrm{kV} / \mathrm{cm}, \mathrm{R}_{1}=0 \mathrm{M} \Omega$
$\mathrm{C} 2 \mathrm{H} 2+\mathrm{O} 2+85 \% \mathrm{Ar}$ at $\mathrm{Po}=28 \mathrm{kPa}$,

which confirms the same interaction mechanism between the detonation and the electric field. Similar to the results in $\mathrm{C} 2 \mathrm{H} 2+\mathrm{O} 2+85 \% \mathrm{Ar}$ at $\mathrm{Po}=28 \mathrm{kPa}$ Figure 3-19 shows no perturbation of the detonation by the electric field. However, unlike in the case of $\mathrm{C} 2 \mathrm{H} 2+\mathrm{O} 2+85 \% \mathrm{Ar}$ at $\mathrm{Po}=28 \mathrm{kPa}$ where the detonation started the interaction with the electric field $9 \mathrm{~cm}$ before the electrode, in the case of the $2 \mathrm{CO}+\mathrm{O} 2$ mixture at $1 \mathrm{~atm}$ the interaction is only observed at the moment the detonation comes in contact with the electrode. This is a result of higher initial pressure. Even though the electric field extends far from the electrode the ions that are attracted to the electrode do not reach the electrode before the detonation does due to a higher collision rate with neutral species at 1 atm vs $28 \mathrm{kPa}$. Moreover, we see that the magnitude of the ion current is higher in the case of $2 \mathrm{CO}+\mathrm{O} 2$ mixture at 1atm. This is expected due to a higher ion concentration in the detonation plasma and larger area of the electrode. The magnitude of the ion current is in agreement with the theoretical results obtained in Table 3-1. Since in the experiment by Bone and coworkers a series resistor $\left(\mathrm{R}_{1}=1 \mathrm{M} \Omega\right)$ was used to limit the current supplied by the capacitor it is of 
interest to look at the case when a resistor is present to see what the voltage and current profiles will look like in this case, since these measurements were not conducted by Bone and coworkers [2].

\section{$\underline{\text { Detonation-Electric Field interaction }\left(\mathrm{R}_{1}=1 \mathrm{M} \Omega\right)}$}

When $1 \mathrm{M} \Omega$ is inserted in series between the capacitor and the electrode, the current that is allowed to flow in the test section is significantly reduced. This prevents the development of any discharges between the electrodes, and it also reduces the magnitude of the ion current that is drawn in by the electrode. Moreover, since the resistance of $R_{1}$ is significantly higher than the resistance of the wire connecting the capacitor to the
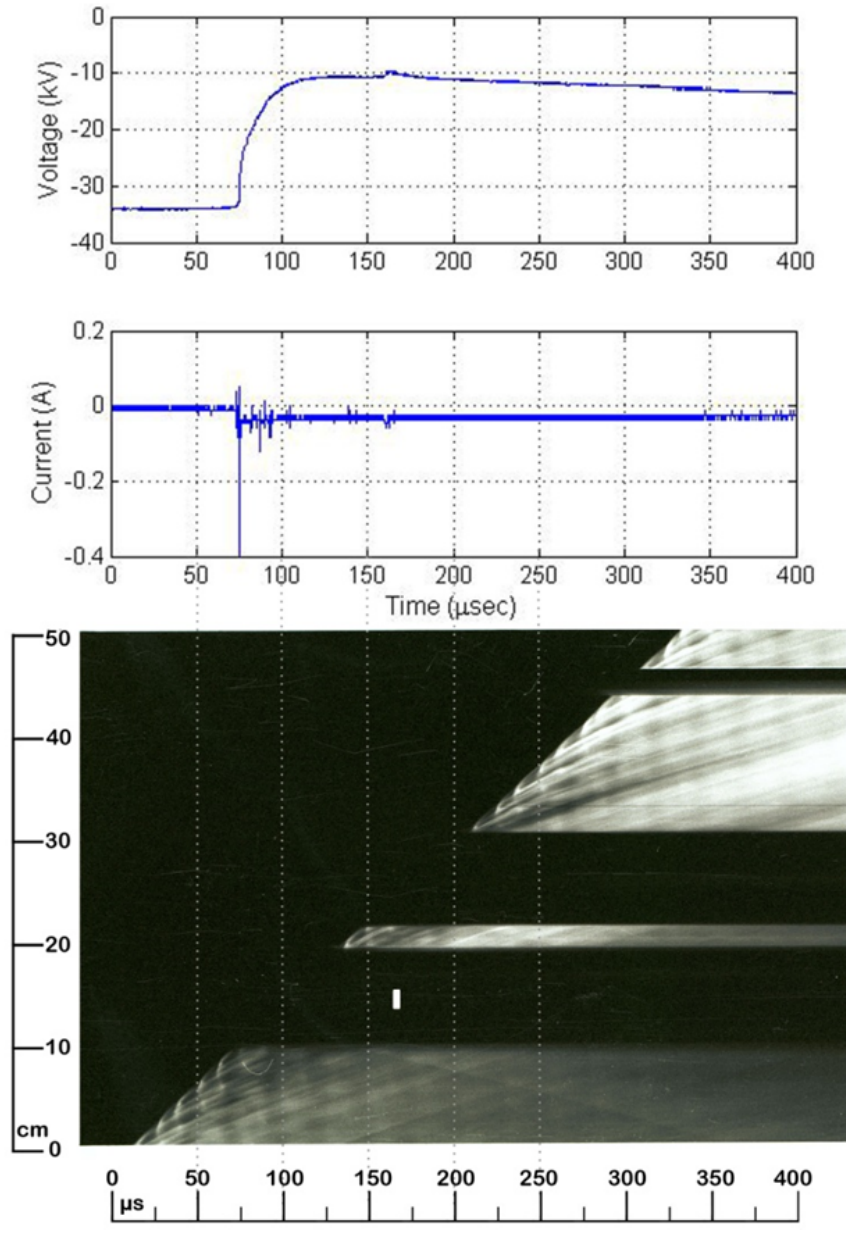

Figure 3-20. \#106 2CO+O2 (moist), $\mathrm{P}_{0}=1 \mathrm{~atm}$, $\mathrm{Vo}=-30 \mathrm{kV} / \mathrm{cm}, \mathrm{R}_{1}=1 \mathrm{M} \Omega$

the magnitude of voltage decrease was less than $2 \%$ of the initial voltage $\left(\mathrm{V}_{\mathrm{o}}\right)$. As it was electrode we should expect the highest voltage drop to occur across the $1 \mathrm{M} \Omega$ resistor. These assumptions are confirmed by the following composite streak photograph (Figure 3-20).

Figure 3-20 shows a composite streak photographs where the detonation trajectory as well as current in the test section and voltage on the first electrode (just after the $\mathrm{R}_{1}$ resistor) are shown as functions of time. Figure 3-20 shows one important feature, which was not seen in the case when $\mathrm{R}_{1}$ was set to $0 \mathrm{M} \Omega$ : it shows that the voltage on the first electrode decreases significantly as the detonation passes by it. By the time the detonation exits the first electrode the voltage on the electrode is reduced by about $60 \%$ of the initial voltage $\left(\mathrm{V}_{\mathrm{o}}\right)$. In the case when no resistor was present 
explained in the earlier section the voltage drop on the electrode is a result of collection of an ion current by the electrode as the detonation passes through it. The ions from the ionized gas behind the detonation get neutralized at the walls of the electrode and thus they draw electrons from the capacitor resulting in a voltage drop across the resistor $\mathrm{R}_{1}$. Since the resistance of $R_{1}$ is significantly higher than the resistance of the wire connecting the capacitor to the electrode voltage drop across $\mathrm{R}_{1}$ (Figure 3-20) is much higher than in the case of just a wire connecting the electrode to the capacitor. Even though the experiments above were conducted with a single charged electrode (the second electrode was disconnected) the voltage drop across the resistor $\mathrm{R}_{1}$ is not dependent on the presence or absence of the second electrode and was observed in all cases when $R_{1}$ was present in the circuit. It is worth noting that the drop in voltage across the resistor $R_{1}$ resulting in a significant $(60 \%)$ reduction of the magnitude of the electric field across two electrodes was not considered by Bone and coworkers [2]. They assumed a constant value of the electric field across the electrodes as the detonation traversed the test section.

The experiments with a single charged electrode showed that the interaction mechanism between the detonation wave and the electric field is governed by the interaction with the electrode sheath, which results in a current being drawn in by the electrode. Due to the shielding effect of the sheath no influence on the detonation was observed. Experiments described in the next section show that when a second electrode is connected to ground another mechanism of interaction between the detonation and the electric field is observed. 


\subsection{Interaction between a detonation and the electric field from two electrodes}

When a second electrode is connected to the ground, the electric field distribution upstream (before the test section) remains the same. However, downstream of the first electrode (in between the two electrodes) the electric field distribution changes (see Figure A-6-5 in Appendix A). Thus, before the detonation enters the test section we should expect the same behaviour as in the case of a single charged electrode. As seen in Figure 3-21 and Figure 3-22 the behaviour of the detonation in the presence of the second

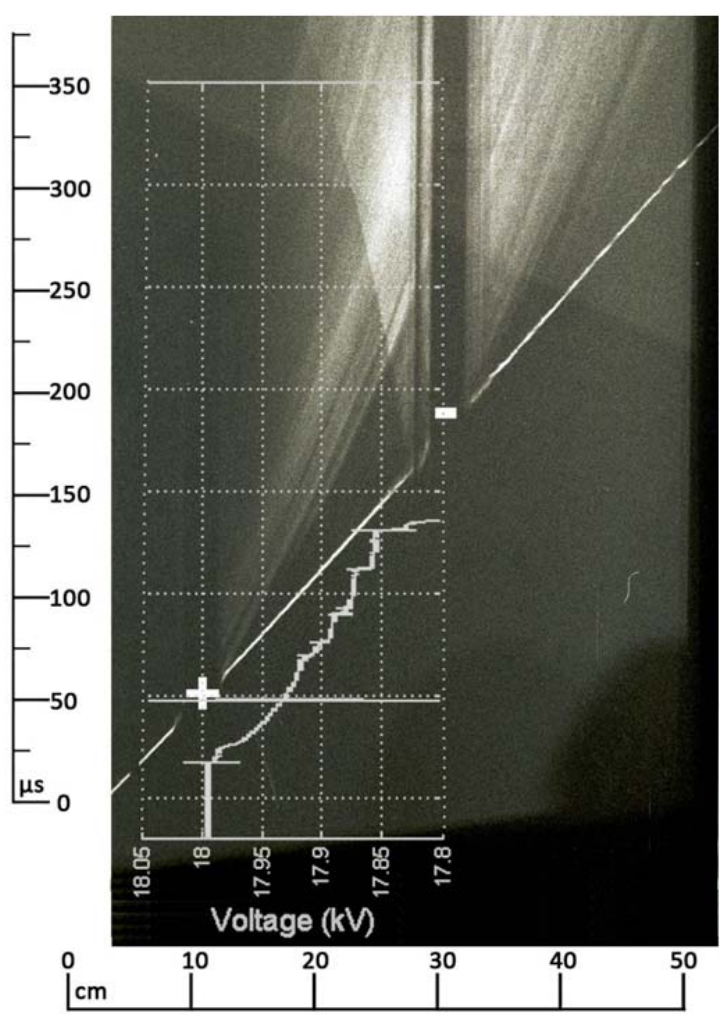

Figure 3-21. \#197 $\mathrm{C} 2 \mathrm{H} 2+\mathrm{O} 2+85 \% \mathrm{Ar}$, $\mathrm{Po}=28 \mathrm{kPa}, \mathrm{E}=0.9 \mathrm{kV} / \mathrm{cm}, \mathrm{R}_{1}=0 \Omega$
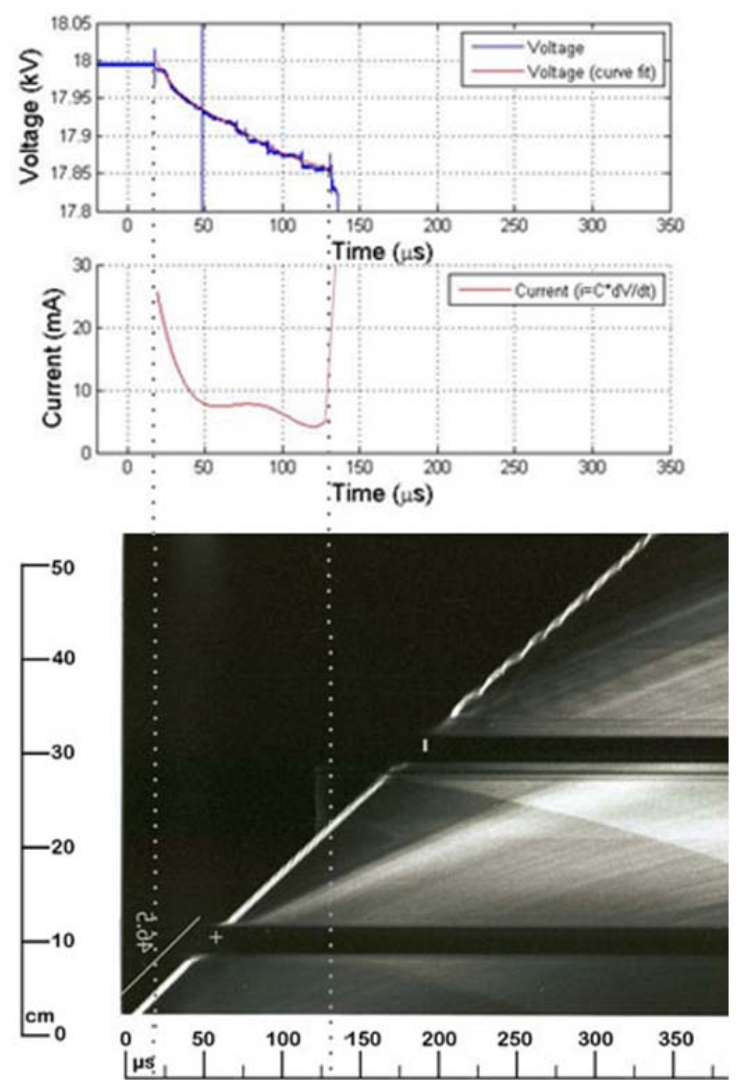

Figure 3-22. $\# 218 \mathrm{C} 2 \mathrm{H} 2+\mathrm{O} 2+85 \% \mathrm{Ar}, \mathrm{Po}=28 \mathrm{kPa}$, $\mathrm{E}=0.8 \mathrm{kV} / \mathrm{cm}, \mathrm{R}_{1}=0 \Omega$

electrode is very similar to the single electrode case both before and after the first electrode. As in the case of a single electrode there is no perturbation of the detonation structure or velocity as it passes through the first electrode. The voltage and current traces 

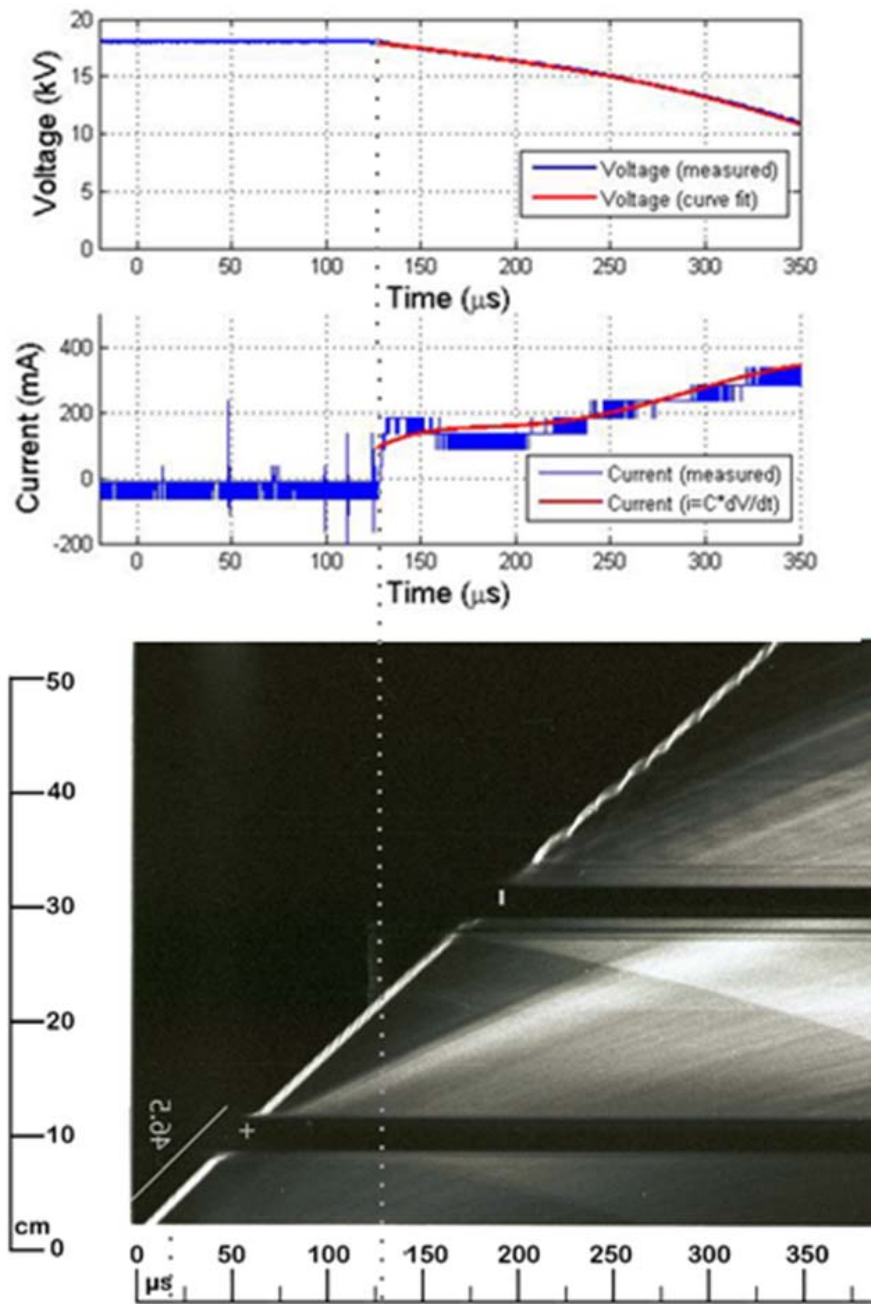

Figure 3-23. $\# 219 \mathrm{C} 2 \mathrm{H} 2+\mathrm{O} 2+85 \% \mathrm{Ar}, \mathrm{Po}=28 \mathrm{kPa}$, $\mathrm{E}=0.8 \mathrm{kV} / \mathrm{cm}, \mathrm{R}_{1}=0 \Omega$

the detonation between two electrodes. look very similar to the single electrode case (Figure 3-12 and Figure 3-16). However, once the detonation travels $16 \mathrm{~cm}$ into the test section we see a sharp drop in voltage (at $140 \mu \mathrm{s}$ ). The sharp voltage drop is a result of the development of a discharge. This is also accompanied by a rise in current from a few $\mathrm{mA}$ to a few hundreds of $\mathrm{mA}$. The presence of the discharge is confirmed by increasing the voltage measurement scale to capture the whole voltage drop as seen in Figure 323. Even though there is a discharge ahead of the detonation wave it does not seem to perturb the detonation structure significantly. In order to understand why the detonation promotes the development of the discharge we need to look at the voltage distribution in the presence of 


\section{Voltage Distribution between two electrodes}

In order to determine why the presence of the detonation wave between the two electrodes promotes the development of a discharge we need to look at the voltage distribution between the

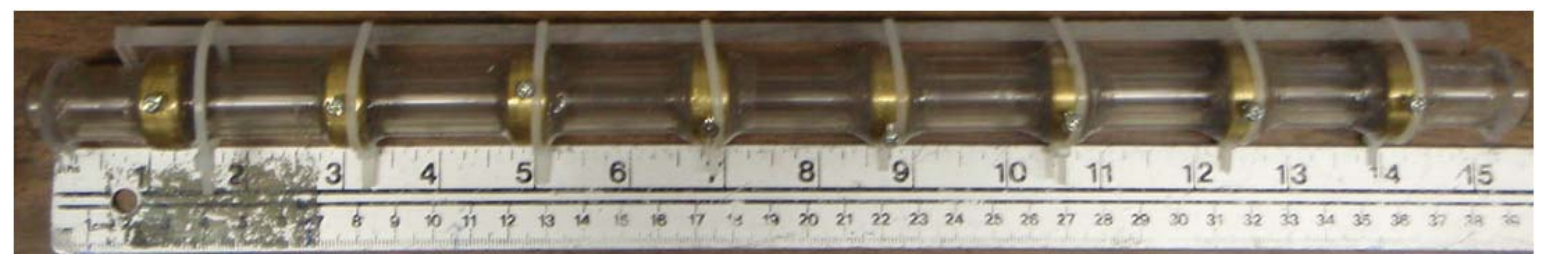

Figure 3-24. Composite Tube Section $(40 \mathrm{~cm})$

two electrodes as the detonation traverses the gap between the electrodes. To obtain the voltage distribution in the inter-electrode gap we need to measure the voltage not only at the first electrode, but also at other location in between the electrodes. This is done by replacing the clear polycarbonate tube in the test section with a composite tube consisting of a combination of polycarbonate tube sections and coaxial brass rings, which are used as probes for measuring voltage at a given location (Figure 3-24). Figure 3-26 shows how the voltage varies at eight different locations in the test section as the detonation passes by each point.

As seen in Figure 3-26 as soon as the detonation enters the test section, the initial voltage distribution between the two electrodes changes and it keeps changing in time as the detonation traverses the test section. Figure 3-26shows that the voltage on the positive electrode is carried by the detonation. As the detonation propagates in the test section it reduces the gap between the high voltage potential that it carries and the grounded electrode. This produces a constantly increasing electric field in the gap between the detonation front and the grounded electrode. The steepening of the electric field leads to the eventual gap breakdown at $t=274 \mu$ s. The start of the discharge is confirmed by a rise in current from 0 to $70 \mathrm{~mA}$ as the detonation approaches the ground electrode (Figure 3-25). Figure 3-25 shows that the discharge occurs when the detonation is about $7 \mathrm{~cm}$

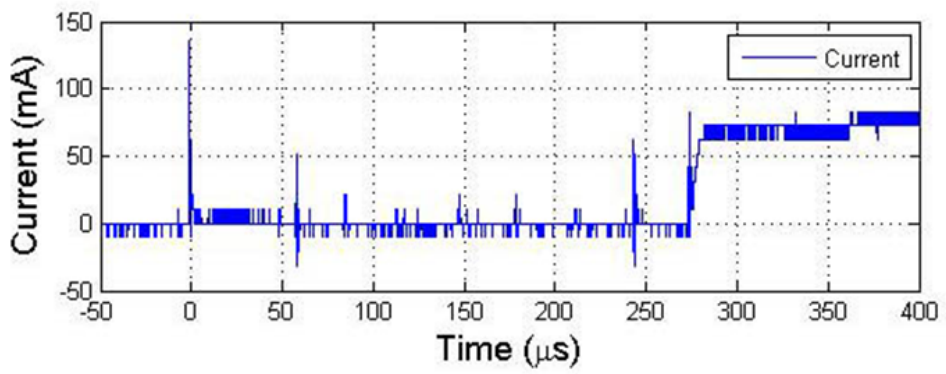

Figure 3-25. Current vs time (\#54_C2H2-O2-85\%Ar, Po=25kPa, E=0.45kV/cm) 

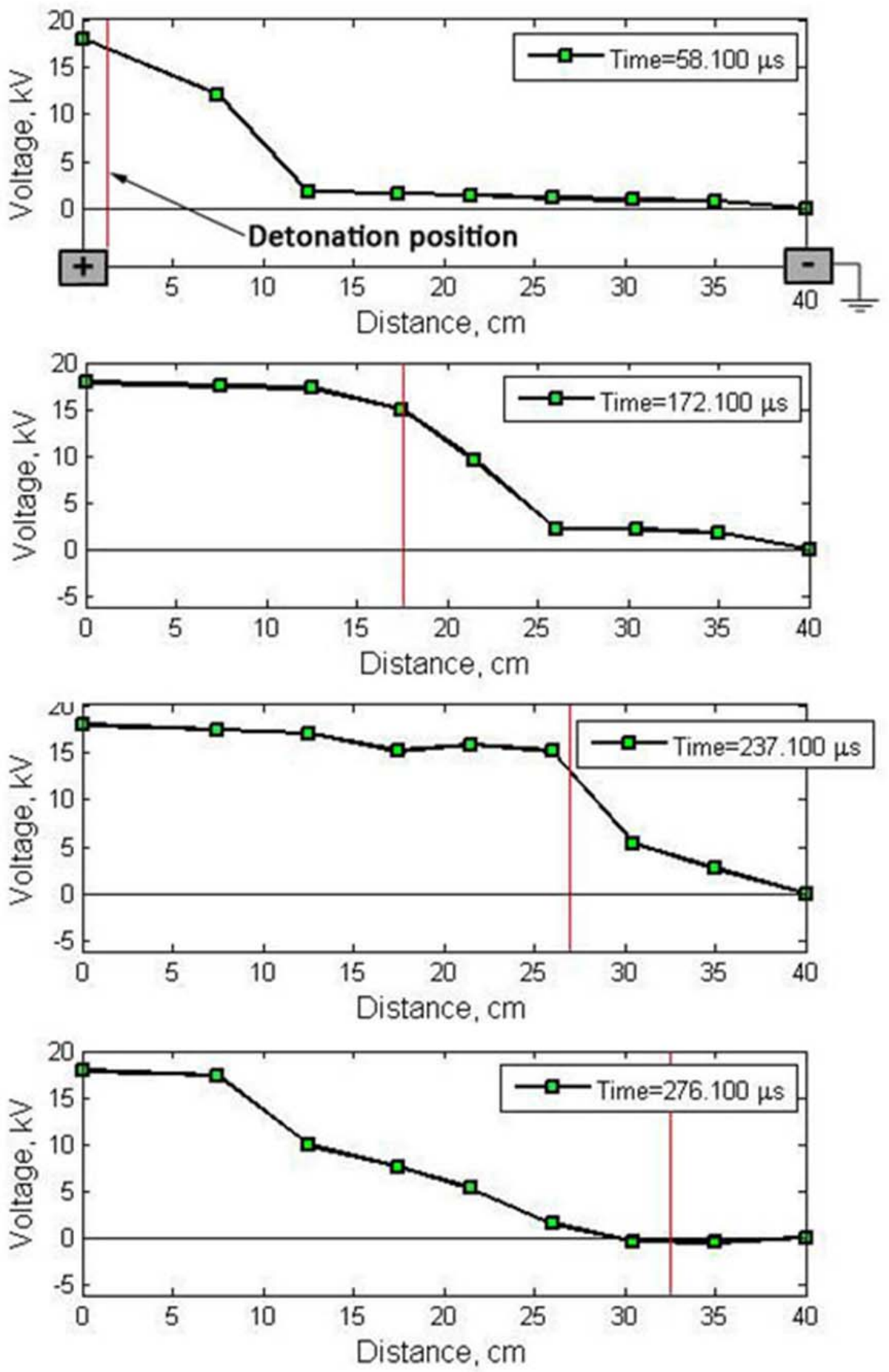

Figure 3-26. Voltage evolution between two electrodes (40 cm apart) (\#54_C2H2-O2-85\%Ar, $\mathrm{Po}=25 \mathrm{kPa}, \mathrm{E}=0.45 \mathrm{kV} / \mathrm{cm})$ 
away from the grounded electrode. The location of the discharge is governed by Paschen's Law which relates the breakdown voltage to the product of the initial gas pressure and electrode gap width. From Pachen's Law for a gap of 5-7cm in argon at $28 \mathrm{kPa}$ the breakdown voltage is between $16-19 \mathrm{kV}$. These values are in good agreement with the current experimental results.

Even though the experiments above did not show significant changes in the detonation structure or velocity, they are essential in understanding the interaction of the detonation wave and the axial electric field. The experiments above showed that:

1. In the case of the single electrode the interaction between the detonation and the electric field of the electrode is governed by the interaction with the electrode sheath. An ion or electron current (depending on electrode bias) to the electrode is induced as the detonation approaches the electric field region. Due to the electric field shielding effect of the sheath there is no influence the detonation structure or velocity.

2. The voltage on the charged electrode is carried by the ionized gas behind the detonation.

3. Thus, the detonation behaves essentially as a conductor carrying the voltage on first electrode with it. When a second electrode is connected to the ground the detonation shortens the gap between the electrodes bringing the potential of the first electrode closer to the grounded electrode as it traverses the inter-electrode space. For a given initial voltage the shortening of the gap between the electrodes leads to an eventual breakdown of the field and development of a discharge across the electrodes.

The current experiments show that the interaction process between the detonation and the axial electric field can be broken down into two mechanisms: 1. Interaction of the detonation plasma with the electrode sheath and 2. Interaction of the detonation with a discharge across the electrodes. 
In the case of the electrode sheath no influence on the detonation was observed. This is a result of the screening effect of the sheath and the fact that the current to the sheath is limited by its saturation value, beyond which no increase in current is possible.

The discharge, on the other hand, can potentially have significant influence on the detonation since it perturbs the fresh mixture ahead of the detonation. This effect will be explored further in the next section for both the $2 \mathrm{CO}+\mathrm{O} 2$ mixture at $1 \mathrm{~atm}$ and $\mathrm{C} 2 \mathrm{H} 2+\mathrm{O} 2+85 \% \mathrm{Ar}$ at $28 \mathrm{kPa}$.

\subsection{Effect of the discharge on the detonation wave}

In order to maximize the effect of the discharge the resistor $\mathrm{R}_{1}$, was removed from the circuit (Figure 2-1). Thus, the first electrode was directly connected to the capacitor. The only circuit resistance in this case is bulk resistance of the detonation plasma.

\subsubsection{Experiments with 2CO+02 mixture (Po=1atm)}

Figure 3-27 illustrates what happens to the detonation wave when it is subjected to a

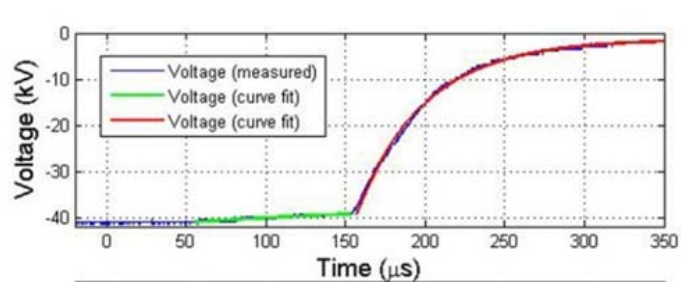
$5 \mathrm{kV} / \mathrm{cm}$ electric field. The streak
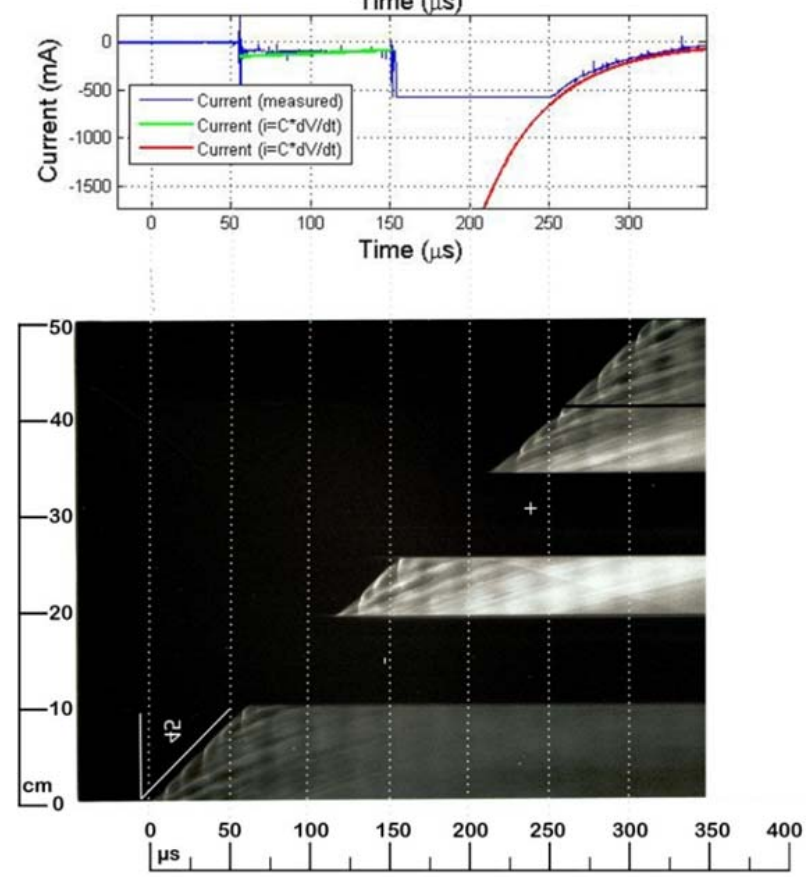

photograph shows no perturbation of the detonation. The current and voltage traces show the electrical interaction with the field. Similar to the results obtained in the case of a single electrode, as the detonation reaches the first electrode an ion current is drawn by the electrode. The ion current corresponds to the green line in the Figure 3-27. As the detonation enters the first electrode the current increases in magnitude and remains at a more or less constant value of about $100 \mathrm{~mA}$. The negative values for the

Figure 3-27. \#116 2CO+O2 (moist), $\mathrm{P}_{0}=1 \mathrm{~atm}$, $\mathrm{E}=5 \mathrm{kV} / \mathrm{cm}, \mathrm{R}_{1}=0 \mathrm{M} \Omega$ 
current indicate that the electrons are moving away from the negatively biased capacitor plate to the surface of the electrode. Initially this electron movement is the result of ions being neutralized at the surface of the electrode. As the detonation gets closer to the second electrode an electron cascade (breakdown) to the grounded electrode contributes to the current. The discharge current is significantly higher than the ion current due to secondary electrode emission by the negative electrode (cathode). The breakdown current is shown in red in Figure 3-27. Its initial spike is cut off from the graph, but it reaches all the way to 4A. As seen from Figure 3-27 the breakdown occurs as the detonation is about to enter the grounded electrode. The detonation is not affected by this event since the breakdown occurs when the detonation is only a few $\mathrm{mm}$ away from the electrode and most of the discharge occurs in the combustion products. In order to determine if the discharge can significantly perturb the detonation as it approaches the positive

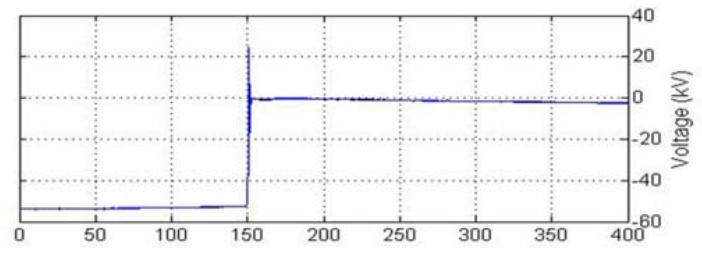
electrode, the initial electric field was increased to $5.6 \mathrm{kV} / \mathrm{cm}$ and the pressure was reduced to $0.9 \mathrm{~atm}$ to achieve an arc discharge conditions.

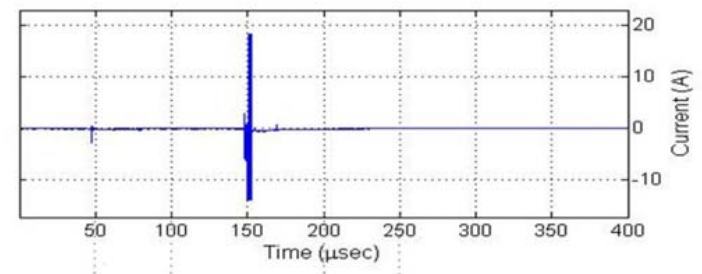

The arc discharge is visible Figure 3-28. However, similar to the previous results, the detonation does not appear to suffer any changes in either its structure or velocity. The voltage trace shows a very fast drop and the current trace is reduced to a very fast spike, indicative of an arc discharge. Moreover, a luminous line (due to a bright arc) connecting the two electrodes is clearly seen in the streak photograph in Figure 3-28. The discharge has

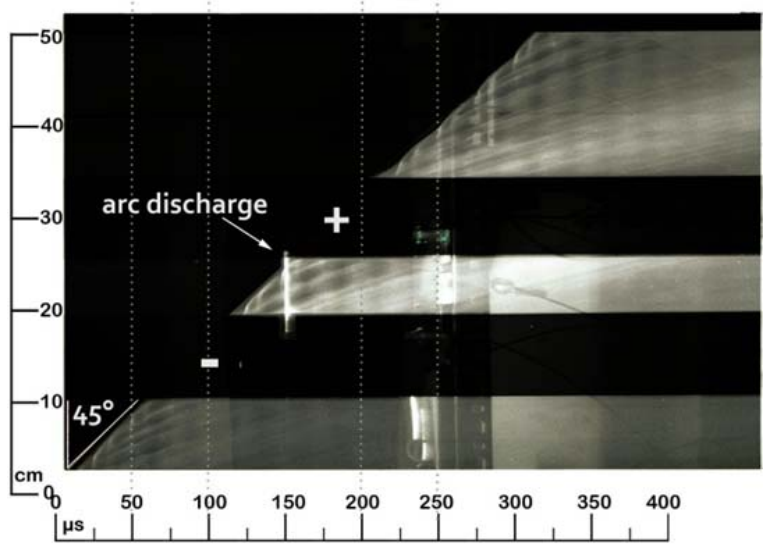

Figure 3-28. \#115 2CO+O2+H2O, $\mathrm{Po}=0.9 \mathrm{~atm}$, $\mathrm{E}=5.6 \mathrm{kV} / \mathrm{cm}, \mathrm{R}=0 \Omega$ the potential to significantly change both the structure and the propagation velocity of the detonation by igniting the mixture ahead of the detonation. However, this effect is highly dependent on electric field strength and the location of the discharge which is a function 
of initial pressure. For the case of the $2 \mathrm{CO}+\mathrm{O} 2$ mixture at 1atm (as seen in Figure 3-27 and Figure 3-28) with the electric field strength ranging from $4-7 \mathrm{kV} / \mathrm{cm}$ the discharge occurs only when the detonation reaches the second electrode. Thus, most of the discharge occurs in the combustion products behind the detonation. In order to investigate the effect of the discharge occurring a few $\mathrm{cm}$ ahead of the detonation (before the second electrode) a mixture of $\mathrm{C} 2 \mathrm{H} 2+\mathrm{O} 2+85 \% \mathrm{Ar}$ at a lower initial pressure of $28 \mathrm{kPa}$ was used. These results are presented in next section.

\subsubsection{Experiments with $\mathrm{C} 2 \mathrm{H} 2+02+85 \% A r$ Mixture $(\mathrm{Po}=28 \mathrm{kPa})$}

As seen so far in both $\mathrm{C} 2 \mathrm{H} 2+\mathrm{O} 2+85 \% \mathrm{Ar}$ and $2 \mathrm{CO}+\mathrm{O} 2$ mixtures the ion current drawn in by the electrode has no significant influence on the detonation due to Debye shielding of the detonation plasma. The discharge, on the other hand, has the capability to significantly disturb the propagation of the detonation since it affects the fresh mixture ahead of the detonation. In the case of $2 \mathrm{CO}+\mathrm{O} 2$ at $1 \mathrm{~atm}$ the discharge occurred when the detonation was a few $\mathrm{mm}$ from the electrode, and thus it had no significant effect on the detonation. In order to produce a discharge in $2 \mathrm{CO}+\mathrm{O} 2$ (at 1atm) $2-3 \mathrm{~cm}$ before the electrode the electric field of a much higher strength $30-60 \mathrm{kV} / \mathrm{cm}$ is required. These electric field values are beyond the capabilities of the HV power supply used in this experiment. However, by lowering the initial pressure of the mixture we can reduce the magnitude of the field needed to breakdown a large gap between the detonation front and the ground electrode. That is why the mixture of $\mathrm{C} 2 \mathrm{H} 2+\mathrm{O} 2+85 \% \mathrm{Ar}$ mixture at $28 \mathrm{kPa}$ was used to investigate further the effect of the discharge on the detonation. At $28 \mathrm{kPa}$ initial pressure the electric field needed to breakdown the gap of $20 \mathrm{~cm}$ in this mixture is only $1.8 \mathrm{kV} / \mathrm{cm}$, which is well within the capabilities of the current HV power supply. 


\subsubsection{Minor effects of the discharge on the detonation wave}

At low potential gradients (below $0.8 \mathrm{kV} / \mathrm{cm}$ ) the influence of the electric field and the discharge that it creates is minimal. Only a very slight change in the detonation structure and is observed in Figure 3-29 and Figure 3-30. In order to determine the type and the location of the discharge we have to look at the current and voltage traces associated with propagation of the detonation in the test section. Figure 3-31 shows the variation of voltage across the electrodes and current as functions of time as the detonation traverses the inter electrode gap. As seen earlier as soon as the electric field in the gap between the detonation front and the grounded electrode reaches a high enough value a breakdown occurs. In Figure 3-32 and Figure 3-33 this occurs when the detonation is about $6 \mathrm{~cm}$ away from the grounded electrode. Even though the discharge is present as the detonation closes the inter-electrode gap, it is too faint to show up on the streak photograph in Figure 3-31. As the camera is moved closer and the lens aperture is increased the development of the discharge is seen on the streak photograph (Figure 3-32). There is a bright line connecting the detonation front to the grounded electrode. The voltage and current traces

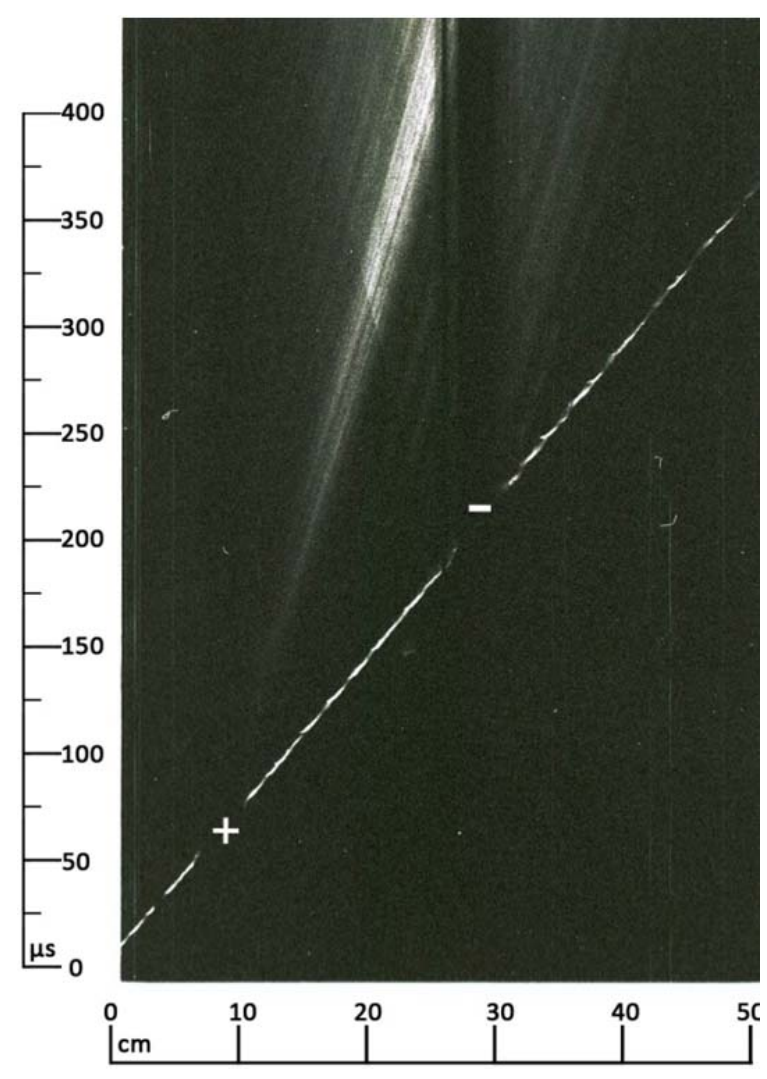

Figure 3-29. \#203 $\mathrm{C} 2 \mathrm{H} 2+\mathrm{O} 2+85 \% \mathrm{Ar}$, $\mathrm{P}_{0}=28 \mathrm{kPa}, \mathrm{E}=0.8 \mathrm{kV} / \mathrm{cm}, \mathrm{R}_{1}=0$

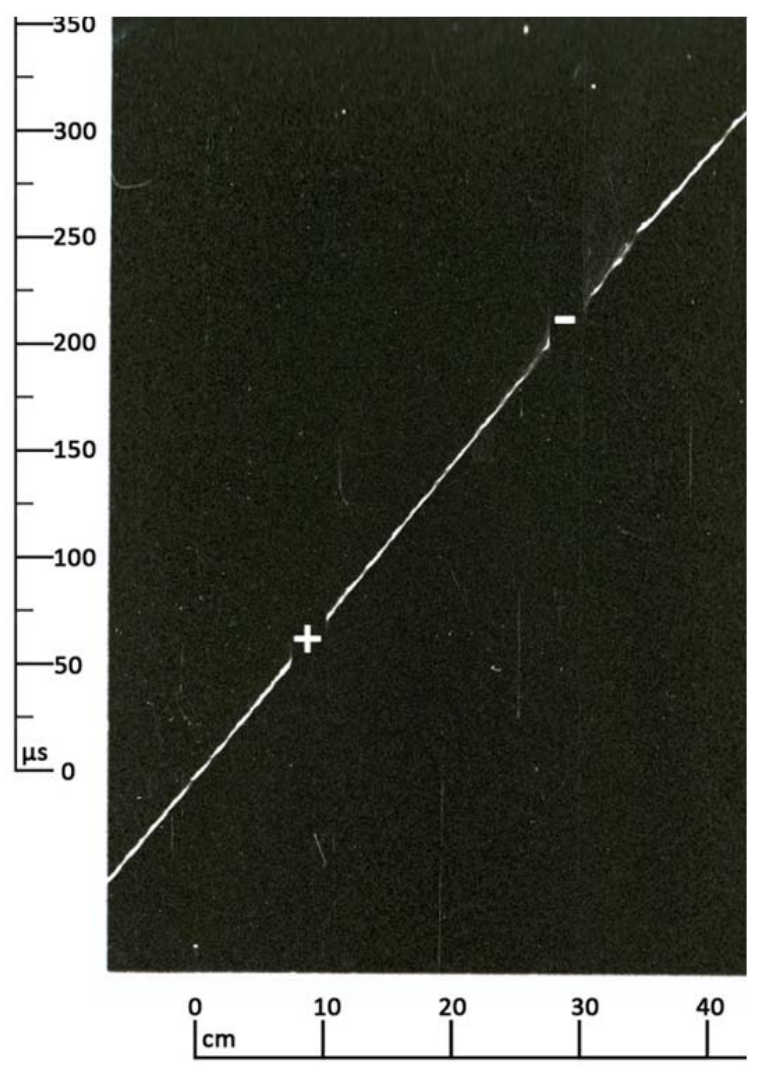

Figure 3-30. \#12 $\mathrm{C} 2 \mathrm{H} 2+\mathrm{O} 2+85 \% \mathrm{Ar}, \quad H 1$ $\mathrm{P}_{0}=28 \mathrm{kPa}, \mathrm{E}=0.8 \mathrm{kV} / \mathrm{cm}, \mathrm{R}_{1}=0$ 

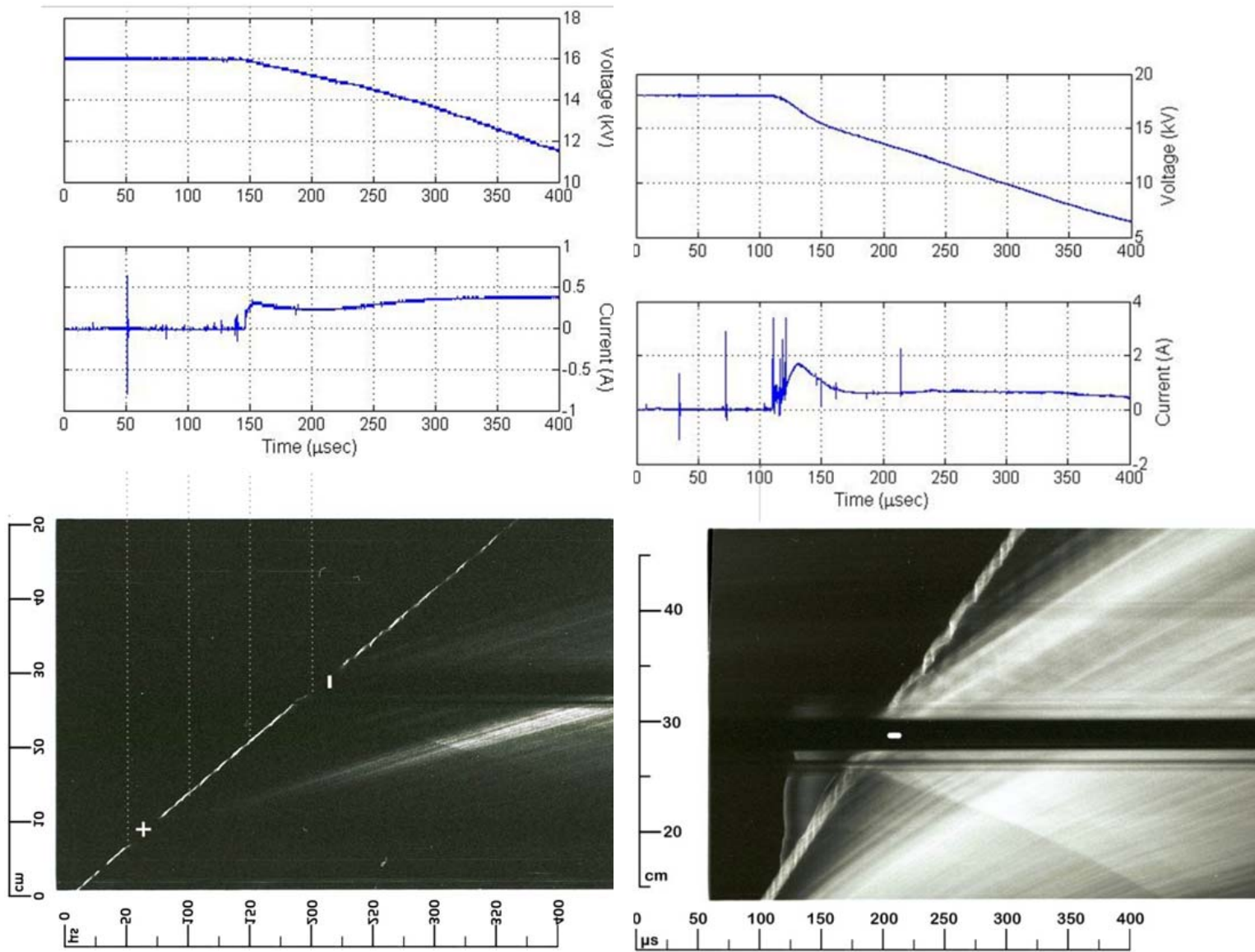

Figure 3-31. \#203 C2H2+O2+85\%Ar, $\mathrm{P}_{0}=28 \mathrm{kPa}$, $\mathrm{E}=0.8 \mathrm{kV} / \mathrm{cm}, \mathrm{R}_{1}=0$

Figure 3-32. $\# 268 \mathrm{C} 2 \mathrm{H} 2+\mathrm{O} 2+85 \% \mathrm{Ar}, \mathrm{P}_{0}=28 \mathrm{kPa}$, $\mathrm{E}=0.85 \mathrm{kV} / \mathrm{cm}, \mathrm{R}_{1}=0$

point to the development of a glow discharge. However, even though the discharge is present ahead of the detonation it's not enough to significantly change the structure of the detonation. As seen in Figure 3-32 the detonation structure is only slightly disturbed. A multi-head structure which is seen before the discharge turns into a wobbling spinning structure as the detonation exits the grounded which then quickly transits back to its original multi-head structure. The reason for the perturbation of the detonation structure can be seen by looking at the pressure trace for the time after the discharge. It is shown in Figure 3-33. As seen in Figure 3-33 as soon as the discharge starts at $110 \mu$ s there is a spike in the pressure signal. This is a result of a shock wave created by the discharge. 

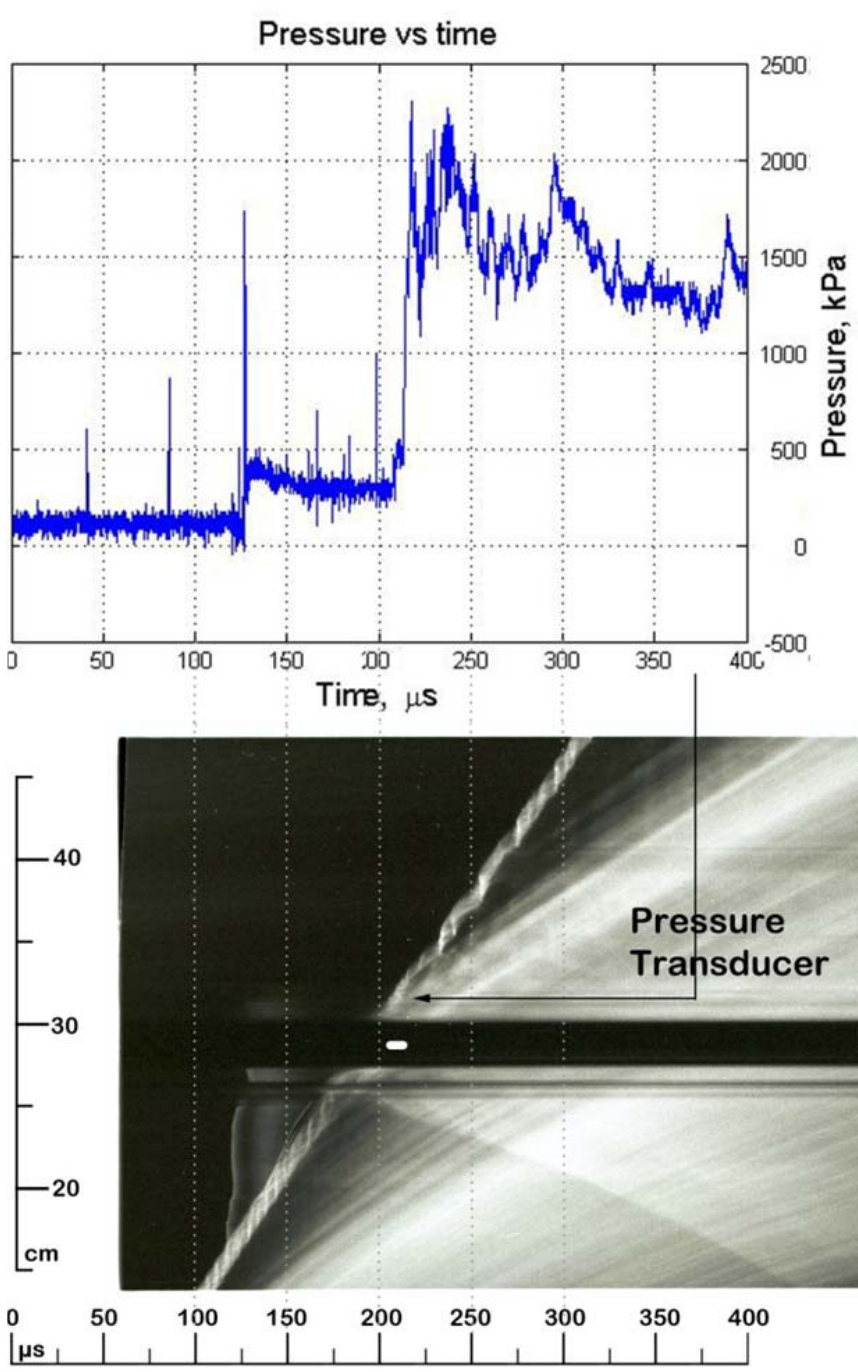

Figure 3-33. \#268 C2H2+O2+85\% Ar, $\mathrm{P}_{0}=28 \mathrm{kPa}$, $\mathrm{E}=1.025 \mathrm{kV} / \mathrm{cm}, \mathrm{R}_{1}=0$

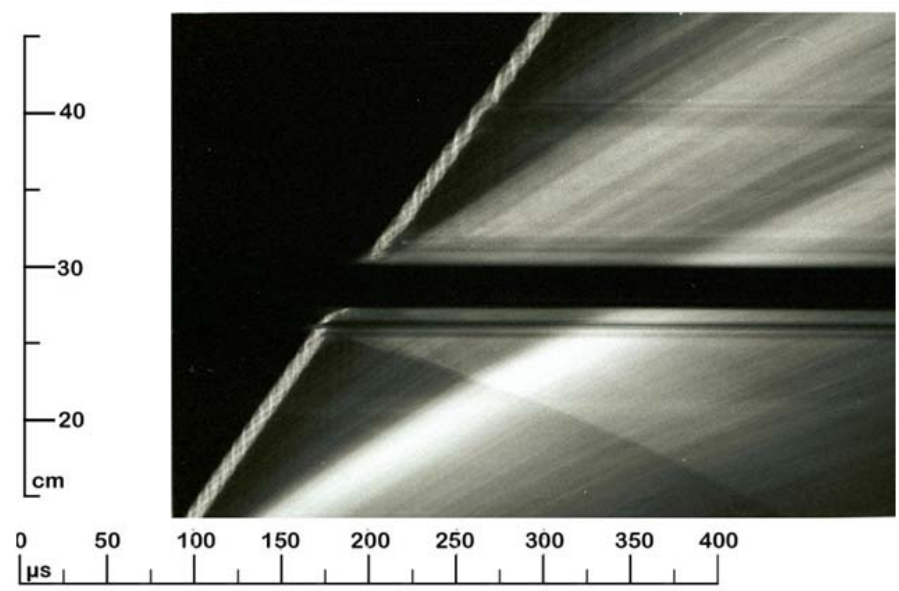

Figure 3-34. \#265 C2H2+O2+85\%Ar, $\mathrm{P}_{0}=28 \mathrm{kPa}, \mathrm{E}=0$ $\mathrm{kV} / \mathrm{cm}, \mathrm{R}_{1}=0$
The precompression of the mixture and high temperatures present in the discharge column cause localized ignition of the mixture. The minimum ignition energy for stoichiometric acetylene oxygen mixtures is extremely low $\sim 10^{-2} \mathrm{~mJ}$ and therefore ignition is ensured by almost any discharge. Since the initial conditions are far from the flammability limits the flame can easily propagate in the tube with laminar flame speed, which is on the order of $1.5 \mathrm{~m} / \mathrm{s}$ for acetylene oxygen mixture. This very slow flame that burns out a small amount of the fresh mixture upstream of the detonation, resulting in a slight perturbation in the detonation structure as seen in the streak photograph in

Figure 3-33. When no field and no discharge are present, the structure of the detonation is intact (Figure 3-34). As the electric field is increased the effects of the discharge become more pronounced. 


\subsubsection{Large effects of the discharge on the detonation wave}

At the electric field values below $0.9 \mathrm{kV} / \mathrm{cm}$ only a slight perturbation of the detonation is observed. As the electric field strength is increased above $0.9 \mathrm{kV} / \mathrm{cm}$ the voltage and current characteristics of the discharge change. Looking at the voltage and current traces in Figure 3-35 and Figure 3-36 we see a much faster voltage drop across the electrodes as the detonation closes the gap between electrode. This faster voltage drop is an indication of a transition of the discharge from a glow phase to an arc phase. In Figure 3-35 the bright flash from an arc is clearly seen. Higher current values associated with an arc discharge vs glow discharge are also seen in the current traces. The arc discharge that is developed ahead of the detonation is not self-sustained discharge (it dies out fast) due to a
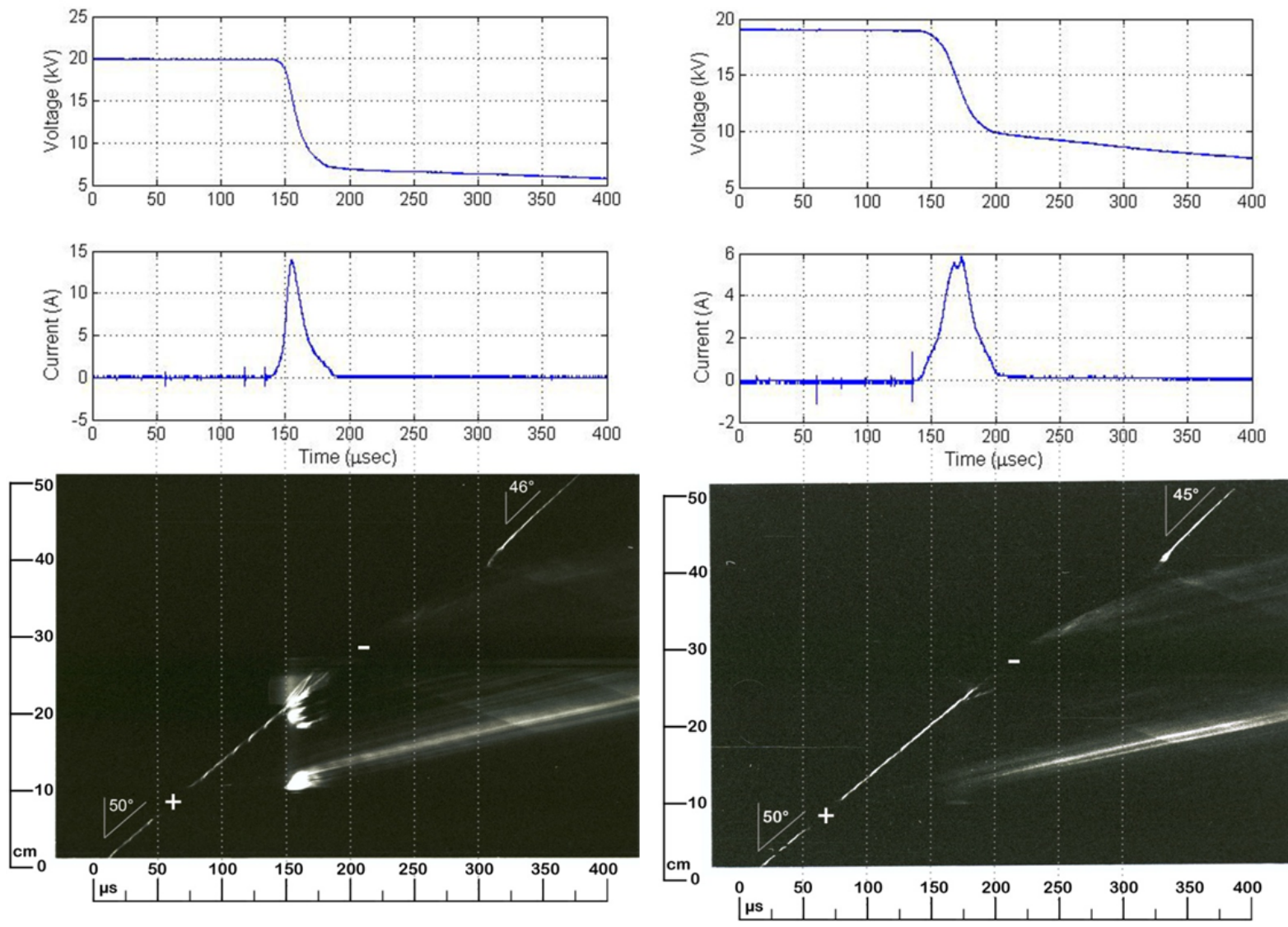

Figure 3-35. $\# 210 \mathrm{C} 2 \mathrm{H} 2+\mathrm{O} 2+85 \% \mathrm{Ar}, \mathrm{P}_{0}=28 \mathrm{kPa}$, $\mathrm{E}=1 \mathrm{kV} / \mathrm{cm}, \mathrm{R}_{1}=0$

Figure 3-36 \#207 C2H2+O2+85\%Ar, $\mathrm{P}_{0}=28 \mathrm{kPa}$, $\mathrm{E}=0.95 \mathrm{kV} / \mathrm{cm}, \mathrm{R}_{1}=0$ 
rapid discharge of the capacitor. However, it is enough to ignite the mixture ahead of the detonation. From about $20 \mathrm{~cm}$ mark in Figure 3-35 the detonation is now propagating in the reacted mixture. Very high temperature and pressure gradients of an arc column generate a shock wave that propagates downstream in the tube. The presence of the shock wave is more evident in Figure 3-37 and Figure 3-38, where the electric field is increased even further to $1.2 \mathrm{kV} / \mathrm{cm}$ (Figure 3-37) and $1.5 \mathrm{kV} / \mathrm{cm}$ (Figure 3-38). The lack of fresh mixture ahead of the detonation coupled with the interaction of the detonation leading shock wave with the shock wave created by the discharge leads to the failure of the detonation. This failure is clearly seen in the Figure 3-38. The deflagration which is created as result of the detonation failure propagates further down the tube and will transfer back to detonation as instabilities develop in the turbulent flame-shock interaction region. The DDT phenomenon is seen in Figure 3-37. In summary, the discharge occurring ahead of the detonation can significantly perturb its structure and velocity by igniting the mixture ahead of the detonation leading to failure of the detonation.
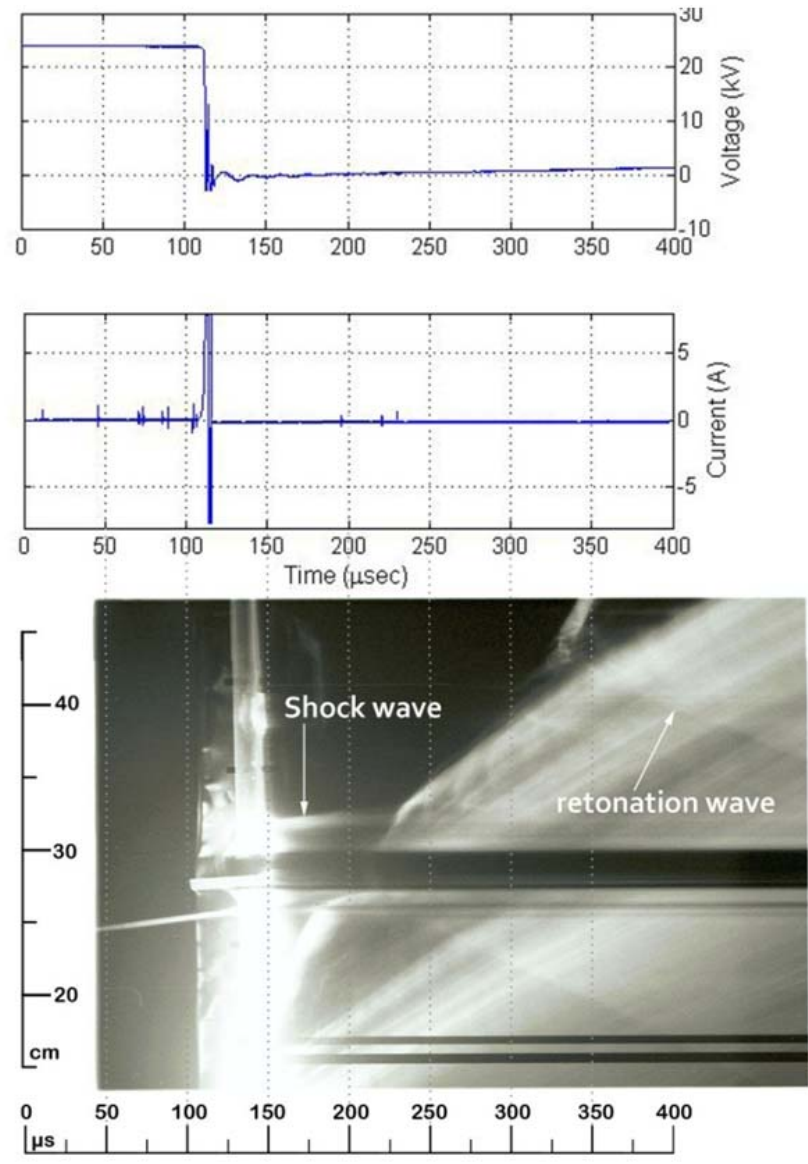

Figure 3-37. \#274 C2H2+O2+85\%Ar, $\mathrm{P}_{0}=28 \mathrm{kPa}$, $\mathrm{E}=1.2 \mathrm{kV} / \mathrm{cm}, \mathrm{R}_{1}=0$
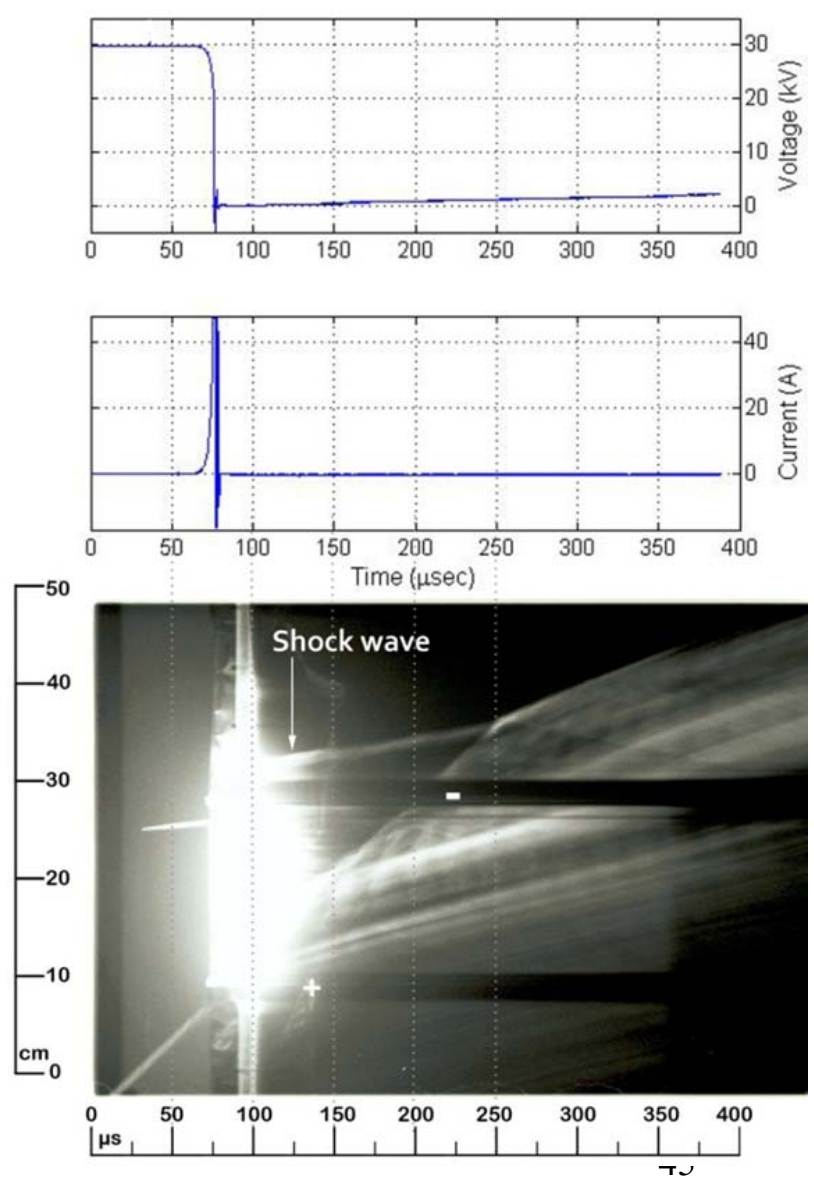

Figure 3-38. \#282 C2H2+O2+85\% $\mathrm{Ar}, \mathrm{P}_{0}=35 \mathrm{kPa}$, $\mathrm{E}=1.5 \mathrm{kV} / \mathrm{cm}, \mathrm{R}_{1}=0$ 


\section{Conclusion}

The present thesis reports an investigation of the effects of an axial electric field on the propagation of detonation waves in mixtures of $2 \mathrm{CO}+\mathrm{O} 2$ and $\mathrm{C} 2 \mathrm{H} 2+\mathrm{O} 2+85 \% \mathrm{Ar}$. The results show that as the detonation approaches the electric field region around the electrode, the charged particles at the boundary of the detonation plasma reorient themselves relative to the charge on the electrode. If the electrode is negatively biased the electrons are repelled and the ions are attracted to the surface of the electrode. The opposite is true when the electrode is positively biased. This movement of charged species due to the electric field results in an ion or an electron current (depending on electrode bias) to the electrode. The charged particles that are attracted to the surface of the electrode create a sheath at the boundary of the electrode that shields the bulk of the plasma from further influence of the DC electric field of the electrode. The present results also show that the neither the detonation structure nor its velocity are influenced by the presence of the sheath and the resulting current to the electrode.

It is also found that the conducting gas behind the detonation wave carries the voltage across the test section to the second (ground) electrode. In an axial electrode configuration the detonation wave essentially reduces the gap between the two electrodes progressively as it propagates in the test section. The increase of the electric field ahead of the detonation may result in a breakdown of the unburned mixture ahead of the detonation and the development of a glow or an arc discharge. In the case of low electric field strength a glow discharge occurs resulting in only a slight perturbation of the detonation. However, if a sufficiently high electric field is developed an arc discharge occurs ahead of the detonation and igniting the unburnt mixture upstream of the detonation. The lack of fresh mixture ahead of the detonation results in failure of the detonation, but subsequent reinitiation of the detonation may occur.

The present study also indicates that contrary to the previous observations by Bone et el, no significant effect of the applied electric field on the detonation is observed except for cases where breakdown of the unburned mixture ahead of the detonation occurs. 


\section{LIST OF REFERENCES}

1. Dixon HB, Campbel LC, Slater WE (1914) Photographic analysis of explosions in the magnetic field. Proc. Roy. Soc. A 90:506-511

2. Bone WA, Fraser RP, Wheeler WH (1935) A Photographic Investigation of Flame Movementsin Gaseous Explosions. VII. The Phenomenon of Spin in Detonation" Phil. Trans.Roy. Soc., A235:53-68.

3. Kelly J R and Toong T Y Prc. Eleventh Int. Symp. on Combustion, Berkley, CA (Pittsburgh, PAThe Combustion Institute) p 6.57

4. Thomas, G.O., Edwards, D.H., Edwards, M.J. and Milne, A., ' Electrical enhancement of detonation', J.Phys D:Applied Physics 26:20-30, (1993).

5. E. G. Plett and T. Y. Toong, "Electromagnetic effect on flows behind gaseous detonation,"AIAA J., 7, No. 6,. 1127-1133 (1969)

6. S. Basu and J. A. Fay, "Ionization in detonation waves," in: Seventh Symp. (Int.) on Combustion, Oxford, Lon- don (1959).

7. Cavenor M.C. "The Behaviour of Electric Probes in Gaseous Detonation". Proc. R. Soc. Lond. A May 4, 1971322 p.469-481; doi:10.1098/rspa.1971.0079

8. K.Terao. "Irreversible Phenomena: Ignitions, Combustion and Detonation Waves", Springer, $1^{\text {st }}$ ed. (2007) p.150

9. K. Saito, "Measurements of the high electron density zone in $\mathrm{C} 2 \mathrm{H} 2-\mathrm{O} 2$ detonation waves by microwave re- flection," Combust. Flame, 21, 241-251 (1973).

10. A. A. Fridman and L. A. Kennedy. "Plasma physics and engineering", Taylor and Francis, (2004).

11. Hutchinson, I.H. (2005), Principles of Plasma Diagnostics (2nd ed.), New York, NY: Cambridge University Press, pp. 77

12. D. Bradley, in: F.J. Weinberg (Ed.), Advanced Combustion Methods, Academic Press, New York, 1986, p. 331.

13. Lawton, J., and Weinberg, F. J., Electrical Aspects of Combustion, Clarendon Press, Oxford, 1969. 
14. H.F. Calcote, C.H. Berman, Proc. ASME Fossil Fuels Combust. PD-25 (1989) $25-31$.

15. J. Lawton, P.J. Mayo and F.J. Weinberg, Electrical Control of Gas Flows in Combustion Processes, Apr. 17, 1967, p. 275-298, vol. 303, Imperial College, London.

16. D. H. Edwards, G. Hooper. Ionization measurement in reactive shock and detonation waves using microwave techniques. et al 1971 J. Phys. D: Appl. Phys. 4854

17. CHAPMAN, S. and COWLING, T. G. The Mathematical Theory of NonUniform Gases, Sec. 18.12 and 14.2, and Table 6, Sec. 10.53. 1952.London; Cambridge University Press 
APPENDIX A 


\section{A.1 Undistorted Electric Field (single electrode)}

The axial electric field produced by a charged cylindrical electrode can be obtained by first determining the variation of electric potential due to the charged electrode and then

differentiating the potential function with respect to $\mathrm{x}: E_{x}=\frac{d V}{d x}$ to obtain the variation of the $\mathrm{x}$ component of the electric field along the axis of the cylinder.

To obtain the variation of potential in the $\mathrm{x}$ direction due to a charged cylinder we first obtain the variation of potential due to a charged annular disk (Figure 1) and then we integrate this result to obtain the variation of potential due to a charged cylinder.

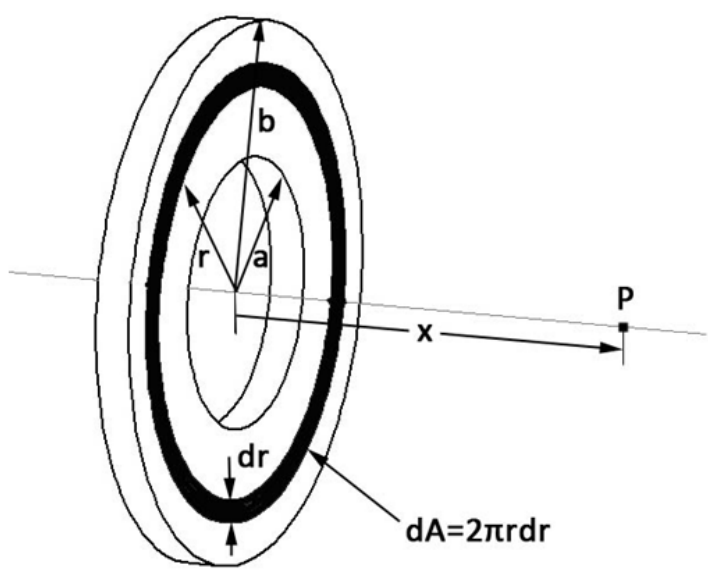

Figure A-5-1. Charged disk

The potential at point $\mathrm{P}$ from a charged ring of thickness $d r$ is given by:

$$
d V=\frac{k_{e} d q}{\sqrt{r^{2}+x^{2}}}
$$

Assuming the net charge on the ring $d q=$ $\sigma d A=\sigma 2 \pi r d r$, where $\sigma$ is the surface charge density (unknown) we can replace $d q$ in the equation above. Substituting $d q$ into the above and integrating yields:

$$
V=2 \pi \sigma k_{e} \int_{a}^{b} \frac{r d r}{\sqrt{r^{2}+x^{2}}}=2 \pi \sigma k_{e}\left[\sqrt{x^{2}+b^{2}}-\right.
$$

$$
\left.\sqrt{x^{2}+a^{2}}\right](2)
$$

For a charged conductor all the charge

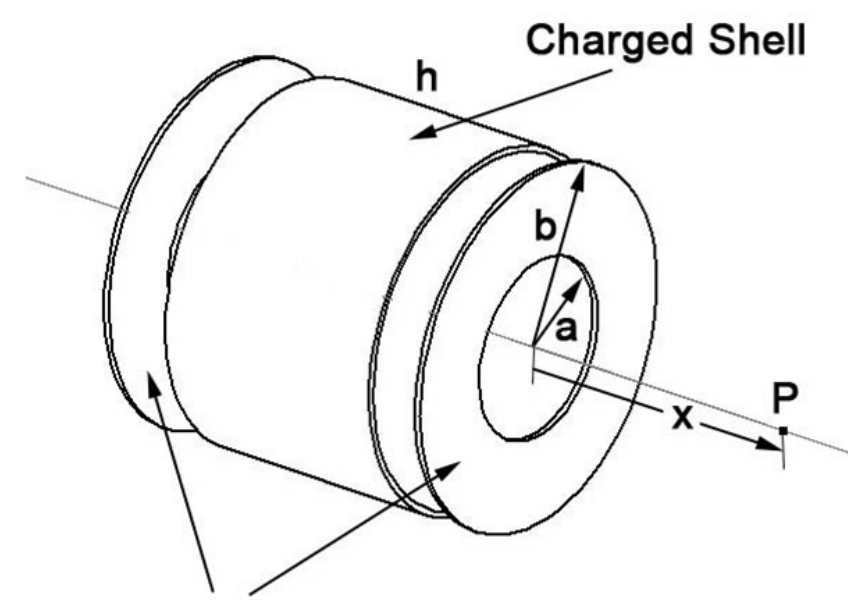

resides on the outer surface of the conductor. Thus in order to evaluate the electric potential or electric field we have to assume that the net charge $\mathrm{Q}$ is evenly distributed on the outer surface of the cylinder (not the entire volume) consisting of a cylindrical shell and two disks on the sides as shown in Figure A-2:

\section{Charged Disks}

Figure A-5-2. Combination of charged shell and two charged disks 


$$
\begin{gathered}
V_{\text {at } P}=V_{\text {charged disk at } x}+V_{\text {charged disk at } x+h}+V_{\text {charged shell from } x \text { to } x+h} \\
V_{p}=2 \pi \sigma k_{e}\left[\sqrt{x^{2}+b^{2}}-\sqrt{x^{2}+a^{2}}\right]++2 \pi \sigma k_{e}\left[\sqrt{(x+h)^{2}+b^{2}}-\sqrt{(x+h)^{2}+a^{2}}\right]+ \\
\left.+\left[\int_{x}^{x+h} \frac{k_{e} \sigma(2 \pi b h)}{h \sqrt{x^{2}+b^{2}}} d x=k_{e} \sigma 2 \pi b \ln \left(x+\sqrt{x^{2}+b^{2}}\right)\right]_{x}^{x+h}=k_{e} \sigma 2 \pi b \ln \left(\frac{x+h+\sqrt{(x+h)^{2}+b^{2}}}{x+\sqrt{x^{2}+b^{2}}}\right)\right]
\end{gathered}
$$

Plotting the above expression yields:

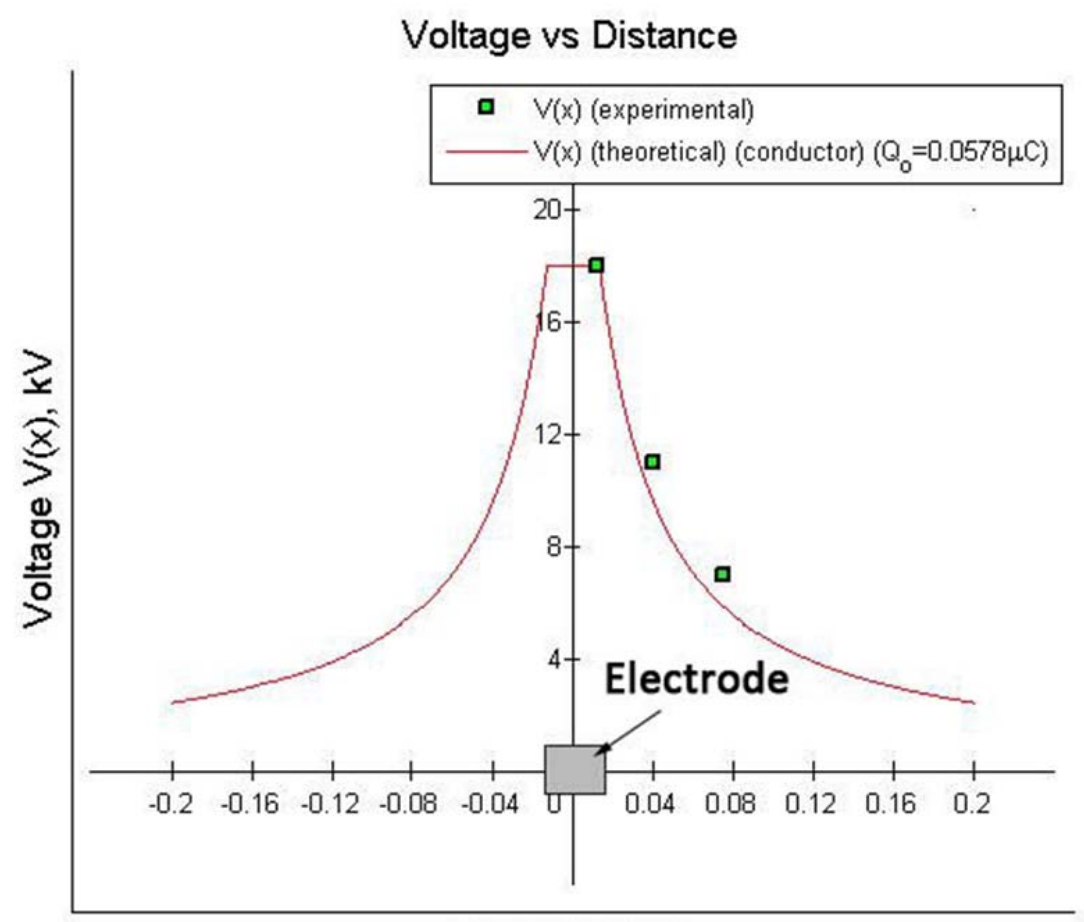

Distance $\mathrm{x}, \mathrm{m}$

Figure A-5-3. Initial Voltage Distribution at $18 \mathrm{kV}$

Note that in the equation above the net charge on the electrode $Q$ is unknown. However, since we know the initial voltage on the electrode we can easily determine it. For example for the initial voltage of $18 \mathrm{kV}$ the net charge on the electrode $Q=0.0578 \mu \mathrm{C}$. Also the above voltage distribution is valid only along the axis of the cylinder. This is due to the fact that if we calculate the electric field due to a charge dq anywhere on the cylinder the electric field will have two components $E_{x}=-\frac{d V}{d x}$ and $E_{y}=-\frac{d V}{d y}$. However, when integrating along the axis of the cylinder the $E_{y}$ components cancel out due to the symmetry around the axis. Thus, the electric field along the axis has only $E_{x}$ component. 
To determine the value of the electric field at any point along the $\mathrm{x}$ the above the expression for voltage is numerically differentiated to obtain the following graph:

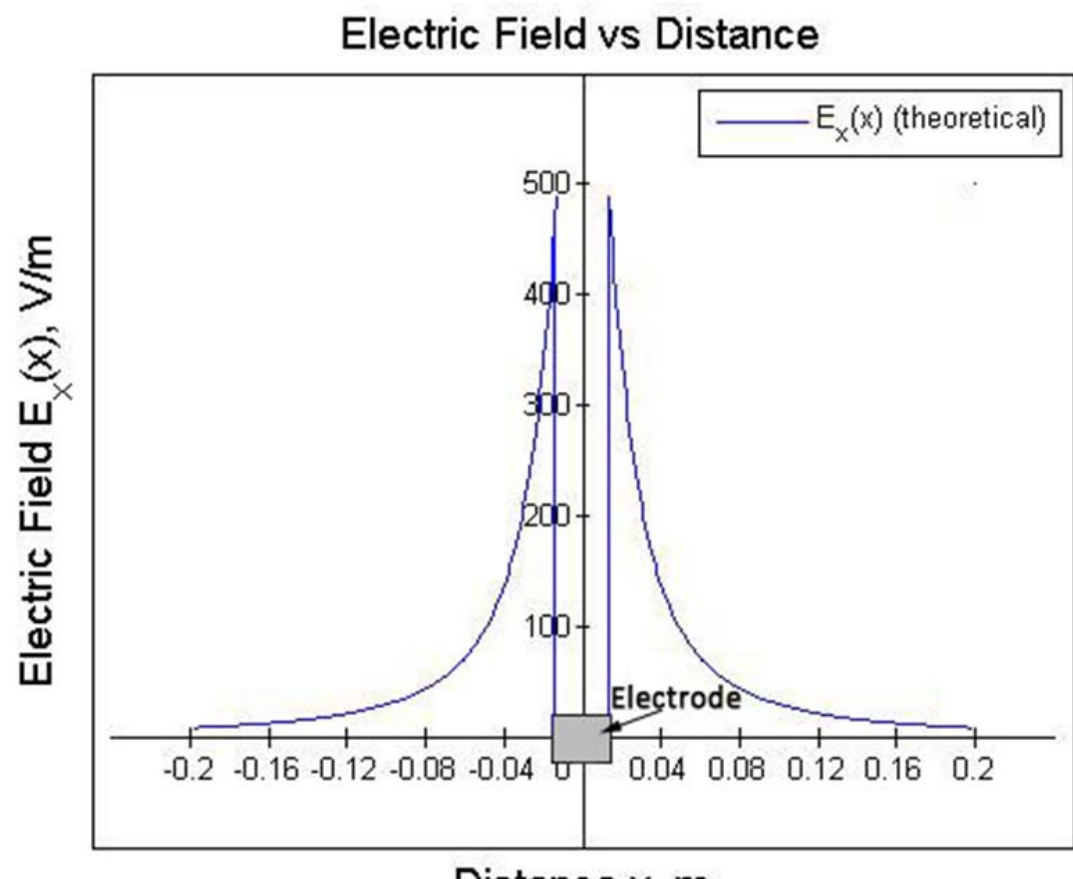

Distance $\mathrm{x}, \mathrm{m}$

Figure A-5-4. Initial Electric Field Distribution at $18 \mathrm{kV}$

\section{A.2 Undistorted Electric Field (prior to arrival of the detonation) (two electrodes)}

When a second electrode is placed at $0.2 \mathrm{~m}$ from the first one the voltage and electric field profiles changes. Since we are only considering a one dimensional problem, V is a function of $\mathrm{x}$ only and its variation is governed by the Poisson equation:

$$
\frac{d^{2} V}{d x^{2}}=-\frac{\rho}{\epsilon_{o}}, \text { where } \rho \text { is volumetric charge density }
$$

Since there is no net charge in the test section prior to arrival of the detonation $\rho=0$ and the Poisson equation reduces to :

$$
\frac{d^{2} V}{d x^{2}}=0
$$

Solving it by integrating twice yields: $V=A x+B$. Applying Dirichlet boundary conditions $V(0)=V_{0}=18 \mathrm{kV}=18000$ and $V(0.2)=0$ :

$$
V(x)=-90000 x+18000
$$


Thus when the two electrodes are present the voltage profile looks as shown in Figure 14. The electric field is constant and is equal to:

$$
E(x)=-\frac{d V}{d x}=900000=0.9 \mathrm{kV} / \mathrm{cm}
$$

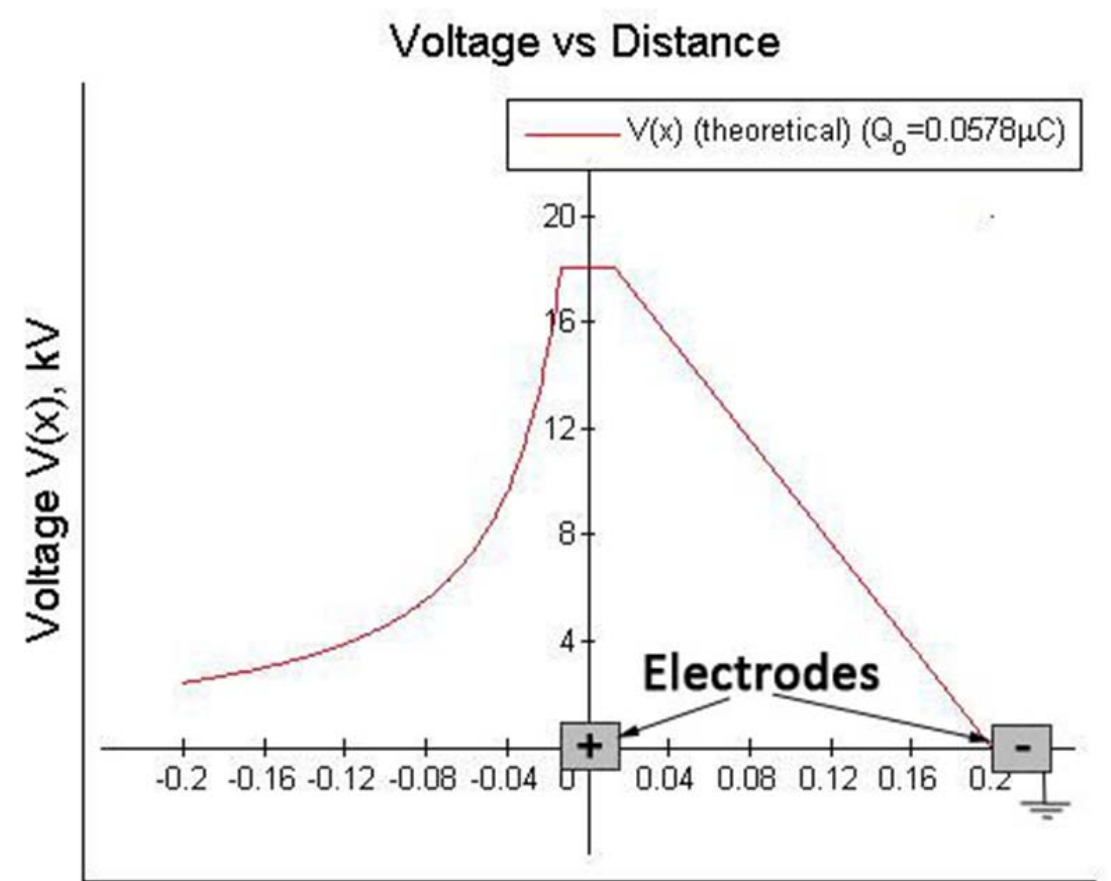

Distance $\mathrm{x}, \mathrm{m}$

Figure A-5-5. Voltage Profile (two electrodes) at $18 \mathrm{kV}$ 
APPENDIX B 


\section{B.1 Langmuir Probe Measurements}

A symmetrical double probe was used to obtain the I-V characteristic curve. For each experiment the probe was biased at a

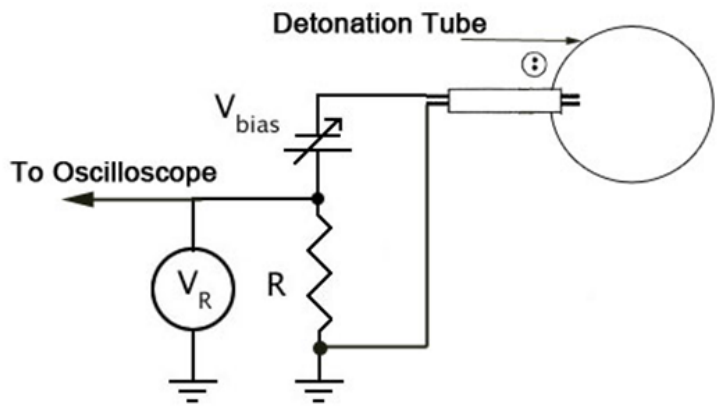

Figure B-6-1. Langmuir Probe Setup constant potential. As the detonation passed by the probe the voltage drop across the resistor $\mathrm{R}=5 \mathrm{kOhm}$ was recorded on the oscilloscope. The current was obtained from the recorded voltage drop and was plotted against the bias voltage for various times after the arrival of the detonation. The I-V characteristic plot is shown in Figure 20. As seen in the graph in all three curves two distinct regions are visible. In the first region the current linearly increases with increasing voltage, however past around $45 \mathrm{~V}$ the current reaches a plateau and only increases slightly with an increase in voltage. Using the procedure outlined by Terao [8] the ion saturation current is found as a point where a straight line from the plateau region of the curve intersects the ordinate.

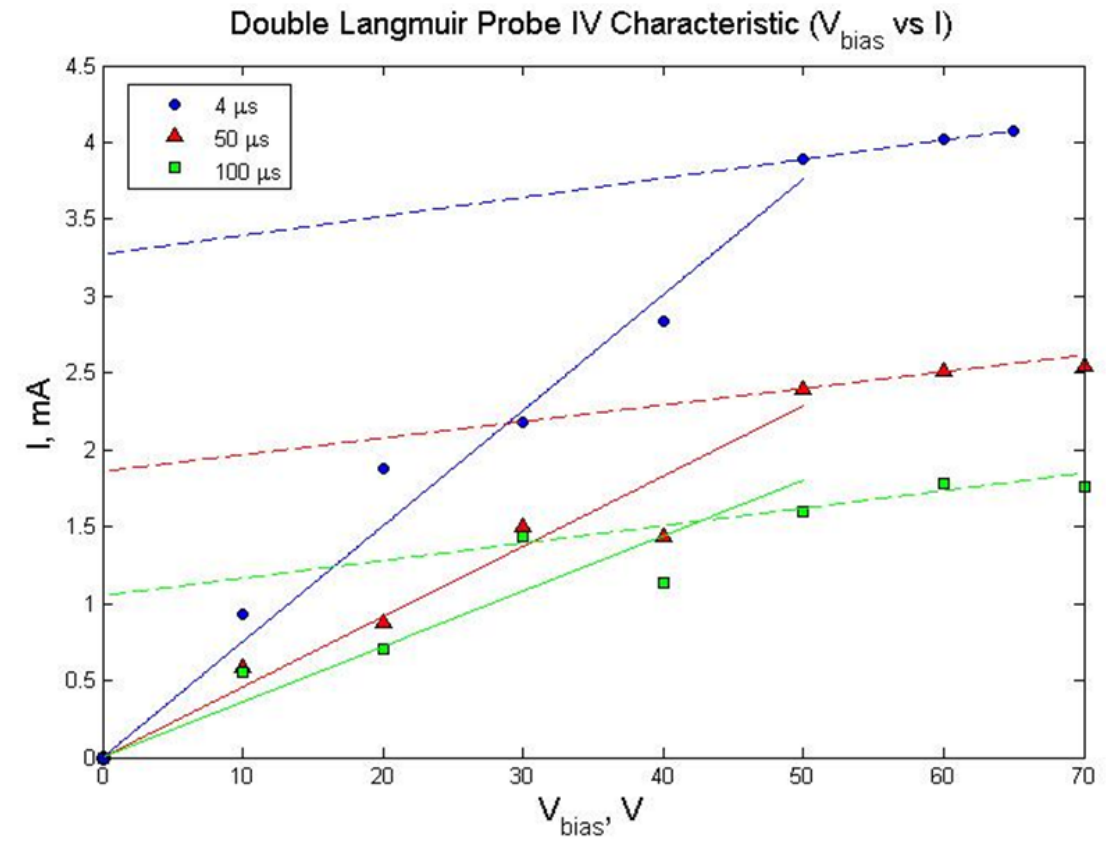

Figure B-6-2. IV Characteristic for a double Langmuir Probe, (only positive bias voltages shown) 
Knowing the saturation current and the slope of the linear region electron temperature $T_{e}$ ion density $N_{i}$ can be obtained using the following relationships:

$$
T_{\mathrm{e}}=\frac{e}{k} \frac{i_{\mathrm{s}}}{2(\mathrm{~d} i / \mathrm{d} V)_{0}}, \quad N_{\mathrm{i}}=\frac{i_{\mathrm{s}}}{F e \sqrt{k T_{\mathrm{i}} /\left(2 \pi m_{\mathrm{i}}\right)}} .
$$

Where $(\mathrm{d} i / \mathrm{d} V)_{0}$ is the slope of the linear region and $\mathrm{F}$ is the surface area of the probe.

The results for times 4,50 and $100 \mu$ s are summarized in Table 2 .

Table B-1. Electron temperature and ion density in $2 \mathrm{CO}+\mathrm{O} 2$ at 1atm

\begin{tabular}{|l|r|l|l|r|l|l|r|l|}
\hline \multicolumn{3}{|c|}{$\mathbf{4} \mathbf{\mu s}$} & \multicolumn{3}{c|}{$\mathbf{5 0} \boldsymbol{\mu} \mathbf{s}$} & \multicolumn{3}{c|}{$\mathbf{1 0 0} \boldsymbol{\mu s}$} \\
\hline \hline Isat $_{\text {slope }}$ & 3.27 & $\mathrm{~mA}$ & $\mathrm{I}_{\text {sat }}$ & 1.86 & $\mathrm{~mA}$ & $\mathrm{I}_{\text {sat }}$ & 1.05 & $\mathrm{~mA}$ \\
\hline $\mathrm{Te}$ & 0.07525 & & slope & 0.04573 & & slope & 0.03605 & \\
\hline $\mathrm{Ni}$ & 2.824490508 & $\mathrm{eV}$ & $\mathrm{Te}$ & 0.438956 & $\mathrm{eV}$ & $\mathrm{Te}$ & 0.178124 & $\mathrm{eV}$ \\
\hline
\end{tabular}

The electron temperature $T_{e}$ is given in electron volts. After conversion $(1 \mathrm{eV}=11,600 \mathrm{~K})$ the electron temperature is the region 4,50 and $100 \mu$ s are $9563 \mathrm{~K}, 5091 \mathrm{~K}$ and $2064 \mathrm{~K}$ respectively. This is in agreement with Cavenor [7] who reported electron temperatures just behind the detonation a few times higher than the equilibrium value. In the case of $\mathrm{CO}$ mixture the equilibrium electron temperature value is the same as the adiabatic flame temperature which is around $3500 \mathrm{~K}$. 
APPENDIX C 


\section{C.1 Plasma-Sheath model}

In order to understand and quantify how the ionized gas (plasma) interacts in the presence of a charged electrode we have to understand basic interaction between plasma and the DC electric field. In general, as plasma passes a charged boundary, the charged species within plasma reorient themselves (polarize) in a way that will shield (or screen) the bulk of the plasma from the external electric field. This way the condition of quasi neutrality of plasma (the number of negative charges equals to the number of positive charges $n_{e}=n_{i}$ ) is preserved. In the absence of external electric field the plasma has net zero charge: it is quasi-neutral, and thus, in the presence of an external electric field it seeks to preserve this state by creating a thin layer of charged species (sheath) at the boundary of the electrode that shields it from the influence of the DC electric field (see Figure C-1). For example, if the

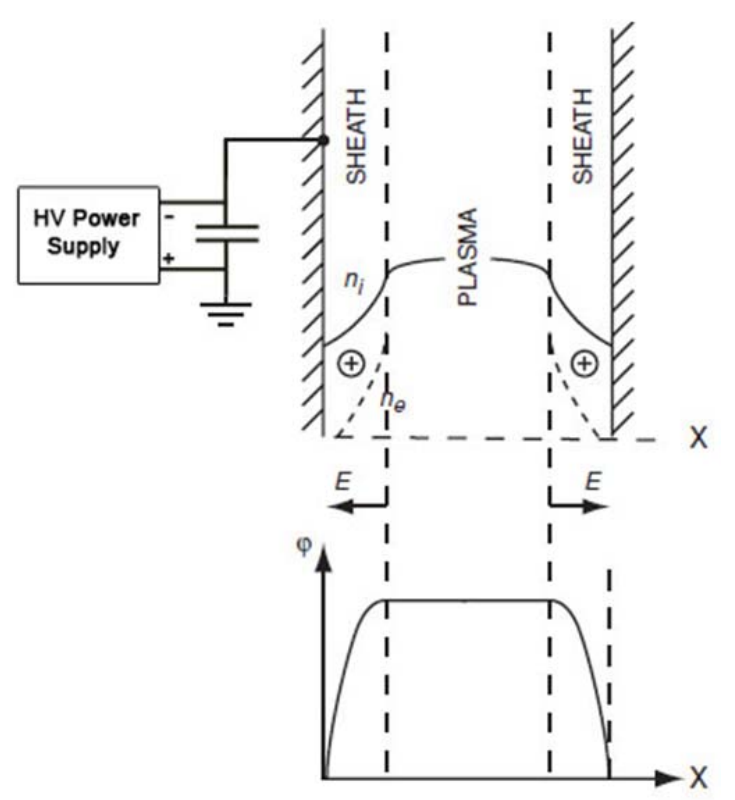

Figure C-1. Distribution of density of charged particles and potential in plasma and sheaths. Source [10] p.334

electrode is negatively biased all the electrons are repelled from the electrode and the electric field is screened by the thin layer of positive ions which are attracted to the surface of the electrode. The thickness of the sheath is a few Debye lengths. From the 1-D solution of Poisson equation for the region between charged boundary and plasma [10] the Debye length is given by:

$$
\lambda_{D}=\left(\frac{\varepsilon_{0} k T_{e}}{e^{2} n_{e 0}}\right)^{1 / 2}
$$

Where,

$\varepsilon_{0}=8.854187817 \times 10^{-12} \mathrm{~A} \cdot \mathrm{s} /(\mathrm{V} \cdot \mathrm{m})$

$k=1.3806503 \times 10^{-23} \mathrm{~m}^{2} \mathrm{~kg} / \mathrm{s}^{2} \mathrm{~K}$

$T_{e}=$ electron temperature $=3526 \mathrm{~K}$

(The electron temperature in oxy-combustion is equivalent to the adiabatic flame temperature, for $2 \mathrm{CO}+\mathrm{O} 2 \mathrm{~T}_{\text {adiabatic }}=3526 \mathrm{~K}$ )

$e=1.60217646 \times 10^{-19} \mathrm{C}$ 
$n_{e 0}=$ initial electron density $=10^{11} \mathrm{~cm}^{-3}=10^{17} \mathrm{~m}^{-3}$ (for typical flames)

Substituting these values into the equation for Debye length:

$\lambda_{D}=\left(\frac{\varepsilon_{0} k T_{e}}{e^{2} n_{e 0}}\right)^{1 / 2}=\left(\frac{8.854187817 \times 10^{-12} * 1.3806503 \times 10^{-23} * 3526}{\left(1.60217646 \times 10^{-19}\right)^{2} * 10^{17}}\right)^{1 / 2}=0.13 \mathrm{~mm}$

From the solution of the Poisson equation between the plasma and the charged boundary the space potential distribution is given by:

$V(x)=\phi(x)=\frac{q}{x} \exp \left(-\frac{x}{\lambda_{D}}\right)$

Thus, as seen in Figure $\mathrm{C}$ - and Figure C-2, the voltage follows an exponential decay from the wall of the electrode. Within a few Debye lengths $\left(x_{S} \approx 3 \lambda_{D}\right)$ away from the electrode wall the voltage decays to zero. Therefore, as the detonation propagates inside the electrode the bulk of the detonation plasma is shielded from the very high negative potential of the electrode. This shielding is provided by the fact that the electrons are repelled and the ions are attracted to the walls of the electrode. As

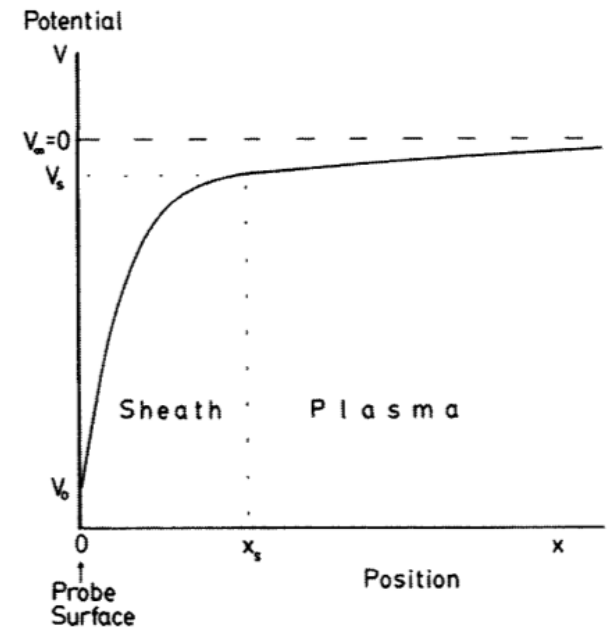

Figure C-2. Electric potential variation near the surface of a negatively charged probe. Source: [10] p.61

the ions strike the wall of the electrode they are

neutralized and thus more ions are needed to maintain the layer of positive charge around the electrode. This movement of ions toward the negative electrode is referred to as the ion current. The maximum amount of ions drawn in by the electrode is limited by the ion saturation current. The magnitude of this current was first derived by Bohm in 1949:

$$
I_{s a t, i}=0.6 n_{e} e A\left(\frac{k T_{e}}{m_{i}}\right)^{1 / 2}
$$

Where $A$ is the probe (electrode) area, and $m_{i}$ is the mass of the positive ions. From the above equation we can calculate approximate values of saturation current for mixtures and electrode geometries used in the current study. These results are summarized in the table below: 


\begin{tabular}{|l|l|r|r|r|r|r|}
\hline Mixture & Ions & Pressure $(\mathbf{k P a})$ & $\mathbf{n}_{\mathbf{e}}\left(\mathbf{c m}^{-3}\right)$ & $\mathbf{T}_{\mathbf{e}}(\mathbf{e v})$ & $\mathbf{A}_{\text {electrode }}\left(\mathbf{c m}^{\mathbf{2}}\right)$ & $\mathbf{I}_{\text {sat }}(\mathbf{m A})$ \\
\hline \hline $2 \mathrm{CO}+\mathrm{O} 2$ & $\mathrm{CO}+$ & 101.3 & $8.00 \mathrm{E}+11$ & 0.30 & 23.14 & 180.9 \\
\hline $\mathrm{C} 2 \mathrm{H} 2+\mathrm{O} 2+85 \% \mathrm{Ar}$ & $\mathrm{CHO}+$ & 28 & $3.00 \mathrm{E}+11$ & 0.26 & 5.19 & 15.2 \\
\hline
\end{tabular}

Table C-1. Saturation current values for various mixtures

For example, assuming the dominant ions in the reaction zone in $2 \mathrm{CO}+\mathrm{O} 2$ detonation are the $\mathrm{CO}^{+}$ions with $m_{i}=27.9949 u * 1.6605 \times 10^{-27} \mathrm{~kg} / \mathrm{u}=4.64951 \times 10^{-26} \mathrm{~kg}$ and the area of the electrode is equal to the inner surface area $A=0.002314 m^{2}$ and $n_{e} \approx$ $8 \times 10^{11} \mathrm{~cm}^{-3}$ (flame equilibrium electron density)

$$
I_{s a t, i}=0.6 n_{e} e A\left(\frac{k T_{e}}{m_{i}}\right)^{1 / 2}=180 m A
$$

In summary, as the detonation approaches the region of electric field created by the charged electrode a sheath consisting of a layer of positive charge develops around the electrode. The sheath shields the bulk of the plasma from the applied DC field. In order to maintain the sheath positive ions are drawn in by the electrode resulting in an ion current. In order to confirm this interaction mechanism between the detonation and the electric field the current to the electrodes is measured in the following set of experiments and its effects on the detonation are discussed. 